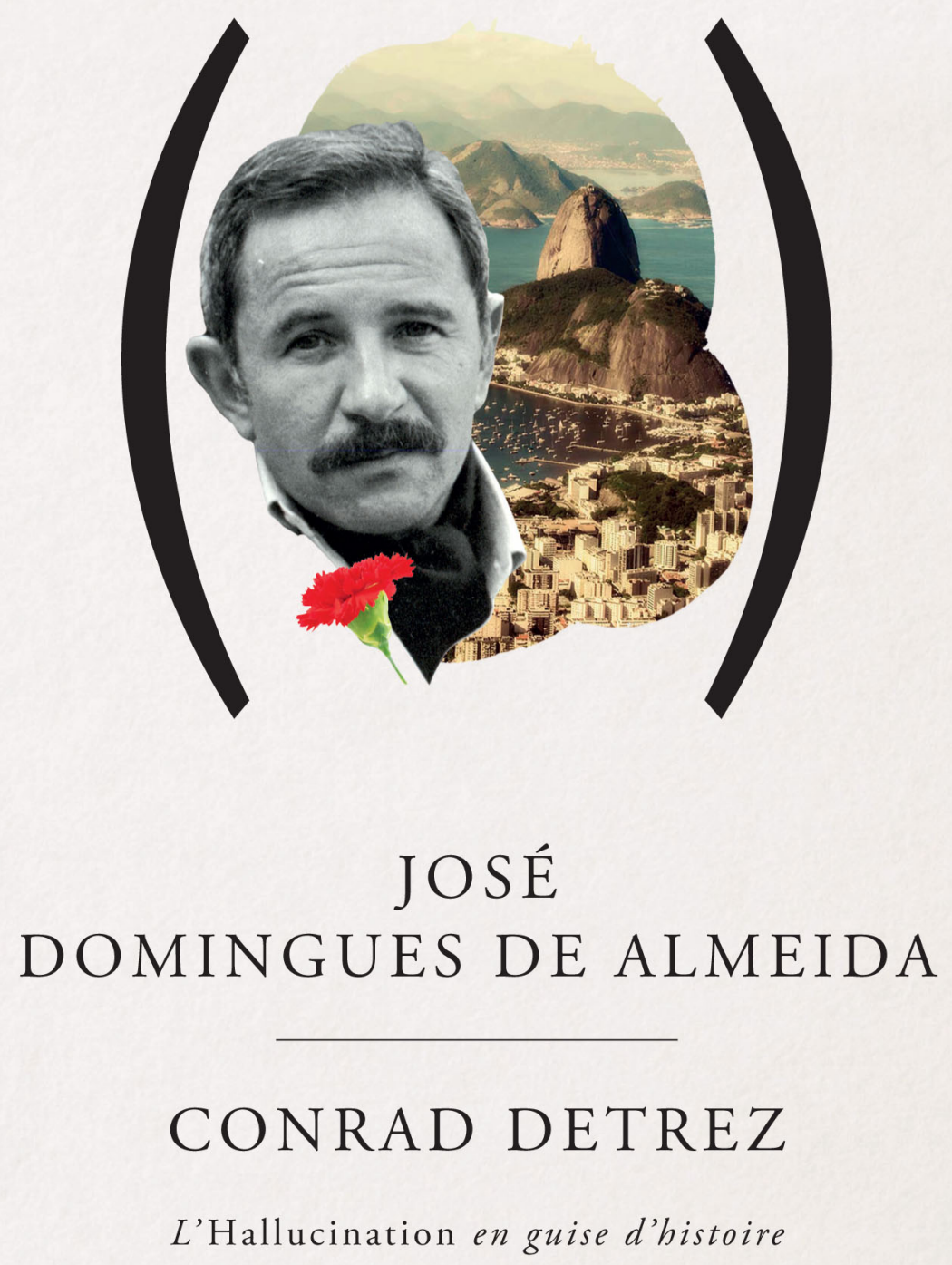

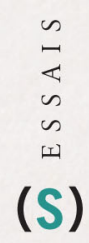

Passage(s)

E S S A I 


Conrad Detrez 
Collection «Essais », dirigée par Laury-Nuria André, Christophe Ippolito, Dominique Lanni, Aurore Petrilli, Nicolas Pien \& Mathilde Poizat-Amar.

La présente publication s'insère dans la recherche menée dans le cadre du Programme Stratégique de l'Instituto de Literatura Comparada financé par la Fundação para a Ciência e para a Tecnologia (UIDP/00500/2020)

Éditions Passage(s) www.editionspassages.fr ISBN : 979-10-94898-83-3 
José Domingues de Almeida

\section{Conrad Detrez}

L'Hallucination en guise d'Histoire

Passage(s)

« Essais » 

Conrad Detrez 
à João

à Sara 


\section{UN ECRIVAIN DANS LE SIECLE, UN BELGE DU MONDE}

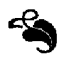

Évoquer le parcours personnel, politique et littéraire de Conrad Detrez revient forcément à exhumer des pans entiers de passions collectives et de débats de société qui ont marqué le XXe siècle, et dans lesquels plusieurs générations se sont, au sens très précis du terme, « engagées ». En effet, la vie de l'éternel jeune Belge, bien que fugace et prématurément interrompue, donne à voir le foisonnement des convictions, des certitudes et des engagements, souvent contradictoires, qui ont nourri toutes formes de militance, voire de martyre.

Detrez est issu de ce milieu rural Belge dont les rythmes étaient inlassablement et immémorialement ponctués par les travaux des champs, la logique des rapports endogamiques et le calendrier des fêtes liturgiques chrétiennes. Au départ, rien ne prédestinait ce futur prêtre précipitamment défroqué et éminemment laïque, aux aventures et combats sociopolitiques de son temps. Pourtant, c'est exactement là que Detrez s'avère non seulement témoin, mais acteur, et pour ce qui est de la production romanesque qui nous occupe dans cette étude, un personnage.

Entrer dans l'univers fictionnel detrézien permet ainsi de revisiter un monde révolu où s'affrontaient des récits existentiels et sociétaux concurrents : le catholicisme social de gauche, encouragé par le personnalisme, la mystique 
évolutionniste du Père Teilhard de Chardin et les mutations théologiques et liturgiques introduites par le Concile Vatican II d'une part, et le marxisme et maoïsme militants dans les contextes politiquement troublés de l'Amérique latine et du Tiers-Monde en général, d'autre part.

Cet univers (auto)fictionnel exhume également une Belgique qui n'existe décidément plus: unitaire, transethnique, francophone, mais déjà promise aux débats fédéralistes et communautaires qui occuperont la vie politique du Royaume de Belgique pendant les années soixante-dix. À cet égard, il n'est pas sans intérêt de rappeler l'engagement personnel de l'écrivain liégeois et wallon dans ce débat tant culturel, identitaire que politique de la " belgitude $»^{1}$, lequel marquerait définitivement l'avenir de la création et de la diffusion de l'écriture littéraire en Belgique francophone, et finirait par introduire de plain-pied les lettres belges de langue française dans le concert des littératures francophones et, plus tard, dans celui, plus vaste et plus complexe, de la littérature-monde en français.

Bien sûr, les temps ont changé. Les approches, tant esthétiques que politiques, qui tâchent d'interpréter aujourd'hui la réalité sociale et économique, ainsi que la création littéraire et artistique ne correspondent plus à celle que Detrez a subtilement mobilisée pour l'écriture de son autofiction en trois tomes et en trois étapes: la psychanalyse, ou celle qu'il a caricaturée, et dont il s'est ouvertement moqué dans ses derniers romans: le poststructuralisme, ou encore le marxisme théorique ou révolutionnaire.

Un peu à son insu, comme Conrad Detrez devait l'avouer dans un essai ultérieur, face à un monde en mutation $^{2}$, son écriture et sa pensée rejoignaient déjà les soucis nouveaux et les lignes de force majeures de

\footnotetext{
${ }^{1}$ José Domingues de Almeida, De la belgitude à la belgité. Un débat qui fit date, Bruxelles, P.I.E. Peter Lang, 2013.

${ }^{2}$ Conrad Detrez, Les Noms de la tribu, Paris, Seuil, 1981.
} 
l'interprétation du fait littéraire tels qu'ils ont fini par s'imposer à la critique aujourd'hui, et qui ont pour noms études postcoloniales, ethnicité, sexualité / genre, études culturelles et études régionales (Area Studies). En effet, la poétique detrézienne prend assez tôt acte du tournant du discours (idée) vers la culture (réel), raison pour laquelle elle s'avère toujours si stimulante et captivante, et continue d'interpeler la recherche en littérature dans ses différentes tendances, perspectives et thématiques.

Aussi s'invite-t-elle dans plusieurs communications en colloque, et se voit-elle glosée dans plusieurs articles et essais à la faveur de sujets aussi diversifiés que l'évolution politique et institutionnelle de l'État belge et de l'Europe, les récits de voyage, les représentations du Brésil, de l'Amérique latine, du Tiers-Monde dans son ensemble, du Portugal révolutionnaire, de l'Autre, du Noir, de l'homosexuel, du « subalterne », de la nature, de l'environnement dans la fiction narrative contemporaine.

Cette poétique exemplifie et éclaire aussi, pour la critique et la théorisation littéraires du tournant du XXIe siècle, tout un renouveau de la fiction romanesque en langue française après l'obsession du Texte, laquelle renoue avec une certaine idée de la représentation du réel et du sujet, notamment pour ce qui est du jeu autofictionnel. Ce faisant, l'univers romanesque detrézien illustre à sa façon ce sur quoi une récente contribution critique de Dominique Viart attirait justement l'attention, à savoir le caractère " relationnel » du contemporain, transversal à toute la production littéraire française du jour, à savoir « en relation " précisément avec d'autres périodisations esthétiques antérieures, avec la modernité littéraire, avec le monde référentiel et les réalités sociales, avec l'environnement au sens large, et avec d'autres disciplines et savoirs ${ }^{1}$.

\footnotetext{
${ }^{1}$ https://www.fabula.org/atelier.php?Comment_nommer_la_litterature_contemp oraine
} 
En effet, l'œuvre de Conrad Detrez s'affirme « relationnelle » à plus d'un titre tant elle sous-entend d'autres esthétiques, un rapport problématique et complexe au monde sociopolitique, à la nature et à la pensée et urgence écologiques. Voilà certainement énoncée la raison pour laquelle Conrad Detrez continue de marquer et d'inspirer plusieurs générations d'écrivains tels que le poète belge William Cliff, qui lui rend un bel hommage ${ }^{1}$, ou encore l'écrivain africain Tierno Monénembo, qui lui dédie son roman postcolonial $U n$ rêve utile ${ }^{2}$; tous deux s'avouant en quelque sorte frères d'écriture du romancier belge naturalisé français, de l'écrivain du monde.

Bien que Conrad Detrez soit décédé si prématurément, à l'âge de quarante-sept ans, emporté par une des plus persistantes pandémies que l'humanité ait jamais connue, le sida, on peut assez aisément, à la lecture de ses tout derniers écrits, se lancer dans l'exercice divinatoire d'imaginer dans quels combats et débats sociétaux, culturels et politiques il se serait engagé aujourd'hui, dans quel type de militance citoyenne il se serait investi avec conviction, à quels manifestes il aurait souscrit, voire qu'il aurait suscités.

Sans doute aurait-il signé, comme ses deux condisciples belges, le regretté Jean-Claude Pirotte et le très prometteur Grégoire Polet, le « Manifeste pour une littérature-monde en français $»^{3}$, à l'instar de Jean-Marie Gustave Le Clézio, le prix Nobel de littérature 2008, puisant ainsi dans sa vaste expérience de vie et d'écriture cosmopolite et internationaliste, et dans les réalités multiculturelles qu'il a côtoyées, notamment au Brésil. Peut-être aurait-il contribué à l'activisme de certaines organisations non gouvernementales, et se serait-il mobilisé pour la défense du climat et de l'environnement, pour le commerce équitable, les droits de

\footnotetext{
${ }^{1}$ William Cliff, Conrad Detrez, Paris, Le Dilettante, 1990.

2 Tierno Monénembo, Un rêve utile, Paris, Seuil, 1991.

${ }^{3}$ https://www.lemonde.fr/livres/article/2007/03/15/des-ecrivains-plaident-pourun-roman-en-francais-ouvert-sur-le-monde_883572_3260.html
} 
l'homme et de toutes les minorités, de la communauté LGTB, pour la survie de la planète dans sa biodiversité et pour le développement durable. Sans doute aurait-il milité dans l'altermondialisme. Mais ce ne sont là bien évidemment qu'extrapolations et hypothèses.

Ce qui est sûr, par contre, c'est que dans son parcours personnel et ses derniers textes, Conrad Detrez annonce, et prélude à la mutation majeure de la gauche occidentale : le passage d'une gauche sociale marxiste, axée sur le prolétariat, l'ouvrier et la lutte des classes, à une gauche éminemment identitaire, solidaire et écologique. Autrement dit, la subtile transition du pauvre et de l'aliéné économique et social vers l'obsession de l'étranger fascinant et de l'autre " subalterne » dans toutes ses variantes comme passion postcoloniale d'un Occident renvoyé à sa mauvaise conscience, à la gestion de sa repentance et, pour reprendre l'expression consacrée de nos jours, à son "identité malheureuse $»^{1}$.

À cet égard, Conrad Detrez est notre contemporain intemporel, notre frère de destin collectif et notre compagnon de route culturel. Mais, rappelons-le, il est avant toutes autres considérations un grand écrivain, né quelque part, dans un lieu en creux qu'il ne cesse d'évoquer, et à une époque dont il fut, en le payant très cher, le témoin lucide. Mais, au départ, nous avons affaire à un sujet conscient de sa mise en scène et des opacités de son existence, et qui cherche à se (faire) comprendre et à se connaitre. C'est ici qu'entre l'écriture hallucinante de soi, l'écriture tout court.

${ }^{1}$ Alain Finkielkraut, L'Identité malheureuse, Paris, Stock, 2013. 



\section{UNE BIOGRAPHIE HALLUCINANTE L'ECRIVAIN AUX PRISES AVEC L'HISTOIRE}

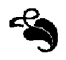

L'intensité de la vie de Conrad Detrez et la densité de son œuvre romanesque, publiée entre 1974 (Ludo) et 1984, date de sa maladie et de son ultime "récapitulation ", donnent au lecteur un sentiment d'urgence de l'écriture, qui ne trouve son pareil que chez quelques rares prosateurs contemporains de langue française, notamment René Kalisky pour le théâtre. Tout se passe et s'écrit comme si le temps pressait de témoigner d'une réalité tiers-mondiste inintelligible pour ceux qui ne l'ont pas vécue du dedans, mais aussi, et peut-être surtout, d'une existence qui s'est trouvé des ailes partout, mais qui a de fortes racines en Wallonie, dans le pays de Liège. En effet, la manière prématurée, voire brutale, dont Conrad Detrez s'est éteint dans la nuit du 11 février 1985, victime du sida - que l'on voudra bien appeler par un euphémisme, ou en vertu des conjectures médicales de l'époque, "pneumonie », ou mystiquement, comme le fait l'auteur lui-même, « boussole » ${ }^{1}$ - peut laisser entendre qu'à la suite de tant de convictions, de combats, de passions diverses et changeantes, l'écrivain wallon se démarquait à son corps

${ }^{1}$ Hector Bianciotti, « Une boussole pour Conrad », Le Nouvel Observateur, 22 février 1985, p. 75. 
défendant d'un monde et d'une fin de siècle qui n'étaient décidément plus les siens, qui n'avaient plus grand-chose à voir avec son credo, sa plateforme ou son programme. Par ailleurs, un mal nouveau et foudroyant commençait de ronger les corps et les cœurs des apprentis de l'amour affranchi de toutes contraintes. Detrez quittait à plus d'un titre « vaincu » notre siècle désabusé et consensuel, où les consciences s'avèrent si facilement recyclables.

Pourtant le ton foncièrement récapitulatif et confidentiel de l'œuvre romanesque de Detrez dans son ensemble, mais dans La Mélancolie du voyeur (1986) en particulier, nous fait pencher vers d'autres conclusions moins moroses. Il y a l'urgence dictée par le besoin de comprendre ses échecs ${ }^{1}$, mais aussi par la proximité de la mort, moment vespéral terrible où il faut faire vite et aller à l'essentiel. Cette urgence, Hector Bianciotti l'a bien pressentie dans son dernier entretien avec Conrad Detrez qu'il livre en préface à La Mélancolie du voyeur :

Je ne saurais jamais pourquoi Conrad Detrez se mit à récapituler sa vie, comme s'il y avait urgence à le faire - et pour moi seul. Depuis les champs de betteraves à proximité desquels il était né, près de Liège, jusqu'à la conscience de la mort qui l'habitait et dont il parlait comme d'une loterie ${ }^{2}$.

Mais il y a surtout dans ce surprenant virage opéré par l'ancien guérillero d'Amérique latine une capacité de « perpétuel étonnement $»^{3}$, confinant parfois à la passivité et qui lui fait accepter chaque étape et chaque lieu comme un nouveau défi, une perpétuelle découverte.

En outre, la prose narrative telle que Detrez l'a pratiquée dans le corpus qui nous occupera ici, et en une moindre

\footnotetext{
${ }^{1}$ Conrad Detrez, « Le jardin de la vie », Le Figaro, 21 novembre 1978, repris dans Conrad Detrez, Ludo, Bruxelles, Labor, 1988, p. 198.

2 Préface d'Hector Bianciotti à Conrad Detrez, La Mélancolie du voyeur, Paris, Denoël, 1986, p. 10. Cf. aussi Pierre Mertens, « Detrez à la croisée des chemins ?», Le Soir, 10 février 1981.

${ }^{3}$ Idem.
} 
mesure au-delà de ce corpus, opère un rapport étroit et subtil entre la vie et la fiction que nous référons au concept d'autofiction, ce dont Detrez souligne mieux que quiconque le caractère foncièrement oxymorique et paradoxal par le titre générique dont il affuble sa trilogie autoanalytique: « autobiographie hallucinée » ${ }^{1}$. L'hallucination, avec toute sa connotation fantastique, maladive, irréelle, permet à l'autobiographe en herbe de brouiller les pistes quant à son histoire personnelle, et préfigure un symptomatique évitement de l'Histoire.

Elle coïncide historiquement avec l'atmosphère de « déréliction $»^{2}$ régnant - en tous cas pour les intellectuels sur la Belgique à cette époque, et relaie une « hallucination des faits ${ }^{3}$ héritière de celle des lieux, propre au réalisme magique belge. Décidément l'écriture des années soixante-dix ne parvient pas à saisir l'Histoire, à l'envisager sur un mode dialectique. Les romans de Detrez n'y font - il est vrai - qu'une mince allusion, prétexte à faire évoluer un narrateur ressemblant à s'y méprendre à l'auteur; lui-même « individu[s] encore aux prises avec l'histoire et l'idéologie, mais déjà déconnecté[s] d'elles $\rangle^{4}$. Aussi l'écriture de cette « autobiographie hallucinée » brasse-t-elle - d'où aussi bien sa spécificité que sa subtilité - les métamorphoses psychologiques et politiques de l'auteur, les portraits biaisés et surtout allusifs d'un pays somme toute blafard. Elle rend aussi compte d'un choix délibéré d'écriture romanesque propice à l'écriture de soi, mais qui évite toute propension à l'épanchement.

Voilà comment, d'une part, la notion d'« espace autobiographique »de Philippe Lejeune ${ }^{5}$ - en tant que pratique diffuse, élastique et déviante de l'autobiographie

\footnotetext{
${ }^{1}$ Conrad Detrez, « Le jardin de la vie », p. 198.

2 Marc Quaghebeur, Lettres belges entre absence et magie, Bruxelles, Labor, 1990 , p. 96.

${ }^{3}$ Ibid., p. 95.

${ }^{4}$ Ibid., p. 427.

${ }^{5}$ Philippe Lejeune, Le Pacte autobiographique, Paris, Seuil, 1975, p. 14.
} 
proprement dite, conventionnelle et normative, telle qu'il le définit - semble convenir au projet autoanalytique poursuivi par Detrez. Considéré dans le cadre de la fiction narrative française de la fin du XXe siècle, Conrad Detrez est l'un de ces auteurs dont l'écriture signale, pour reprendre Bruno Blanckeman, " le retour du sujet narratif » en tant que «reconsidération du sujet psychique ${ }^{1}$. Et Blanckeman de poursuivre en s'appuyant justement sur la notion d' «autofiction » forgée par Serge Doubrovsky, et de souligner « l'autre du moi, la dimension imaginaire d'une identité, se met[tant] en scène $»^{2}$ à l'œuvre dans cette écriture.

Conrad Detrez reviendra - sur le tard, il est vrai - sur la nature et l'urgence de ce projet : " J'ai lu Freud et j'ai commencé la plume à la main, à me livrer à une sorte d'analyse $»^{3}$. À Christian Panier, Detrez confiait la raison de sa foisonnante inspiration : "Qu'il s'agisse de mon vécu ou de l'imagination (...) les images, les situations, les histoires me viennent facilement à l'esprit $»^{4}$. Et l'autobiographe halluciné de livrer la recette scripturale sous-jacente au projet poursuivi dans la trilogie : « Le gros travail consiste en fait à mêler étroitement le réel et l'imaginaire $»^{5}$. D'autant plus que ce romancier a vécu tout ce qu'il a écrit. Pierre Mertens ne dit pas autre chose. Selon lui, Detrez « se fictionnalise $»^{6}$, tout comme Jean-Claude Pirotte d'ailleurs. Ce très singulier retour à l'autobiographie constituerait même l'un des plus précieux et intéressants apports des lettres belges contemporaines à la francophonie littéraire : «Le Moi Je est un Moijeu, mais où le ludisme peut être mélancolique et mortel $»^{7}$.

\footnotetext{
${ }^{1}$ Bruno Blanckeman, Les Récits indécidables : Jean Echenoz, Hervé Guibert, Pascal Quignard, Paris, Presses Universitaires du Septentrion, 2000, p. 21.

${ }^{2}$ Idem.

${ }^{3}$ Conrad Detrez, « Le jardin de la vie », p. 198.

4 Entretien avec Christian Panier, « Du Brésil à Paris et détours », Revue Nouvelle, LXXIV, décembre 1981, p. 200.

${ }^{5}$ Idem.

${ }^{6}$ Pierre Mertens, « Detrez à la croisée des chemins ? », Le Soir, 10 février 1981.

7 Pierre Mertens, « Du retour à l'autobiographie », Revue de l'Institut de Sociologie, ULB, 1990 / 91, p. 62.
} 
(...) la cité la plus antiroyaliste du pays, la maçonne, la rouge, l'égorgeuse de princes et d'évêques, la dissidente : Liège à nouveau possédée par les démons du paganisme et de la république, Liège et sa turbulente banlieue, sa ceinture d'anarchistes et de libidineux ${ }^{1}$.

La mère de Detrez, Maria Vandeclée, meurt en 1959 « après trente-cinq ans de travail pénible, à la ferme de ses parents d'abord et ensuite dans la boucherie qu'avec mon père elle avait ouverte $»^{2}$. Ce funeste événement précède l'inscription de Conrad Detrez en théologie à l'Université catholique de Louvain, une institution qui sera bientôt en pleine effervescence linguistique et en instance de divorce, et ce à une époque plutôt houleuse du point de vue social. $L$ 'Herbe à brûler fait une allusion très ironique à la fracture communautaire au sein de l'Université de Louvain connue sous le nom «Walen buiten » (Les Wallons dehors) ${ }^{3}$, laquelle évite subtilement l'Histoire au sens factuel. En effet, le récit se penche surtout sur des détails plus ou moins piquants, censés jeter le discrédit sur une " révolution » insignifiante au vu de celle qui devait occuper Detrez par la suite :

La rumeur de la rue, après une accalmie, avait repris. La tactique des Flamands consistant à attirer l'adversaire dans le canal de boue. Les Wallons découvrirent le piège alors que leurs premières troupes s'embourbaient ${ }^{4}$.

Quant aux affrontements linguistiques déclenchés à la faveur du " régime d'austérité » décrété par le premier ministre Gaston Eystens en 1960 - « année mémorable » ${ }^{6}$ à

\footnotetext{
${ }^{1}$ Ibid., p. 97.

${ }^{2}$ Conrad Detrez, Les Noms de la tribu, Paris, Seuil, 1981, p. 22.

3 Même si Marc Quaghebeur relativise le traitement narratif de cet épisode historique chez Detrez. Cf. Lettres françaises de Belgique. Mutations, Bruxelles, AML / Éd. Universitaires de Bruxelles, 1980, p. 91.

${ }^{4}$ Conrad Detrez, L'Herbe à brûler, p. 83.

${ }^{5}$ Georges-Henri Dumont, Histoire de la Belgique, p. 592-593.

${ }^{6}$ Conrad Detrez, «Une fureur de Wallon », p. 202.
} 
plus d'un titre - Detrez y revient rétrospectivement en 1979 dans une description satirique de l'ambiance manichéiste régnant sur son pays de Liège natal et qui n'est pas sans rappeler la diabolisation de Liège, la frondeuse, opérée par les enseignants de Saint-Trudon dans Les Plumes du coq: " À Liège, les futurs théologiens de Flandre souffraient. Cette ville était Sodome, Gomorrhe et Moscou réunies (...). Ces garçons croyaient avoir approché l'enfer $»^{1}$. Il y est question des " maux de la Wallonie » (chômage, industrie vétuste, vieillissement démographique) que Detrez, en fédéraliste, mettait en exergue pour mieux entrevoir l'avenir improbable du Royaume : « Au lieu de faire, comme en Flandre, des enfants, en Wallonie on faisait l'amour (...). L'inquiétude, le désarroi gagnaient les populations. Des mouvements de protestation s'esquissaient. La colère grondait $»^{2}$. Qui plus est, l'heure est aux remaniements territoriaux arbitraires, administratifs et ecclésiastiques. Les Fourons sont arrachés à la Wallonie, avec la complicité des socialistes, en compensation du rattachement à la Wallonie de Mouscron-Commynes, tandis que le diocèse de Liège est « défait du Limbourg » ${ }^{3}$.

À Louvain justement, Detrez fraternise avec le milieu catholique et marxiste sud-américain. Il prend conscience des questions sociopolitiques affectant le tiers-monde. La décolonisation, la guerre d'Algérie, la Révolution cubaine ont vite fait leur travail de « conscientisation » chez un futur prêtre de plus en plus perméable à tous les appels et cris du monde et de l'Histoire. Comme il le rappellera dans son essai-témoignage, Les Noms de la tribu, à Louvain « un petit groupe de Latino-Américains organisait des conférences, des débats. De toute la population scolaire, ils étaient les plus politisés $»^{4}$. Ces données idéologiques, marxistes pour la plupart, commencent à saper et à remettre

\footnotetext{
${ }^{1}$ Ibid., p. 203.

${ }^{2}$ Ibid., p. 204.

${ }^{3}$ Ibid., p. 207.

${ }^{4}$ Conrad Detrez, Les Noms de la tribu, p. 131.
} 
en cause une vocation religieuse qui avait tout pour devenir conventionnelle et politiquement neutre. Pour ce qui est de ses lectures et maîtres à penser, Detrez est alors davantage épris de Mounier et de la mystique évolutive de Teilhard de Chardin que du thomisme, ce qui l'amène à redéfinir et réorienter sa vocation en tant que $«$ missionnaire laïc $»{ }^{1}$, ou " apôtre laïc $»^{2}$. Cet infléchissement apparent dans les convictions et dans les exigences actait en fait un basculement irrépressible dans la vie du candidat à la prêtrise.

Dans L'Herbe à brûler, c'est le personnage de Rodrigo, jeune Brésilien marxiste qui renonce à sa vocation et repart au Brésil, qui influence le narrateur, sème le doute, induit la réflexion sur la réalité sociale. Ses idées politiques ont fini par « contaminer $[\mathrm{sa}]$ foi, $(. .$.$) le faire perdre »^{3}$. C'est lui qui incite le futur prêtre wallon, dont la vocation bat déjà de l'aile, à embrasser la cause révolutionnaire qui déferle sur l'Amérique latine : « Chez nous, c'est se battre pour en [des biens sociaux] avoir, et pour en avoir il faut faire la révolution... Communiste ? - La révolution, c'est tout ! $\gg{ }^{4}$. Ainsi, dans ce troisième et dernier volet de l'« autobiographie hallucinée », Rodrigo représente toute la mouvance gauchiste latino-américaine de Louvain dont l'impact sur Detrez a été décisif : « Avec eux, le tiers monde a fait irruption dans ma vie. Avec eux, ensuite, je me suis détaché de l'Église $»^{5}$.

Cette période signale aussi, chez un homme jusqu'alors pieux et chaste, les premiers appels ou insinuations de la sexualité, les premières contradictions ou ambigüités du désir, d'un désir autre qui ne répond plus au nom de Dieu, mais ne s'en montre pas pour autant moins puissant et, pour l'heure, déconcertant. Dans L'Herbe à

\footnotetext{
${ }^{1}$ Conrad Detrez, L'Herbe à brûler, p. 91.

${ }^{2}$ Ibid., p. 101.

${ }^{3}$ Ibid., p. 83.

${ }^{4}$ Idem.

${ }^{5}$ Conrad Detrez, Les Noms de la tribu, p. 131.
} 
brûler, deux épisodes préfigurent le brutal apprentissage d'une sexualité ambigüe, douloureuse, voire dévoreuse, un « amour tous azimuts $»^{1}$. D'une part, Conrad - puisque c'est bien son nom - surprend Rodrigo, qui a déjà reçu la tonsure, mais qui s'apprête à la renier en flagrant délit, au lit avec une jeune étudiante brésilienne. Les râles et gémissements du couple suggèrent au très naïf Conrad une plainte, une agression, un soupçon vite dissipé au vu de la nudité, tout sauf honteuse, des corps. Le narrateur autodiégétique avoue son désarroi : "l'idée que l'amour fit mal me désorientait $»^{2}$. De ce fait, le narrateur s'avère n'être qu'un enfant, sexuellement parlant.

Plus tard, juste avant de quitter Louvain, « comme on quitte, recru d'air vicié, un W.-C. public $»^{3}$, le narrateur, déjà fort bouleversé par les métamorphoses idéologiques en cours et les images quasi incestueuses des fornications de Rodrigo, éprouvera un trouble identique en surprenant cette fois un pensionnaire " exsangue $»^{4}$ jouant trop intimement, selon lui, avec son chien sur son lit. Cette nouvelle « scène païenne $\|^{5}$ venait à bout d'une sérénité chaste, si durement cultivée : « (...) les paroles d'amour de mon saint Jean se retournaient contre moi, suscitant des visions d'intimité du gras jeune homme et de son chien $»^{6}$. Et Conrad, narrateur et personnage principal de L'Herbe à brûler, auteur et autobiographe « halluciné », quitte Louvain et la Belgique non sans prendre tout d'abord congé de son « grand paysage $»$ natal, celui de son enfance.

Après son décès, son instituteur de Roclenge confiera ce souvenir plutôt émouvant : Detrez était venu lui expliquer « pourquoi il abandonnait la pretrise et allait au

\footnotetext{
${ }^{1}$ Jean Muno, « L'homme en exil. Mertens-Detrez-Modiano », Revue Générale, $n^{\circ} 11$, novembre 1978 , p. 87.

${ }^{2}$ Conrad Detrez, L'Herbe à brûler, p. 86.

${ }^{3}$ Ibid., p. 95.

${ }^{4}$ Ibid., p. 93.

${ }^{5}$ Ibid., p. 94.

${ }^{6}$ Idem.
} 
Brésil alphabétiser les pauvres $»^{1}$. Les véritables raisons de ce désaveu, Detrez ne devait véritablement les livrer que dans sa trilogie autofictionnelle en guise d'introspection et de récapitulation.

En 1962, Conrad Detrez débarque au Brésil. Ce pays vit dans l'instabilité sous le régime de João Goulart (196164), même si ce président a tenté quelques réformes sociales et démocratiques. Ces troubles et autres dérives politiques lui vaudront d'être renversé en 1964 à la manière sudaméricaine par un coup d'État militaire orchestré par les États-Unis. L'Herbe à brûler décrit très bien ce débarquement d'un jeune Wallon dans ce Brésil exotique, torride, imprévisible et en pleine ébullition : « (...) dockers et porteurs refusaient de monter à bord, la grève était générale, elle durerait jusqu'au lendemain matin ; chacun n'avait qu'à emporter avec lui ce qu'il pouvait. 'Ces sales communistes !' entendis-je grommeler (...) $»^{2}$.

Très vite, Detrez fraternise avec la « gauche du Christ $»^{3}$, les mouvements ouvriers et estudiantins chrétiens et la mouvance politique souvent (crypto)marxiste de l'Église catholique, celle qui soutiendra les thèses de la théologie de la libération et qui sera à l'origine des communautés ecclésiales de base (CEBs) dont l'importance au Brésil est indiscutable. C'est dans ce contexte que Detrez fait la connaissance de Frei Betto, acteur incontournable de cette mouvance, ou encore de Dom Hélder Câmara. À cet égard, le témoignage de Frei Betto après le décès de Detrez procure un éclairage émouvant et complice sur cette première période du séjour de Detrez au Brésil. Ainsi apprend-on que Detrez « travaillait comme militant à la JOC internationale à Rio de Janeiro où j'[Frei Betto] étais

\footnotetext{
1 « Roclenge : la plaque du pont Conrad Detrez... », La Meuse, 21 mai 1987 (éditorial).

${ }^{2}$ Conrad Detrez, L'Herbe à brûler, p. 97.

${ }^{3}$ Représentée en France par des intellectuels chrétiens de gauche tels que JeanClaude Barreau dont le parcours rejoint quelque part celui de Detrez.
} 
dirigeant de la JEC $»^{1}$. Cette amitié sincère et chrétienne se fonde sur des idéaux communs : conscience de l'injustice en Amérique latine et de son incompatibilité avec le message évangélique, acception de la foi en tant qu'engagement, espérance d'une société égalitaire, importance du processus révolutionnaire, les mêmes maîtres à penser (Maritain, Mounier et le Père Teilhard de Chardin), mêmes références littéraires et politiques ${ }^{2}$.

En 1963, Detrez milite au sein du Movimento de Ação Popular (MAP), premier embryon d'un parti chrétien de gauche et prolongement politique de la JOC. Il met à l'épreuve ses projets et brouillons de règle d'un apostolat laïc. Conrad a vingt-deux ans ${ }^{3}$, il se sent exalté et euphorique: " Je vivais dans un état de pieux émerveillement et dressait le bilan spirituel de ma vie : j'étais né pour l'amour de Dieu et des hommes, j'étais un mystique d'un genre nouveau (...) $»^{4}$. Toutefois, l'atmosphère exubérante, métisse et déréglée du Brésil devait vite venir à bout de ce chaste et naïf projet de vie et d'ascèse. La réalité locale, ses rythmes et cultes devaient littéralement " dévorer $»^{5}$ le jeune Belge, l'écraser. Detrez n'y va pas par quatre chemins. Il applique à sa « renaissance » tropicale les catégories baptismales de sa théologie louvaniste :

Je suis né en 1937 au pays de Liège. Une deuxième vie a surgi et a bouleversé la première, en 1963, à Rio de Janeiro. Dans le premier temps, je fus villageois, de race wallonne, de religion catholique et de langue française. Dans le second, je devins banlieusard, d'appartenance carioque et de langue portugaise $^{6}$.

\footnotetext{
${ }^{1}$ Frei Betto, « Souvenirs d'un ami de Detrez au Brésil », Toudi. Culture et société, $\mathrm{n}^{\circ} 2,1988$, p. 266.

2 Idem.

${ }^{3}$ Conrad Detrez, L'Herbe à brûler, p. 111.

${ }^{4}$ Ibid., p. 110.

5 Conrad Detrez, « Dévoré par le Brésil », Le Magazine Littéraire, septembre 1982, repris dans Ludo, p. 199-200.

${ }^{6}$ Conrad Detrez, Les Noms de la tribu, p. 36.
} 
D'ailleurs ce qui le sauve, le libère et le fascine, c'est ce Brésil métissé, populaire, «plus africain qu'européen » ${ }^{1}$. À cet égard, Frei Betto rappelle le rôle essentiel joué par Detrez dans l'introduction et divulgation du concept francophone de " négritude ", politiquement dangereux et embarrassant dans la " deuxième nation nègre du monde " car, avoue-t-il, « son cœur était noir $»^{2}$. En effet, a posteriori, Detrez voit dans l'assomption de la condition de Noirs une chance et un projet pour la forte population nègre brésilienne, même si cette revendication très « postmoderne » fait quelque peu oublier l'urgence d'une quelconque révolution : "Comme pour Beatriz, la négritude confère à sa vie un sens $»^{3}$. Mais le 2 avril 1964, la situation sociopolitique du Brésil change. Un coup d'État militaire renverse le régime plutôt démocratique de João Goulart et impose une dictature militaire des plus cruelles, appuyée par les États-Unis sous le général Castello Branco. Detrez fait allusion à l'exil politique du président déposé : « L'ancien magistrat suprême et sa femme s'envolèrent en pyjama pour l'exil $»^{4}$. L'histoire prendra désormais un cours plus tragique. Les différents mouvements progressistes entrent dans la clandestinité et dans la résistance armée, souvent sous un jour plus maoïste que léniniste. Le MDB (Movimento Democrático Brasileiro), mouvement de résistance fondé par le mythique guérillero Carlos Marighela, gagne du terrain et s'organise en cellules de base infiltrées à tous les niveaux de la société tandis que le mécontentement populaire suscité par le régime dictatorial augmente.

Conrad Detrez s'engage dans les rangs de l'opposition clandestine dirigée par Marighela. La description de la résistance où le narrateur joue le guérillero étranger infiltré

\footnotetext{
${ }^{1}$ Idem.

${ }^{2}$ Frei Betto, « Souvenirs d'un ami de Detrez au Brésil », p. 266.

${ }^{3}$ Conrad Detrez, Les Noms de la tribu, p. 35.

${ }^{4}$ Conrad Detrez, L'Herbe à brûler, p. 128.
} 
occupe une bonne part du récit de L'Herbe à brûler. La diégèse de ce roman reproduit très fidèlement la militance clandestine de Detrez dans un Brésil où règnent la complicité et le danger : les tracts, les réunions secrètes, les transports d'armes, les raids contre des banques et des casernes, les enlèvements de personnalités liées au régime dictatorial, jusqu'à son arrestation par le DOPS (Departamento de Ordem Política e Social), la torture et l'expulsion du pays. Detrez a le sentiment de vivre une épopée d'un genre nouveau, grisante et périlleuse. Il joue le justicier au sein d'une société inique et corrompue : « Nous étions en fait des anarchistes chrétiens. Nous vécûmes dans l'illusion lyrique pendant un an $»^{1}$. Les personnages et militants de ce roman sont souvent des prête-noms de compagnons de route ou de guérilleros que Detrez a fréquentés à cette époque terrible, tous admirateurs de Fidel Castro et Che Guevara, tous sous le commandement de Carlos Marighela et dont le narrateur a parfois trouvé bon de maintenir les vrais noms ${ }^{2}$. Ils revêtent les traits de martyrs d'une religion nouvelle et naissante. Il y a Maura, Teresa, Rogério, Romando, Regina, Beatriz (qui prête ses traits au personnage de Sónia dans L'Herbe à brûler), Fernando, etc.

La face « respectable » de Detrez, indispensable pour déjouer la vigilance de la police politique et pourvoir aux besoins de l'organisation, consiste à donner des cours privés de français à des familles bourgeoises et à travailler à l'édition internationale du journal Folha da tarde où s'affairent plusieurs sympathisants du mouvement ${ }^{3}$, un poste somme toute important du point de vue stratégique, obtenu grâce à Frei Betto, lui-même journaliste ${ }^{4}$. Pour Detrez, cette période de " guérilla urbaine » est aussi l'occasion d'épouser toutes les richesses culturelles de

\footnotetext{
${ }^{1}$ Conrad Detrez, Les Noms de la tribu, p. 29.

${ }^{2}$ Ibid., p. 22 et 34.

${ }^{3}$ Ibid., p. 50-51. Cf. aussi Frei Betto, « Souvenirs d'un ami de Detrez au Brésil », p. 267.

${ }^{4}$ Conrad Detrez, Les Noms de la tribu, p. 79.
} 
l'exubérant Brésil, de faire sien ce métissage ethnique, de se laisser " dévorer » par ses cultes africains et païens, d'intégrer son carnaval sensuel et déréglé, de confronter sans cesse son nouvel ici tropical et exotique au là-bas de ses origines et de sa race wallonnes ${ }^{1}$. Lui, le séminariste de Saint-Trond (Saint-Trudon, Saint-Rémy), lui, l'étudiant chaste de Louvain, le voilà initié aux rites afro-brésiliens : « (...) je suis un fils d'Ogum-des-Sept-Épées, l'orisha impétueux, esprit de la guerre et du feu $(\ldots) »^{2}$. Il a subi des « fermetures du corps » aux mauvais esprits, des rites de purification, a fréquenté des pères-de-saint et mères-desaint. La période du carnaval carioque, dans son dérèglement des sens, sa réhabilitation des bas instincts, son goût intense du chaos feront le pont entre ces deux univers denses en émotions, hauts en couleurs et en odeurs : les dieux et le sexe. En quelques mois, l'ambiance populaire brésilienne sapait deux décennies d'éducation catholique dans la sereine mais terne Belgique. Cette évolution personnelle ou, pour tout dire, ce " baptême » cultuel, culturel et sexuel, Conrad Detrez l'a longuement décrit dans ses moindres épisodes marquants dans L'Herbe à brûler, roman " initiatique » s'il en est. Conrad, le narrateur autodiégétique, « subit » son dépucelage dans un bidonville de Volta-Redonda par les soins de Dona Josefa, sacristine rêvant de devenir prêtre, prêtresse d'un culte pathologique : « Tel fut mon dépucelage : un coït turbulent, difficile à pratiquer dans cette caisse mal assurée, un mauvais moment $»^{3}$.

Mais ce faux pas devait s'avérer un introït vers une plus vaste découverte, une reddition plus intense et voluptueuse. Au son de la samba, envoûté par les rythmes afro-brésiliens, le narrateur apprend à ses risques et périls combien " pendant le carnaval on fait ce qu'on veut ${ }^{4}$ et

\footnotetext{
${ }^{1}$ Ibid., p. 36.

${ }^{2}$ Ibid., p. 88.

${ }^{3}$ Conrad Detrez, L'Herbe à brûler, p. 105.

${ }^{4}$ Ibid., p. 115.
} 
que « l'amour [fait] mal $»^{1}$. Voilà qu'une jeune fille l'attire, le suce, extirpe de son corps chaste et clérical « un plaisir insupportable et délicieux, une douleur indicible mais bonne $»^{2}$, qu'une autre s'offre à lui sur la plage ${ }^{3}$ avant que, par inadvertance, il ne pénètre une vieille femme couchée à même le sable de Copacabana ${ }^{4}$. Conrad se sent la victime d'un culte orgiaque qui le dépasse, le broie : « Tout le carnaval m'avait envoûté. On avait abusé de moi $»^{5}$. Ses vieux réflexes ascétiques ne l'ont toutefois pas encore quitté : « Le remords me tenaillait, mon âme se tordait ${ }^{6}$.

L'initié compulsif n'est pas pour autant au bout de ses peines. Il lui faut encore éprouver l'orgie homosexuelle, celle dont le désir n'était que latent, mais qui insiste désormais à se montrer au grand jour. $\mathrm{La}$ folie carnavalesque le conduit vers le jeune nègre, Fernando, lui aussi « apôtre laïc » des favelas de Rio dont il tombe sur la perverse et aberrante confrérie : « Nous sommes tombés à genoux l'un devant l'autre, toujours enlacés, mouillés, baignant dans sa puissante odeur de nègre, et on s'est regardé $\gg{ }^{7}$. Or ce Fernando ressemble comme deux gouttes d'eau à cette " personne de race noire, elle-même éduquée dans la religion umbanda », et qui rendit Detrez «très réceptif à cette culture afro-brésilienne $»^{8}$. Quelques années plus tard, Detrez devait apprendre que ce même Fernando avait - retour postmoderne à une certaine " authenticité » oblige - « retrouvé la religion de ses ancêtres $»^{9}$. Cette ambiance festive intermittente ne doit pas faire oublier la gravité de la situation politique et la dureté de l'engagement du guérillero. Les opérations armées s'intensifient en

\footnotetext{
${ }^{1}$ Ibid., p. 86.

${ }^{2}$ Ibid., p. 118.

${ }^{3}$ Ibid., p. 119.

${ }^{4}$ Ibid., p. 120.

${ }^{5}$ Ibid., p. 121.

${ }^{6}$ Ibid., p. 120.

${ }^{7}$ Ibid., p. 122.

${ }^{8}$ Conrad Detrez, « Dévoré par le Brésil », p. 200.

${ }^{9}$ Conrad Detrez, Les Noms de la tribu, p. 35.
} 
réponse au durcissement du régime militaire. À la demande de Carlos Marighela, Detrez traduit en français le Manuel pratique du guérillero urbain dont devaient s'inspirer les groupes terroristes européens des années soixante-dix dans leurs actions clandestines. En février 1967, de plus en plus suspect aux yeux de ses élèves et peut-être victime de trahison au sein de l'organisation elle-même ${ }^{1}$, Conrad Detrez est arrêté à Rio de Janeiro par le DOPS, la police politique du régime militaire. Étant donné le climat de durcissement de la dictature et les suspicions du DOPS, l'Organisation confère une fausse identité à Detrez, tout comme au narrateur de L'Herbe à brûler. Il s'appellera Domingués, ce qui n'a pas évité les soupçons de la police : «Domingués, ça fait portugais, très portugais! Mais avec ces yeux bleus... $»^{2}$. Ce pseudonyme semble reproduire fidèlement la stratégie de guérillero de Detrez. Alors qu'il revisite le Brésil après avoir été amnistié, Detrez ne craint-il pas une revanche et un rappel de son passé : "'En bon agitateur, n'est-ce pas, Senhor Domingues ?', va peut-être me lancer, ironique, mon interrogateur $\rangle^{3}$.

Lors du premier interrogatoire et avant les tortures, le DOPS saura déjouer cette ruse de guérillero en lui imposant son véritable nom, dur rappel de sa belgité, évocation du père et déni ou amputation de sa condition exotique : «Tout à coup on crie mon nom, le vrai, celui de mon père $»^{4}$. Échappant à des tortures supplémentaires par l'intermédiaire de l'ambassade de Belgique, pour laquelle cet énergumène s'avère plutôt gênant, Detrez se voit expulsé du Brésil. Censé retourner dans une Belgique qui, à première vue, ne lui dit plus grand-chose, il s'installe un peu

\footnotetext{
${ }^{1}$ Comme le laisse entendre le narrateur de L'Herbe à brûler, la police politique l'aurait capturé grâce au témoignage d'un agent infiltré dans l'organisation clandestine, notamment pendant son exil à Montevideo (Uruguay). Cf. L'Herbe à brûler, p. 191.

${ }^{2}$ Ibid., p. 188.

${ }^{3}$ Conrad Detrez, Les Noms de la tribu, p. 10.

${ }^{4}$ Conrad Detrez, L'Herbe à brûler, p. 190.
} 
malgré lui à Paris en 1968. Il y vit de travaux divers, s'interroge sur les raisons profondes qui le conduiront à l'écriture, s'essaie au genre romanesque dans lequel il excellera plus tard : «J'essaie bien d'écrire un roman mais il faudra encore travailler cinq ans avant de maitriser ce genre d'expression $\rangle^{1}$, ce qui se produira avec la publication de Ludo en 1974. Entre-temps, Detrez « ressasse [ses] échecs, [sa] jeunesse perdue $»^{2}$.

Cette année-là, Paris s'apprête à vivre un printemps houleux. Si, à un premier stade, "Paris s'ennuie $\|^{3}$ et si cette ville le « dégoûte $»^{4}$, la France allait se réveiller pour un temps de sa léthargie bourgeoise. L'Herbe à brûler décrit le spleen d'un Belge fraîchement débarqué à Paris après quelques années de dures épreuves de guérillero au Brésil où il s'agissait d'implanter une révolution d'inspiration cubaine. Pour le narrateur, tous les remous dans cette ville européenne embourgeoisée « ne pouvaient (...) augurer d'une révolte, moins encore d'une révolution $»^{5}$. Dès lors, c'est avec la lucidité blasée de quelqu'un qui en a vu d'autres que Detrez observe les soixante-huitards et leurs débordements, leurs barricades et leurs mots d'ordre « a-nar-chiste[s] $»^{6}$, même s'il a failli se prendre à ce jeu-là : « C'est ainsi qu'à mon insu j'avais contracté une nouvelle fièvre idéologique : 1 'anarchisme $»^{7}$. Il est vrai que l'anarchisme n'était assurément pas au programme de la révolution latino-américaine dont l'appareil hiérarchique et l'organigramme s'avéraient plutôt rigides. Cet infléchissement préfigure déjà le recyclage qu'actera Les Noms de la tribu.

L'exil parisien constitue néanmoins l'occasion de

${ }^{1}$ Conrad Detrez, Les Noms de la tribu, p. 59.

${ }^{2}$ Idem.

${ }^{3}$ Conrad Detrez, L'Herbe à brûler, p. 200.

${ }^{4}$ Conrad Detrez, Les Noms de la tribu, p. 59.

${ }^{5}$ Conrad Detrez, L'Herbe à brûler, p. 206.

${ }^{6}$ Ibid., p. 208.

${ }^{7}$ Ibid., p. 214. 
fréquenter quelques exilés brésiliens, de divulguer des nouvelles accablantes sur le régime militaire, de maintenir des contacts internationaux et des relais. En somme, la lutte se poursuit par d'autres moyens. C'est précisément le souci de divulgation de la cause brésilienne qui amène Detrez à rentrer clandestinement au Brésil à la demande de Carlos Marighela. Celui-ci veut faire entendre son message à Paris et en français. Un entretien paraissant à Paris, dans un journal parisien, serait en effet un coup médiatique dur pour le régime dictatorial brésilien. Pour Detrez, cette interview « offre (...) sur le plan politique, une tâche en or et, sur le plan journalistique, un vrai scoop $\rangle^{1}$. Voilà Detrez à nouveau au Brésil, rentré via Montevideo pour mieux semer la vigilance du DOPS alors que le climat politique s'alourdit. En effet, l'organisation de Marighela ne lésine plus sur les moyens pour contrecarrer le régime en place. $\mathrm{La}$ guérilla urbaine s'intensifie, les vols d'armes et les assauts de banques se multiplient, les enlèvements sont fréquents. Le plus retentissant est celui de l'ambassadeur des ÉtatsUnis. Ce retour est l'occasion de retrouver clandestinement son ami et camarade Frei Betto ${ }^{2}$, de s'informer de l'état de l'Église brésilienne, de l'impact des CEBs et de la théologie de la libération sur le tissu social.

L'interview avec Carlos Marighela a lieu, mais les tensions et les soupçons soulevés par l'enlèvement embarrassant pour le régime - de l'ambassadeur américain $^{3}$, précipitent les événements. Les choses se gâtent ${ }^{4}$. L'organisation enjoint à Detrez l'ordre de quitter le pays. Marighela sera assassiné quelques jours plus tard. C'est de retour à Paris en novembre 1969 que Conrad Detrez apprend le meurtre du leader de la résistance brésilienne qu'il a eu juste le temps d'interviewer. Il y voit la preuve que, seule, la voie politique peut résoudre les

\footnotetext{
${ }^{1}$ Conrad Detrez, Les Noms de la tribu, p. 60.

${ }^{2}$ Frei Betto, « Souvenirs d'un ami de Detrez au Brésil », p. 267.

${ }^{3}$ Conrad Detrez, Les Noms de la tribu, p. 64.

${ }^{4}$ Ibid., p. 67.
} 
grandes questions du tiers-monde : « En le payant de sa vie, il [Marighela] aura nettoyé le terrain de toute illusion militariste ${ }^{1}{ }^{1}$, et contribué au recyclage politique de Detrez. Dérouté, Detrez accepte, à la suite d'une annonce, le poste d'enseignant d'espagnol et de français en Algérie, pays qu'il connaît déjà, du reste ${ }^{2}$. À cette époque, Alger respire « le cosmopolitisme et la révolution $)^{3}$. Cette ville est devenue « La Havane de l'Afrique » ${ }^{4}$. Plusieurs mouvements de résistance s'y croisent et y concertent leur action tant sur le plan politique que diplomatique. C'est ici que Detrez prend conscience des problèmes posés par d'autres dictatures non moins féroces : celle de Marcelo Caetano au Portugal et l'insolite statut des colonies africaines de ce pays dont les mouvements de libération se trouvent bien représentés à Alger. Detrez y fraternise avec plusieurs leaders de ces mouvements aux causes diverses (Arraes, Gabeira, etc.). Il y rencontre aussi le groupe de « quarante prisonniers politiques arrachés à leurs tortionnaires en échange de l'ambassadeur allemand $»^{5}$. Detrez fictionnalise, non sans humour, cet épisode dans $L a$ Lutte finale (1980), roman qui acte lui aussi la fatigue révolutionnaire du guérillero. À la fin du récit, les personnages caricaturaux de Populo et Mambo se trouvent dans un groupe de commandos brésiliens exilés en Algérie en échange de la libération d'un " diplomate teuton $»^{6}$.

Nous sommes en 1970. Detrez habite Sourel-Ghozlan. Il y est professeur. Il se penche sur les « disciplines nouvelles ${ }^{7}$, la psychanalyse surtout qu'il associe et intègre intimement au travail de l'écriture : «Moi, je découvre la psychanalyse et ressuscite mon goût de l'écriture $»^{8}$. Qui

\footnotetext{
${ }^{1}$ Ibid., p. 68.

${ }^{2}$ Ibid., p. 113.

${ }^{3}$ Ibid., p. 109.

${ }^{4}$ Idem.

${ }^{5}$ Idem.

${ }^{6}$ Conrad Detrez, La Lutte finale, Paris, Balland, 1980 et 1996, p. 114ss.

${ }^{7}$ Conrad Detrez, Les Noms de la tribu, p. 116.

${ }^{8}$ Idem.
} 
plus est, Detrez donne de plus en plus libre cours à sa sexualité dont il découvre qu'elle peut « faire mal », même si elle feint de le sauver : "Les choses de l'amour également retrouvent, dans ma vie, une place $»^{1}$, avoue-t-il.

Cette année-là paraît à Paris son retentissant pamphlet politique sur la guérilla brésilienne, résultat de son entretien de l'année précédente avec Carlos Marighela. Cet ouvrage est saisi par le ministère français de l'intérieur (on croit rêver!), ce qui provoque immédiatement une réaction collective de plusieurs éditeurs français solidaires. Detrez confirme de la sorte son indissociable statut d' « émissaire $»^{2}$ du tiers-monde parmi nous. Un besoin irrépressible de dire ce qu'il a vu, de parler de là-bas, d'en dénoncer les conditions ne cesse de le pousser. L'année 1971 marque décisivement un nouveau tournant dans la vie de Detrez. Le guérillero a trente-quatre ans et s'avoue fatigué. Son séjour dans le paysage aride algérien se prête à la contemplation et à l'autoanalyse : « Ce repli dans le silence, au-delà des montagnes du Djurdjura, favorise la méditation $»^{3}$. Detrez renoue presque à son insu avec le cloître et l'introspection religieuse.

Après la politique et son corollaire révolutionnaire, Detrez inaugure une troisième vie - littéraire, cette fois mais où l'amour sexué (et non plus chaste) sera de la partie : «Une saison de ma vie se clôturait, vécue sous le signe de l'action. Une autre saison s'ouvrait, marquée du sceau de l'écriture. Tel un arbre, une écorce nouvelle me naissait. L'enveloppe était littéraire $»^{4}$. Cette écorce ne fait néanmoins qu'entourer une écorce politique bien résistante. En effet, entre 1970 et 1971, paraissent la traduction en français de Les Pâtres de la nuit de Jorge Amado (1970), Révolution dans la paix de Dom Hélder Câmara et Mon Pays en croix d'Antonio Callado (1971).

\footnotetext{
${ }^{1}$ Idem.

${ }^{2}$ Colette Braeckman, « Les iguanes bavards de la cathédrale en ruine », Le Soir, 14 février 1985.

${ }^{3}$ Conrad Detrez, Les Noms de la tribu, p. 118.

${ }^{4}$ Ibid., p. 119.
} 
En 1971, Detrez retourne en Belgique où il entame l'écriture du premier tome de sa trilogie autofictionnelle qu'il désigne d'《 autobiographie hallucinée »" et fait la navette entre Bruxelles et Paris. Il collabore à plusieurs journaux où il tient une activité critique spécialisée ou écrit dans la presse générale : Le Monde, L'Express, Le Nouvel Observateur, Le Magazine Littéraire, Le Soir, Le Matin, Jornal do Brasil, Esprit, France culture, Antenne 2, FR 3, presse audio-visuelle à la $\mathrm{RTB}^{2}$. En 1972, Detrez publie à Bruxelles Les Mouvements révolutionnaires en Amérique latine, un essai qui s'avérera prémonitoire puisque l'année suivante au Chili, le général Pinochet renversait le régime démocratique d'Allende par un violent coup d'État. La gravité de cet événement, son retentissement sur l'intelligentsia européenne et l'afflux d'exilés chiliens en Belgique déclenchent la mobilisation en faveur de l'Amérique latine en général au sein de l'Université belge ${ }^{3}$.

En avril 1974, alors que Detrez prépare son plaidoyer dans le cadre du tribunal Russel sur la torture qui se tiendra à Rome, le Portugal attire l'attention de l'Europe en renversant une dictature fasciste moyennant une Révolution des Eillets plutôt sereine et généreuse, et qui plus est, orchestrée par de tout jeunes officiers. Pour la gauche européenne, « ce pays était devenu un point d'attraction » 4 où les choses bougent très vite, où les complexités et les dangers de la gauche révolutionnaire sont mis à nu : maoïsme, léninisme, l'URSS, la Chine, l'Albanie, la Yougoslavie, etc. Conrad Detrez devient correspondant pour la RTB à Lisbonne. Des tentatives de révolution, il en a vu d'autres. Il connait leur prix, leurs débordements et leurs faux enjeux : « Seul alors m'est devenu acceptable le

\footnotetext{
${ }^{1}$ Ibid., p. 120.

2 Éléments biobibliographiques publiés à la suite d'une " Enquête littéraire ", tapuscrit, Archives et Musée de la Littérature, s/d., p. 322.

${ }^{3}$ Pierre Mertens en fera la matière de son roman Terre d'asile (1978).

${ }^{4}$ Conrad Detrez, Les Noms de la tribu, p. 122.
} 
socialisme démocratique $»^{1}$, avouera-t-il. D'où peut-être sa vision trop " assagie », lucide et blasée des événements portugais, qu'on lui reproche à Bruxelles : « J'en fis pour ma part une description qui, à Bruxelles, parut dénuée de sérénité $»^{2}$. À Lisbonne, Detrez poursuit la récapitulation autofictionnelle de son passé. Il y rédige Les Plumes du $c o q$, roman narrant son adolescence, le séminaire et ses excès. Son essai-témoignage, La Mélancolie du voyeur (posthume) reprend pour une large part son séjour à Lisbonne. Cette ville aura contribué à une dévalorisation du penchant révolutionnaire de sa vie politique au profit d'une conception jouissive, quasi «mystique » de l'existence, raison pour laquelle Detrez raille ces « étrangers » (Belges notamment), adeptes du tourisme gauchiste qui en voudraient davantage, mais qui devront se contenter d'un coup d'État sage et inoffensif. Lisbonne n'est plus vraiment une étape " révolutionnaire " dans le parcours déjà très chargé du guérillero. Au contraire, cette ville le contamine de sa « saudade » : « La saudade. Je la possède. Lisbonne me l'a donnée. Un pan de ma forteresse $»^{3}$. La saudade, il l'éprouvera surtout de retour à Bruxelles en 1976. Il laisse derrière lui un pays où les choses se sont calmées, où la révolution est " casée ». Néanmoins, " la saudade [l']envahit ${ }^{4}$. De retour au pays, Conrad Detrez reprend sa vaste activité journalistique. C'est d'ailleurs à partir de 1977 qu'il prétend ne vivre que de sa plume ${ }^{5}$. Les Plumes du coq - écrit, rappelons-le, à Lisbonne pendant la Révolution des Eillets - paraît en 1975, une année charnière à plus d'un titre si l'on en croit Marc Quaghebeur, qui voit la première crise pétrolière opérer un repli égoïste du vieux continent ainsi qu'une fầcheuse césure dans la croissance économique de l'après-guerre.

\footnotetext{
${ }^{1}$ Ibid., p. 128.

${ }^{2}$ Ibid., p. 125.

${ }^{3}$ Conrad Detrez, La Mélancolie du voyeur, p. 120.

${ }^{4}$ Conrad Detrez, Les Noms de la tribu, p. 131.

5 À nouveau, nous nous en tenons à l'« enquête littéraire » des AML.
} 



\section{L'AUTOFICTION EN TANT QUE MYTHOLOGIE PERSONNELLE}

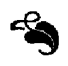

Au dire de Conrad Detrez, son entrée dans la fiction ressortit à un urgent besoin de comprendre les raisons enfouies d'un triple échec existentiel et vocationnel. Au terme de son premier périple brésilien et de son aventure picaresque de militant marxiste des favelas, Detrez confiait sa lassitude, sa solitude et surtout sa triple défaite devant les facettes d'un même désir dévorant, mais ingrat ou trompeur, et qui s'avère prémonitoire, quand on sait son funeste destin : « Mon âme avait tout appris. Elle savait à son tour que Dieu est mort, la révolution broyeuse des hommes qui la font, l'amour impossible. Elle avait payé au prix le plus fort le droit de s'en aller $\rangle^{1}$. Dans un article contemporain de ce troisième et dernier volet de son « autobiographie hallucinée », il ressasse sa hantise de compréhension d'une triple faillite de vie, du cul-de-sac d'un parcours existentiel délaissé au profit d'un stade esthétique de la vie : la quête et la jouissance de la beauté ${ }^{2}$. Mais le souci de saisir les raisons qui ont mené à cette jouissive et malicieuse apathie, et plus tard aphasie, est à l'origine d'une écriture simultanément introspective et fictive. Detrez énonce avec clarté et

${ }^{1}$ Conrad Detrez, L'Herbe à brûler, p. 231.

${ }^{2}$ Conrad Detrez, « Le jardin de la vie », repris dans Ludo, p. 196-198. 
conviction le projet de mise en fiction de son vécu :

J'ai le sentiment d'avoir tout raté. J'ai cherché à connaître les causes de ces faillites, à mettre à nu les racines de mes révoltes. J'ai lu Freud et j'ai commencé la plume à la main, à me livrer à une sorte d'analyse' .

En somme, si « mythologie $»^{2}$ personnelle il y a dans la fiction narrative detrézienne, alliage subtil d'autobiographie et de fiction, d'autoréférence et d'extrapolation fantaisiste, c'est surtout pour mieux cerner un « je » narratif conscient de son inéluctable mise en scène. À cet égard, l'écriture de l' « autobiographie hallucinée » de Detrez s'inscrit dans l'une des lignes de force théoriques par lesquelles la critique littéraire filtre la fiction de la fin du XXe siècle, souvent désignée, et pour de fortes raisons, de « postmoderne », à savoir : le retour du sujet ou plutôt, pour reprendre les mots de Sémir Badir, « résistance d'un premier degré : résistance d'un sujet, résistance du récit, malgré ; c'est-à-dire bien qu'en connaissance, de la psychanalyse et de la sémiologie $»^{3}$. Bruno Blanckeman a bien caractérisé la démarche de mise en fiction du moi que, selon lui, Conrad Detrez partage avec d'autres romanciers contemporains tels que Hervé Guibert : « l'autre du moi, la dimension imaginaire d'une identité, se met en scène (...) », une caractéristique que Dominique Rabaté met lui aussi en évidence ${ }^{4}$. Aussi le retour au (plus que $d u$ ) sujet narratif se conçoit-il avant tout en tant que « reconsidération du sujet psychique $\rangle^{5}$ par le biais de l'écriture.

Cette facette de l'écriture hallucinée de Detrez rejoint pour une large part le contexte dans lequel Blanckeman voit

\footnotetext{
${ }^{1}$ Ibid., p. 198.

${ }^{2}$ Pierre Mertens, «Detrez à la croisée des chemins ?», Le Soir, 10 février 1981.

${ }^{3}$ Sémir Badir, « Vers la postmodernité. Retour à Baudelaire ?», Écritures, no 5 , «Le dépli. Littérature et postmodernité », automne 1993, p. 19.

${ }^{4}$ Bruno Blanckeman, Les Récits indécidables, p. 21. Cf. aussi Dominique Rabaté, Le Roman français depuis 1900, Paris, PUF, 1998, p. 102-111.

${ }^{5}$ Bruno Blanckeman, Les Récits indécidables, p. 21.
} 
l'émergence d'une « subjectivité psychique ». C'est en effet non seulement par l'écriture, mais dans l'écriture, à la faveur de stratégies et de techniques narratives, c'est-à-dire " par pression narrative $\rangle^{1}$ que le sujet se met en scène, se fictionnalise. Et Blanckeman de définir la complexité, et surtout la subtilité de cette parole écrite, une phase génétique $\mathrm{du}$ sujet définie comme " pratique plus que comme substance $»^{2}$. La tentative d'approche autoréférentielle par l'écriture ne se donne plus comme besogne exclusive la récapitulation mature et sage d'une existence accomplie dont on ferait la relecture fidèle en aval. Bien au contraire, le récit de soi n'étant plus astreint aux règles fixes du rendu autoréférentiel récapitulatif, peut procurer au sujet une ou plusieurs phases " génétiques ", productives dont la démarche se situe désormais « en amont de l'existence $»^{3}$. Une telle acception du récit de soi concède tous les pouvoirs à la fiction, se donne tous les moyens et joue avec plusieurs conventions narratives : il « (...) donne l'impression d'anticiper le cours [de l'existence], de l'influencer, d'affirmer à la fois l'irréductibilité de la personne au travers d'une écriture auto-observatrice et l'indécision de la personnalité, dans ses turbulences infraconscientes $»^{4}$.

Ces considérations rejoignent celle d'un théoricien comme Sémir Badir, et permettent de mieux saisir ce par quoi la démarche autofictionnelle entérine un stade postmoderne de la fiction narrative. Dans sa version autofictionnelle, le regain autobiographique contemporain homologue un " troisième degré $»^{5}$. Ici aussi, il ne s'agit plus pour l'écriture autoréférentielle de " dénoter » ou de « connoter », mais bien de « connoter une connotation $»^{6}$. Désormais, l'écriture autofictionnelle n'entend plus « faire

\footnotetext{
${ }^{1}$ Ibid., p. 17.

${ }^{2}$ Ibid., p. 21.

${ }^{3}$ Ibid., p. 20.

${ }^{4}$ Ibid., p. 20-21.

${ }^{5}$ Sémir Badir, « Vers la postmodernité. Retour à Baudelaire ? », p. 18.

${ }^{6}$ Ibid., p. 20.
} 
illusion sur le rapprochement du narrateur et de l'auteur ni d'en dénoncer le leurre, mais au contraire d'affirmer ce rapprochement sans la moindre équivoque $»^{1}$. En tous cas, si le rapprochement entre auteur et narrateur n'est plus perçu comme un écueil théorique, c'est surtout parce que la démarche autoréférentielle est plus aisément livrée aux dérives fictionnelles. Dès lors, l'enjeu devient romanesque : « non pas se raconter, mais se faire [laisser] raconter par le roman, contaminer sa propre identité par sa mise en fiction $(\ldots) »^{2}$. Attentif à la résurgence du moi dans les lettres belges de langue française depuis les années soixante-dix, Pierre Mertens applique souvent l'expression " mythologie personnelle " ou " fiction personnelle » à ce type de construction narrative du $\mathrm{moi}^{3}$ en transgression du genre autobiographique classique. À nouveau, il s'agit de souligner le rôle du récit et du langage dans la construction du moi psychique et narratif de certains écrivains belges contemporains : « Si aveu il y a, il n'aurait guère de portée que dans la mesure où il découle d'un débat noué avec la langue elle-même. Le Moi Je est un Moi-jeu, mais où le ludisme peut être mélancolique et mortel $»^{4}$.

Le projet scriptural detrézien d'une " autobiographie hallucinée » en trois volumes ressortit à la conception contemporaine du récit de soi que d'aucuns appellent autofiction. L'autofiction suppose la possibilité d'un tel écart génétique (construction du moi fictif), et générique (dérogation au genre autobiographique). Or l'expression " autobiographie hallucinée » entérine clairement une proposition pactuelle, paradoxale et oxymorique, alliant un souci d'autoréférence à l'affirmation patente de fiction. Ce faisant, elle homologue le jeu narratif récurrent mais

\footnotetext{
${ }^{1}$ Ibid., p. 15.

2 Ibid., p. 16.

${ }^{3}$ Pierre Mertens applique ces notions à Conrad Detrez, mais aussi à Eugène Savitzkaya et Jean-Claude Pirotte, entre autres, et ce dans différentes contributions critiques.

${ }^{4}$ Pierre Mertens, « Du retour à l'autobiographie », p. 62.
} 
consiste, au début, en tableaux perceptifs mobiles et plastiques, centrés sur l'activité propre $»^{1}$. Ces premiers stades accusent la subtile évolution au sein du « réalisme enfantin », c'est-à-dire le passage de la confusion entre les choses et la pensée, stade où l'enfant est littéralement son monde ${ }^{2}$, vers celui du « réalisme nominal » au cours duquel « [les] enfants distinguent bien le nom de la chose nommée, mais ne comprennent pas que le nom puisse venir d'ailleurs que de la chose $\rangle^{3}$, et le recours à une justification simpliste (en tous cas pour l'adulte) telle que « Le Bon Dieu » ou « Ma maman a dit ». À ces stades, l'interprétation de l'activité onirique s'en ressent. Si dans un premier temps le rêve semble venir du dehors et demeure extérieur dans sa compréhension, à un second stade il semble avoir une origine intérieure, mais est perçu comme extérieur, et ce avant que l'enfant ne perçoive l'origine et la logique intérieures de son rêve ${ }^{4}$.

Dès lors, les petits enfants font preuve d'une tendance égocentrique irrépressible à « inventer des mythes » ou, pour employer une terminologie piagétienne, à la « fabulation ». Incapable d'un raisonnement logique, l'enfant confond la réalité et l'imagination, la référence et la fiction, et élargit ainsi la portée du réel, voire se construit une réalité bien à lui. Pour ce faire, il recourt souvent à l'exagération compte tenu de l'absence à ce stade d' « un système objectif englobant le corps propre [et] sans se centrer sur lui $»^{5}$. La fabulation se traduira çà et là par un recours au mensonge, élément-clé de la morale pré-conventionnelle ou hétéronome dans laquelle l'orientation morale est avant tout tournée vers le binôme obéissance / punition et suppose une vision instrumentale et pragmatique des choses et des échanges. Ceci nous amène

\footnotetext{
${ }^{1}$ Ibid., p. 308.

2 Jean Piaget, La Représentation du monde chez l'enfant, Paris, PUF, 1972, p. 31 .

${ }^{3}$ Ibid., p. 57.

${ }^{4}$ Ibid., p. 78-101.

${ }^{5}$ Ibid., p. 324.
} 
aux considérations de Jean-Marie Sutter sur le mensonge enfantin, qu'il désigne aussi de « pseudo-mensonge », qui « (...) sont [un] produi[t] spontan[é] et origina[1] de la pensée enfantine $\rangle^{1}$, repérable et démontable dans l'usage du langage. À cet effet, il rappelle que « le langage est pour lui [l'enfant] un jeu ; il s'amuse de ce pouvoir nouveau et merveilleux (...) ». Le langage possède aussi bien chez l'enfant que chez le primitif, " une valeur magique, incantatoire $»^{2}$ qui a partie liée avec la spécificité de son activité imaginative. Comme le rappelle Sutter, « alors que, chez l'adulte, la fiction comporte toujours un élément spéculatif et abstrait, elle est ici plus concrète, plus conforme à l'étymologie car l'enfant n'imagine que des 'images' $»^{3}$.

Support irremplaçable de la ferveur de l'enfance, l'animisme enfantin consiste à considérer comme vivants, conscients et intentionnés un grand nombre de corps qui pour les adultes sont inertes. Cet « animisme spontané » traduit « la conscience prêtée aux choses $\rangle^{4}$, laquelle évolue ici encore selon plusieurs stades. Dans un premier temps, « tout est conscient $\|^{5}$. Ensuite, « tout mobile est conscient $»^{6}$. À un troisième stade ne sont considérés conscients que « les corps doués d'un mouvement propre $»^{7}$. Finalement, la conscience est « réservée aux animaux ${ }^{8}$. L'animisme découle d'une vision générale de l'activité et de la vie ${ }^{9}$. Tout semble vivant, les astres et les phénomènes météorologiques notamment, dont on attribue la causalité au « Bon Dieu » ou à d'autres fondements selon la culture religieuse ambiante. À ce niveau, l'animisme se redouble d'un « artificialisme » qui rend compte de l'origine des choses et du monde (naissance,

\footnotetext{
${ }^{1}$ Jean-Marie Sutter, Le Mensonge chez l'enfant, Paris, PUF, 1956, p. 21.

${ }^{2}$ Ibid., p. 25.

${ }^{3}$ Ibid., p. 27.

${ }^{4}$ Jean Piaget, La Représentation du monde chez l'enfant, p. 145ss.

${ }^{5}$ Ibid., p. 148-149.

${ }^{6}$ Ibid., p. 152-153.

${ }^{7}$ Ibid., p. 154-155.

${ }^{8}$ Ibid., p. 157-158.

${ }^{9}$ Ibid., p. 164ss.
} 
création du monde, etc. $)^{1}$. Il n'est d'enfance sans " merveilleux », sans contes de fées et leurs personnages hybrides et fantastiques. Indissociable de la compétence fabulatoire des enfants et de leur propension à « inventer des mythes ", pour reprendre Piaget, le merveilleux en tant que « genre » littéraire ne connait guère de limites matérielles ou formelles, et ce contrairement au fantastique. Comme le souligne Tzvetan Todorov, le merveilleux suppose une simple convention ou alors un stade de développement intellectuel (l'enfance) en vertu duquel " les éléments surnaturels ne provoquent aucune réaction particulière ni chez les personnages, ni chez le lecteur implicite $»^{2}$. Selma $\mathrm{H}$. Fraiberg désigne ce stade d'" années magiques », lequel constitue une étape durant laquelle l'enfant forge sa personnalité en la confrontant à ses peurs et à ses mythes. Ogres et sorcières cohabitent avec l'enfant, contribuent à sa formation personnelle ${ }^{3}$ et conditionnent un moi qui se défend contre toutes sortes de danger. Par ailleurs, ce danger guette partout et se montre multiforme. Michel Zlotowicz énonce ces phobies propres à l'enfance qui, tout en s'avérant très " physiques ", n'en acquièrent pas moins quelques ramifications «symboliques »: noyades, dévorations, animaux sauvages, sorcières épouvantent l'enfant tout en façonnant sa personnalité ${ }^{4}$.

Il serait vain, voire absurde, de s'emparer de Ludo en vue d'une étude scientifique consacrée à la psychologie enfantine. En revanche, confronter ce texte à ces données et à ces travaux de psychologie de l'enfance peut s'avérer pertinent et éclairer la perspective autofictionnelle en l'illustrant sous un jour " puéril » qui souligne son originalité. Cette démarche permet également de démontrer les différents processus de mise en scène du moi, de fictionna-

\footnotetext{
${ }^{1}$ Ibid., p. 294ss.

2 Tzvetan Todorov, Introduction à la littérature fantastique, Paris, Seuil, 1970, p. 59.

${ }^{3}$ Selma H. Fraiberg, Les Années magiques, Paris, PUF, 1967, p. 3-33.

${ }^{4}$ Michel Zlotowicz, Les Peurs enfantines, Paris, PUF, 1974, p. 33.
} 
lisation de soi. Ludo reflète ce souci d'un pacte romanesque autofictionnel déclaré aussi bien dans les franges péritextuelles du récit proprement dit que dans les considérations épitextuelles de l'écrivain sur son écriture (entretiens, textes autobiographiques, témoignages). Nous l'avons dit, Detrez affirme vouloir revenir sur son enfance et procède librement à l'inscription fictive de sa biographie dans les textes. Ce faisant, il s'invente un moi fictif qui, tout en n'étant plus astreint à la ressemblance, n'en laisse pas moins le lecteur en état de « légitime méfiance »" Ludo (1974), écrit après son retour du Brésil, tente d'approcher fictionnellement les souvenirs de l'enfance de Detrez durant la Seconde Guerre mondiale. Le cadre du roman comporte plusieurs éléments diégétiques qu'un narrateur homodiégétique assemble au rythme d'une mémoire infantile : une guerre couve, des avions de guerre déchirent le ciel, la pluie ne cesse de tomber, le Geer déborde, un petit gamin ne pense qu'à rejoindre son petit voisin, Ludo, dans son jardin, sa maison. La mère possessive - « jamais nommée maman $»^{2}-$ s'acharne à l'en empêcher à et interdire leur secrète amitié. Ludo est tout sauf un récit linéaire. Le texte autofictionnel opère un collage de souvenirs stimulé par l'ambiance quasi panique du récit. À maintes reprises Detrez a souligné le fait que ce premier volet de son « autobiographie hallucinée » puisait sa diégèse dans ses souvenirs d'enfance à Roclenge (Pays de Liège), que cette maison et ce jardin furent bien les siens au $\mathrm{n}^{\circ} 2$ de la rue de la Halle, tout près du petit pont qui enjambe le Geer (et porte désormais son nom), entre l'église paroissiale et la place communale où se trouve le monument aux soldats morts des deux guerres.

La hantise de ce lieu dans l'écriture de Detrez a déconcerté, voire déçu, plus d'un critique. N'était-on pas en droit de s'attendre à ce que, de retour des révolutions et des sursauts de l'Histoire, Detrez peigne une fresque épique du

\footnotetext{
${ }^{1}$ Philippe Lejeune, Le Pacte autobiographique, Paris, Seuil, 1975, p. 33.

2 Préface de Jacques Bauduin à Ludo, p. 7.
} 
tiers-monde en ébullition, du Portugal en effervescence ? ${ }^{1}$ Que Detrez se comporte en reporter de l'Histoire ? Son projet était tout autre : tâcher de comprendre par le biais de l'écriture les raisons de ses échecs successifs, lui qui s'avouera déçu de Dieu, de la politique et blessé par l'amour. Cette analyse, Detrez entend la mener dès le plus jeune âge, en revisitant et en ressuscitant par la fiction quelques épisodes fondateurs que la mémoire gardait en jachère. Il eût été tentant de parler de soi, enfant, sur un ton bêtement récapitulatif, complaisant, avec un discours logique et sage de bilan existentiel. Il préfëre le difficile travail qui allie mémoire et langue, souvenir et fable. Le narrateur homodiégétique nous fait part de l'âge du couple formé par les deux personnages principaux : « Il [Ludo] avait six ans, j'en avais cinq ; il me dépassait de quelques centimètres $»^{2}$. Par ailleurs, un peu plus loin, nous apprenons qu'" on a photographié Ludo pour ses six ans $\rangle^{3}$. Ce repère d'âge permettra de mieux saisir la stratégie autofictionnelle à l'œuvre dans le récit, une stratégie que renforce l'usage constant du présent. En effet, un phrasé « panique » ${ }^{4} \mathrm{~s}$ 'acharne à reproduire une agitation et un enthousiasme discursif qui va jusqu'à l'essoufflement, parfois jusqu'à l'hystérie. Par exemple, la noyade imminente du père du petit narrateur est rapportée par un gamin insouciant de la construction phrastique. En outre, l'absence de ponctuation accentue l'affolement de la scène :

Le père de Ludo est arrivé en courant

Le père et la mère sont entrés dans l'eau

La veuve Alphonse est accourue avec le cantonnier

Le père de Ludo a nagé avec le cantonnier jusqu'à Bassenge ${ }^{5}$.

\footnotetext{
${ }^{1}$ C'est ce que rappelle André-Joseph Dubois dans sa lecture de Ludo, p. 166 : «Quel gâchis, ont dû penser les éditeurs (...)!».

${ }^{2}$ Conrad Detrez, Ludo, p. 47.

${ }^{3}$ Ibid., p. 77.

${ }^{4}$ Une expression qui caractérise toute l'œuvre « hallucinée » de Conrad Detrez.

Cf. la préface de Jean-Louis Lippert à Les Plumes du coq, p. 8.

${ }^{5}$ Conrad Detrez, Ludo, p. 88.
} 
Le premier fragment séquentiel du récit plante d'emblée le décor de l'hallucination narrative. Les phrases se suivent à une cadence déchainée qui mime le rythme chaotique de l'action: «Il pleut. Les eaux montent. Les gens se précipitent sur des sacs de jute, les remplissent de sable et de fumier. Ma mère accourt affolée avec, sous le bras, son filet à provision $\gg{ }^{1}$. Detrez puise dans ses souvenirs d'enfant pour reconstruire un cadre où les adultes se signalent par l'hystérie, l'affolement et le désarroi, êtres peureux, tragiquement placés entre deux coordonnées implacables : la Seconde Guerre mondiale, surtout présente dans le ciel où passent les avions de combat, et les crues du Geer : « La guerre se démène à longueur de jours et de nuits entre lac et ciel. Le lac ne monte plus, le ciel ne descend pas. Si la guerre plongeait tout entière dans l'eau (...), qu'est-ce qui se passerait? $»^{2}$.

La restitution du discours enfantin, de son phrasé et de sa syntaxe est l'un des soucis majeurs du narrateur homodiégétique. Réprimandé sévèrement par sa mère pour ne pas avoir vu à temps sortir et flotter un ouf du clapier, le personnage principal oscille entre l'envie de pleurer, le désarroi et la culpabilisation. Ce trouble provoque le hoquet chez le petit garçon, que le récit reproduit par une mimique discursive saccadée, bégayante, balbutiante et confuse et où les virgules concourent à une rythmique du désespoir : « Je me punis, je n'ai rien fait, je me punis quand même, j'ai le hoquet. Je suis innocent raté. Un raté, un innocent raté $! »^{3}$. Le même procédé panique peut être à l'origine de néologismes par agglutination. Piégée entre le feu de la guerre et l'eau des inondations, la mère du narrateur est en proie à l'hystérie : « À la fin, elle courait si vite que je la voyais tout le temps passer devant la porte et crier : 'on brûlera on se noiera, on brûlera on se noiera, on se brûnoie on bruroie...' ’ ${ }^{4}$.

\footnotetext{
${ }^{1}$ Ibid., p. 18.

${ }^{2}$ Ibid., p. 136.

${ }^{3}$ Ibid., p. 138-139.

${ }^{4}$ Ibid., p. 23-24.
} 
Autofiction de l'enfance, Ludo n'est pas trop sourcilleux sur les constructions syntaxiques. La construction interrogative y est souvent libre, restituant mieux le discours du gamin : " Pourquoi Ludo il ne peut pas venir ? » ${ }^{1}$. Comme chez le primitif, le langage y possède « une valeur magique, incantatoire $»^{2}$. Ainsi les crues de la rivière ont contraint les voisins à se relier par un réseau de ponts faits de planches. Cette construction se révèle assez fabuleuse pour que le gamin s'extasie et que le récit s'emballe : « Un pont blanc relie la vieille dame à sa voisine. Un pont (j'y pense depuis le début de la crue). Un pont (j'y pense la nuit). Un pont blanc (comme un lit) $»^{3}$. Ailleurs, c'est le danger de noyade dans le courant du Geer qui est épousé par une cascade narrative saccadée : « La neige fond, les eaux montent, la cascade au bas du ventre de mon camarade ne s'arrête pas. L'eau coule, inépuisable $»^{4}$.

Le recours constant au temps présent dans le récit contribue à maintenir la vivacité de la restitution en tant que reconstruction mémorielle. Il induit l'affolement du discours, corollaire de l'hystérie des adultes, de la panique du contexte et du balbutiement du discours enfantin : « La rivière fait trembler toutes les mères du village. Chaque année un enfant s'y noie. Les mères se liguent, elles proclament que les eaux abritent un dévoreur de chair (...) $»^{5}$. Aussi l'emploi généralisé du présent met-il davantage en relief le caractère non linéaire, foncièrement désorganisé du récit, permet-il de " restituer la matière brute d'une mémoire enfantine $»^{6}$ perçue dans son chaos et sa spontanéité propres, et soulignet-il par là même son atemporalité : « Ma mère ne sort plus, elle nage dans l'eau de la vaisselle, au milieu de la cuisine. Elle m'appelle, mais je ne sais pas nager, elle n'a jamais

\footnotetext{
${ }^{1}$ Ibid., p. 95.

2 Jean-Marie Sutter, Le Mensonge chez l'enfant, p. 25.

${ }^{3}$ Conrad Detrez, Ludo, p. 145.

${ }^{4}$ Ibid., p. 54.

${ }^{5}$ Ibid., p. 43.

${ }^{6}$ Lecture d'André-Joseph Dubois à Ludo, p. 172.
} 
voulu me l'apprendre $»^{1}$. Par ailleurs, la récurrence de certains thèmes et de certaines images concède à Ludo des effets poétiques fascinants qui touchent parfois au mythologique. Par exemple si, dès l'incipit, l'enfant déclare sa reconnaissance à l'égard de sa mère salvatrice : « Tu m'as repêché, ma mère, je le sais, tu m'as sauvé des eaux », cette affirmation se retrouve reprise plus loin avec une légère alternance sous forme de refrain litanique : « Ma mère m'a sauvé du feu $\gg^{2}$. Pareil effet poétique d'envoûtement cautionné par le fonctionnement et l'agencement du texte est procuré par les conjectures d'adéquation et d'assimilation d'un enfant en état d'apprentissage du monde : « La guerre fait un bruit de guêpe (...), un bruit de chat qui dort / un bruit de vieille femme / un bruit de feuille de papier qu'on pose devant ses lèvres / et qu'on fait vibrer $»^{3}$.

En effet, à certains égards, le récit entend renouer avec le poème en prose tant il apparaît maîtrisé, conditionné dans sa construction pour parvenir à restituer l'enfance telle que l'enfant la vit. La restitution du discours de l'enfance passe également par une constante superposition au récit de l'enchaînement logique de l'enfant de sa langue propre et hermétique, étanche vis-à-vis de tout raisonnement logique adulte. Ce procédé met à profit la juxtaposition, parfois saccadée, de phrases refusant toute subordination complexe. Le phrasé bref rassemblé en séquences narratives s'acharne à maintenir ou consolider la cohérence des affirmations de l'enfant par une reprise anaphorique et souvent par un jeu métonymique déconcertant aux yeux d'un adulte. Ce procédé est absolument récurrent, pour ne pas dire obsessif dans Ludo. Il atteste d'un souci de maintien d'une logique enfantine qui, nous y reviendrons, ressortit à l'animisme et à la capacité infinie d'émerveillement.

${ }^{1}$ Conrad Detrez, Ludo, p. 54.

2 Ibid., p. 57.

${ }^{3}$ Ibid., p. 85. 
Pour ce faire, le texte narratif accumule les expressions comparatives que le réalisme transforme plus ou moins en équivalence. Par exemple, le narrateur décrit de façon réaliste l'irruption des rayons de soleil dans la chambre des parents de Ludo. L'éblouissement du soleil et la réfraction de la lumière sur l'édredon suggèrent au petit garçon un "soleil qui se caresse sur l'édredon », c'est-à-dire que « l'édredon m'attire comme l'eau d'un puits » dont l'image acquiert une réalité maintenue, voire confirmée dans le discours de l'enfant : « se baigner dans un puits de soleil $»^{1}$. De même, la joute du jet d'urine par laquelle les deux petits voisins rivalisent est à l'origine d'étranges dessins sur la neige, laquelle s'apparente à une page blanche. Le narrateur, assis sur les épaules de Ludo, « dessine » réellement des constellations jaunes sur la feuille vierge. Le jeu est interrompu par l'irruption de la mère. La « réalité » enfantine, elle, n'est aucunement démentie : « Ma mère sort en trombe, piétine les dessins, renverse monture et cavalier $»^{2}$.

L'épisode où le père du gamin a failli se noyer fournit à nouveau l'occasion d'illustrer ce jeu anaphorique par le biais duquel le récit garantit l'étanchéité magique du discours puéril. Le père soûl quitte la maison, tombe dans les flots du Geer. La mère accourt et essaie de le sauver. Pour le petit personnage et narrateur homodiégétique, témoin de cette anecdote, la tête affolée et gonflée d'eau du père suggère une bouillotte. Cette "réalité » se voit consolidée par le dénouement de la séquence narrative : « Ma mère la saisit, la bouillotte crève, se vide glissant du même coup entre les doigts de la ménagère $»^{3}$. Ce dispositif n'est rendu possible que par la manie du narrateur à assimiler et comparer ce qu'il découvre, ce à quoi il assiste, à d'autres pans de réalité déjà connus. Ce faisant, l'enfant use des pouvoirs comparatifs du langage afin de découvrir, assimiler et conquérir son univers

\footnotetext{
${ }^{1}$ Ibid., p. 30.

2 Ibid., p. 51.

${ }^{3}$ Ibid., p. 87.
} 
propre. Pas étonnant dès lors que le récit de cette double hystérie en temps de guerre accumule les expressions comparatives. Ce procédé rend aussi compte d'un souci de restitution de la part de l'auteur d'une mémoire synesthésique. En fait, la logique enfantine fonctionne essentiellement par rapprochements comparatifs successifs. L'inconnu, le méconnu ou l'étrange ne peuvent être intégrés dans la réalité enfantine que dans la mesure où ils sont susceptibles d'une comparaison avec les objets quotidiens, ceux de l'expérience infantile. Et le petit narrateur de multiplier les termes syntaxiques de la comparaison, les « comme », les « ressemble à » et les « on dirait» :

La soie blanche est plate comme un lit dans lequel on ne dort pas ${ }^{1}$;

Le jardin s'ouvre comme un cahier ${ }^{2}$;

(...) l'urine vagabonde comme un chiot $^{3}$;

(...) les gouttes s'allument comme des insectes de nuit ${ }^{4}$;

La peau du jardin vieillit, on dirait les mains de la veuve Alphonse ${ }^{5}$; fèves ${ }^{6}$;

Les grains [du chapelet] glissent sur son tablier comme des

Son visage [celui de Ludo dernière les carreaux] ressemble $\grave{a}$ un portrait sous un verre ${ }^{7}$;

On dirait [Ludo au nez noirci par la suie] le nègre qui passe avant saint Nicolas dans la cheminée ${ }^{8}$.

Les nuages et le brouillard persistant au-dessus du Geer engendrent le même souci de compréhension et d'assimilation par rapprochement et tâtonnement comparatif: " On dirait des vaches gonflées comme des nuages, des vaches de vapeur $»$. Le dernier cochon abattu par le père, une

\footnotetext{
${ }^{1}$ Ibid., p. 46. C'est nous qui soulignons.

${ }^{2}$ Ibid., p. 48. C'est nous qui soulignons.

${ }^{3}$ Ibid., p. 49. C'est nous qui soulignons.

${ }^{4}$ Idem. C'est nous qui soulignons.

${ }^{5}$ Ibid., p. 54. C'est nous qui soulignons.

${ }^{6}$ Ibid., p. 58. C'est nous qui soulignons.

${ }^{7}$ Ibid., p. 69. C'est nous qui soulignons.

${ }^{8}$ Ibid., p. 81. C'est nous qui soulignons.
} 
fois nettoyé à l'eau chaude et lissé, suscite à nouveau l'expérience de l'enfant : «On aurait dit un noyé » ${ }^{1}$.

Ludo entend donc mener un travail de diction de l'enfance à partir de l'enfant lui-même, ce qui implique une maitrise dans la construction narrative. Or l'enfant compare, assimile, tâtonne dans son discours, procède à l'adéquation comparative du réel. D'où les ambigüités au niveau du récit, ses redites et réélaborations touchant çà et là le poème en prose, faisant primer le personnage principal sur le narrateur, lequel s'efface aux yeux du lecteur à certains moments du récit. Il en va ainsi de ce souvenir de la meule hissée au sommet de la maison du petit personnage principal : « La meule est un lit sur une île. La meule est un lit sur une maison, sur une île $»^{2}$. Toutefois le travail de maîtrise narrative pour restituer l'enfance dans sa logique va plus loin dans Ludo. Le narrateur homodiégétique, de plus en plus effacé au profit du personnage enfantin principal, affiche tous les symptômes de l'animisme enfantin et d'une conception magique de la réalité qui prêtent volontiers une conscience aux choses. Les avions allemands qui croisent le ciel de Roclenge et lâchent leurs bombes destructrices sont perçus comme étant des « oiseaux de fer » : « Des morceaux de fer traversent le ciel au-dessus des prés (...). Des bouquets de fumée fleurissent. Les oiseaux plongent comme des martins pêcheurs, les eaux s'ouvrent jusqu'au lit de vase, les oiseaux s'éteignent $\eta^{3}$. Cette version est récurrente et consolide un effort narratif pour se placer par le discours du côté de l'enfance : « Les oiseaux s'allument au-dessus des peupliers, piquent, s'écrasent dans de gigantesques jets de flammes, d'eau et de terre $\gg^{4}$.

L'artificialisme enfantin renforce l'animisme et lui adjoint la question de l'origine modelée par la religiosité infantile et les préjugés de l'éducation : « Les oiseaux de fer,

\footnotetext{
${ }^{1}$ Ibid., p. 111. C'est nous qui soulignons.

${ }^{2}$ Ibid., p. 83.

${ }^{3}$ Ibid., p. 27.

${ }^{4}$ Ibid., p. 41.
} 
les lourdes constellations volant bas, chargés de poudre, d'éclairs, viennent d'un pays où les enfants ne prient pas. Ils se battent avant de savoir marcher $»^{1}$. Parfois leur forme suggère « un énorme marteau travers[ant] les nuages $(\ldots) »^{2}$, mais toujours muni d'une conscience, ce que l'enfant de cet âge commence à n'attribuer qu'aux animaux : " une bande de rapaces, les plus noirs qu'on ait vus depuis le début de la guerre, sont sortis d'un nuage, ont perdu quelques plumes audessus de la prairie $»^{3}$. Les bombes lâchées ne peuvent être que des « œufs de malheur $»^{4}$ pondus par des rapaces impitoyables, mais fascinants. La guerre et l'eau font également l'objet d'une constante et spontanée personnification de la part de l'enfant, lequel en fait deux véritables personnages très présents au même titre que la mère et aussi hystériques qu'elle. Ce procédé concourt à la mise à distance de l'instance narrative. Ainsi les eaux de la crue du Geer, la guerre ou la neige jouissent d'une personnalité et d'une conscience très vivaces, comme d'innombrables exemples l'illustrent :

\author{
Il [Ludo] attend. L'eau attend ${ }^{5}$; \\ Les eaux montent la garde ${ }^{6}$; \\ La neige et la pluie attaquent ${ }^{7}$; \\ Les chuchotements s'estompent, l'eau se tait ${ }^{8}$
}

Par ailleurs, la guerre est censée se déplacer selon que l'enfant s'aperçoit du vol des avions, ou à mesure que les rumeurs sur l'évolution des opérations sur le terrain, véhiculées hystériquement par les adultes, lui parviennent: « La guerre ronronnait comme [assimilation] une vieille

\footnotetext{
${ }^{1}$ Ibid., p. 59.

${ }^{2}$ Ibid., p. 65.

${ }^{3}$ Ibid., p. 150.

${ }^{4}$ Ibid., p. 149. Cf. aussi Conrad Detrez, L'Herbe à brûler, p. 14.

${ }^{5}$ Conrad Detrez, Ludo, p. 22.

${ }^{6}$ Ibid., p. 21.

${ }^{7}$ Ibid., p. 56.

${ }^{8}$ Ibid., p. 115.
} 
institutrice. Elle fredonnait des comptines. La guerre allait, venait, jouant à des riens. Et on jouait avec elle. Puis soudain la guerre fait volte-face, elle se retourne contre ses partenaires $»^{1}$. La guerre se meut dans la mesure où Ludo lui-même se déplace : «Ludo ne viendra plus ? Ça dépend. Ça dépend ? Ça dépend de la guerre ! La guerre est partie ? Où est-elle partie ? Là, du côté de la mer, du côté de la frontière, en France... $»^{2}$. La personnalité de la guerre lui confère un statut terrifiant, menaçant pour l'enfant, et que la mère sait mettre à profit dans son rapport avec lui. La guerre devient une menace ou un puissant interdit dans l'éducation du gamin : « Si la guerre entre par la porte, je me cacherai sous le garde-manger $»^{3}$. Dès lors, la mère peut invoquer la guerre pour interdire la fugue du fiston rebelle vers le jardin de Ludo : « La guerre ! Ah ! La guerre! Tu la veux, la guerre? Tu l'auras! $»^{4}$.

Tout comme avec l'eau, la mère est censée pouvoir dialoguer avec la guerre, voire la conjurer: « Ma mère devise avec l'eau $»^{5}$, «Elle insiste, vouvoie l'eau $»^{6}$. Parfois, à la faveur d'une accalmie, d'une stabilisation du niveau des eaux, ce dialogue est interrompu, ou bien la balle est du côté de l'eau : « Ma mère et la guerre n'ont rien à se dire (...) »" «L'eau écoute, elle s'est installée définitivement sur le seuil $\|^{8}$. Les phénomènes météorologiques ou naturels connaissent la même animation et induisent la même fascination. C'est le cas des figures dessinées ou suggérées par l'amoncellement des nuages que le narrateur homodiégétique interprète de façon réaliste, ce qui confère aux phénomènes un aspect tantôt fascinant, tantôt effrayant :

\footnotetext{
${ }^{1}$ Ibid., p. 129.

${ }^{2}$ Ibid., p. 113.

${ }^{3}$ Ibid., p. 148.

${ }^{4}$ Ibid., p. 22.

${ }^{5}$ Ibid., p. 70.

${ }^{6}$ Ibid., p. 71.

${ }^{7}$ Ibid., p. 114.

${ }^{8}$ Idem.
} 
« On dirait des vaches gonflées $(\ldots) »^{1}$. Selon l'interprétation magique de l'enfant, le ciel de Roclenge donne l'impression de s'être " cassé en deux ». Cet élément cosmogonique trouve néanmoins une justification magique, mais plausible chez l'enfant : « Dans un ciel on lave et dans l'autre on met sécher, c'est la femme du diable qui fait la lessive $»^{2}$. De même, le soleil est perçu selon un géocentrisme animiste très imagé : " Une tache de soleil court d'une porte à l'autre comme une vague, illumine l'intérieur de la maison, se jette dans les eaux entre les plantes, et les buissons encore émergés $»^{3}$.

Muni d'une personnalité « naturelle » et d'un psychisme propre, le soleil participe du chaos festif des jeux des deux enfants : «Il s'est levé trop tard, il mélange des heures (...); il s'embrouille $»^{4}$ puisqu' « il se lève à l'endroit où il devrait se coucher $\eta^{5}$. Ainsi, le narrateur de Ludo révèle une conception animiste des rêves qui ressortit à la plus tendre enfance. L'imagination onirique se présente comme venant du dehors, mais hésite à demeurer extérieure au sujet onirique. En effet, le narrateur a quelque mal à comprendre le phénomène onirique qu'il subit : « Le jardin de Ludo est sorti de ma nuque. J'ai senti le passage, les plantes, les fleurs ont frissonné, les parterres se sont ramassés, le couloir vers l'intérieur de ma tête s'est élargi (...). Le jardin de Ludo $s^{\prime}$ installe en moi quand je dors $»^{6}$. Plus loin, le narrateur voit ce même jardin rêvé, jardin du désir de fugue et d'évasion, comme « se trouv[ant] aussi dans ma tête. Le jardin s'est logé dans ma tête mais ma mère ne le sait pas $»^{7}$. En tous cas, le processus onirique déconcerte le personnage principal et se confond dans sa tête avec le sommeil : « Je ne dors pas, je

\footnotetext{
${ }^{1}$ Ibid., p. 101.

${ }^{2}$ Ibid., p. 107.

${ }^{3}$ Ibid., p. 69.

${ }^{4}$ Ibid., p. 99.

5 Idem.

${ }^{6}$ Ibid., p. 76.

${ }^{7}$ Ibid., p. 100.
} 
rêve que je ne dors pas $\rangle^{1}$. De même, le processus hypnotique suscite des interprétations animistes. En effet, le sommeil dispose de « conduits » secrets et souterrains ${ }^{2}$, une « porte » qu'il s'agit de franchir ${ }^{3}$. Le sommeil est subi, involontaire : « Je me suis endormi sans le vouloir ${ }^{4}$. Il n'est pas associé à la fatigue et déconcerte le petit enfant dans sa confusion animiste avec son rêve : « Je ne dors pas, je rêve que je ne dors pas $»^{5}$.

En outre, une atmosphère merveilleuse, peuplée de monstres, d'ogres, de personnages fantastiques active les peurs enfantines et délimite, tout en les justifiant, les aires réservées au monde adulte. Ce faisant, elle stipule des tabous. Le danger de la noyade dans les eaux du Geer est conjuré par la croyance au mythe d'« un dévoreur de chair, un homme aux dents rouges $\rangle^{6}$ que le petit narrateur assimile à un $\left\langle\right.$ ogre $»^{7}$ dévoreur. Outre la noyade, c'est l'écrasement qui terrorise l'enfant : « (...) j'ai peur que le plafond ne m'écrase $»^{8}$, ou encore les peurs associées aux tabous alimentaires et comportementaux inculqués par la mère : « Le réglisse, c'est dangereux, on s'endort, le bois s'arrête dans la gorge et on meurt $»^{9}$. De même, un récit cosmogonique merveilleux explique l'origine de la pluie et du beau temps, et ce à une saison véritablement diluvienne. Le narrateur de Ludo ne doute absolument pas du fait mythologique selon lequel « Le ciel [se serait] cassé en deux (...). Il y a deux ciels : un qui pleut, un qui rit ${ }^{10}$. Le ciel qui «pleut » suggère une femme lavant son linge, « (...) c'est la

${ }^{1}$ Ibid., p. 124.

${ }^{2}$ Ibid., p. 44.

${ }^{3}$ Ibid., p. 63.

${ }^{4}$ Ibid., p. 115.

${ }^{5}$ Ibid., p. 100.

${ }^{6}$ Ibid., p. 43.

${ }^{7}$ Idem.

${ }^{8}$ Ibid., p. 131.

${ }^{9} \mathrm{Ibid}$. , p. 78.

${ }^{10}$ Ibid., p. 107. 
femme du diable qui fait sa lessive $»^{1}$. Et le narrateur autofictionnel de le jurer : « Je l'ai vue, j'ai vu sa chevelure, longue et pleine de cendres, et son nez crochu $»^{2}$.

Cette crédulité affichée est bien évidemment à rapprocher de celle que suscitent les contes chez les enfants. D'autres peurs enfantines épouvantent le narrateur de Ludo âgé de cinq ans. Outre la peur des monstres, celle d'une destruction physique le hante. La mère, jamais nommée maman, l'entraîne dans son hystérie, ses sautes d'humeur, ses menaces. Elle devient littéralement une mère castratrice, trouble-fête et surtout trouble-jeu. Aussi, quand le narrateur et son voisin, Ludo, se mettent à rivaliser lors du jeu du jet d'urine, la mère menace-t-elle durement son fiston exhibitionniste : " Elle me gifle, crache sur mon sexe, le frappe. Ludo crie (...). Elle s'empare de mon sexe, le serre, elle va me le couper, c'est fini, c'est la dernière fois $(. ..) »^{3}$. La mère ne relativise pas les peurs de l'enfant. Elle les fomente, s'assure de leur bien-fondé. La crainte d'une destruction physique prend souvent la forme du fantasme immémorial de la disparition, de l'engloutissement : « Je m'enfonce jusqu'aux genoux (...). Je suis mort et je ne suis pas mort $»^{4}$, celui aussi d'une noyade dans les eaux « diluviennes » du Geer, qui longe le jardin de la maison natale du narrateur (et de Conrad Detrez) à Roclenge : « L'eau coule, inépuisable. La noyade est un danger permanent ». Et le discours transductif et hermétique par rapport à toute contestation logique renforce ce fait inéluctable puisque décrété par les mères : "Le geste des mères leur survit. Elles meurent. Les morts continuent à sauver leurs enfants des eaux ${ }^{5}$. Car se noyer peut faire encourir à l'enfant, dans sa vision spatiale imaginaire, un voyage sans retour, un entraînement infini par le cours des eaux :

\footnotetext{
${ }^{1}$ Idem.

${ }^{2}$ Idem.

${ }^{3}$ Ibid., p. 51.

${ }^{4}$ Ibid., p. 52.

5 Ibid., p. 54.
} 
Nous sommes entraînés vers l'immensité des eaux de la cour, vers le Geer qui bouillonne, impatient, qui file vers la Meuse, aspiré par elle, attiré vers Maastricht, vers la Hollande, et bientôt livré aux tourbillons de la mer et la mer du Nord, en hiver, est glaciale, on y meurt de froid ${ }^{1}$.

À côté de ce discours que le récit autofictionnel reproduit, et pour contrecarrer l'épouvante, il y a la création imaginaire du jeu, le ludisme (Ludo ?) infini. L'enfant jouit d'une capacité déconcertante à inventer des jeux, à s'inventer des règles et un univers ludique propre. Jean Chateau l'a bien rappelé : le jeu chez l'enfant de cet âge (le personnage a cinq ans, Ludo en a six) joue un rôle de " pré-exercice » dans le processus développemental infantile ${ }^{2}$. Chez l'enfant de cet âge, l'activité ludique est affublée d'un sérieux qui engage tout son être, qui manifeste sa personnalité ${ }^{3}$. Dès lors, à l'instar de l'autofiction, le jeu de l'enfant allie, par un processus oxymorique, son sérieux intrinsèque (observance d'une règle arbitraire) à l'évasion fictive et à l'imagination. Mais à ce propos, Chateau insiste sur l'incontournable rapport de dépendance du jeu enfantin à l'égard de l'univers des adultes. En effet, imiter ou fuir le monde adulte, c'est toujours et encore dépendre d'un modèle dont il s'agit de prendre une revanche inoffensive ${ }^{4}$.

Ludo et son compagnon et voisin inséparable multiplient les fugues et infractions à l'égard du monde adulte. Dans le jardin « originel » de Ludo, dans cet éden ludique, on s'amuse avant toute faute. On y joue en toute innocence les rôles parentaux : « Mon camarade se prend pour son père, je suis le mien. Il m'appelle mais moi je joue avec le soleil. Et puis, les papas ne se marient pas avec les papas $»^{5}$. On y joue le jeu de l'identité : « Monsieur Ludo

\footnotetext{
${ }^{1}$ Ibid., p. 117.

${ }^{2}$ Jean Chateau, A Criança e o jogo, Coimbra, Atlântida, 1981, p. 8.

${ }^{3}$ Ibid., p. 26.

${ }^{4}$ Ibid., p. 42-45.

${ }^{5}$ Conrad Detrez, Ludo, p. 32.
} 
touche la main de Monsieur-Moi $»^{1}$. Jean Chateau l'a bien décrit : à ce stade, les enfants tendent à vouloir imiter avec réalisme et de « façon stylisée leur modèle $»^{2}$.

Le jeu se veut aussi l'occasion d'un processus initiatique, d'une ruse à l'égard du monde des adultes : « Que faire puisque nous sommes devenus des hommes? $»^{3}$. Alors qu'ils ne boivent que de l'eau pour mieux fournir leur jet d'urine, les deux gamins ont le sentiment de se soûler : « Les hommes se soûlent et s'engagent n'importe où, comme des hommes. Le danger n'existe pas $»^{4}$. Comme les hommes, les gosses jouent à la guerre: "L'adversaire se cache. Nos désirs de guerre nous restent sur le cœur $»^{5}$. Mais, épris d'animisme et de réalisme, on fait le mort : «Le mort couché sur le ventre ouvre un ${ }^{2} i l »^{6}$, ou encore « On va jouer au mort, propose mon camarade. Et les fleurs ? Les fleurs ? Tu les mettras sur moi (...). Je ne joue pas! Je n'aime pas faire le mort, lui dis-je. C'est pour rire... Je ne sais pas pleurer pour rire. Les morts ne pleurent pas! Si, ils pleurent ! $»^{7}$. Ces derniers détails confirment le souci de réalisme dans l'initiative, et le sérieux avec lesquels les enfants conçoivent leur activité ludique. À ce titre, la mort est un jeu terrible, cruel et lent qu'il ne faudrait pas prendre à la légère. Ces observations du narrateur devaient s'avérer prémonitoires si l'on considère le destin de Detrez : « Elles [les fleurs] meurent lentement. Je mourrai comme une fleur $»^{8}$. Par ailleurs, Ludo restitue les souvenirs fictionnalisés des jeux de prouesse du narrateur (et de Detrez). Il s'agit surtout des concours de jet d'urine où les deux compagnons de jeu mettent leur force et leur puissance viriles à l'épreuve. Uriner fort, loin et longtemps détermine la personnalité des garçons.

\footnotetext{
${ }^{1}$ Ibid., p. 34.

2 Jean Chateau, A Criança e o jogo, p. 110.

${ }^{3}$ Conrad Detrez, Ludo, p. 35.

${ }^{4}$ Ibid., p. 39.

${ }^{5}$ Ibid., p. 36.

${ }^{6}$ Ibid., p. 97.

${ }^{7}$ Ibid., p. 103.

${ }^{8}$ Ibid., p. 104.
} 
Ludo, de par son jet continu et enviable, s'affirme comme dominant. Le narrateur d'un récit par lequel Detrez entend déterrer les raisons enfouies de ses échecs ultérieurs y est dépeint comme "dominé ", impuissant ou maladroit : «Ludo a saisi le milieu de sa verge. Il la serre entre le pouce et l'index, imprime au jet des mouvements circulaires, d'avancée, de retrait (...). Je m'applique, j'étudie son art (...). Je n'ai sûrement pas pincé ma verge au bon endroit $»^{1}$.

Conrad Detrez se fictionnalise donc aussi du côté de l'enfance. L'énonciation se fait çà et là complice de l'énoncé autofictionnel. Sa stratégie narrative oscille entre le chaos puéril et la graphie du souvenir. Mais c'est le désordre discursif et mnésique qui l'emporte. Le narrateur, le plus souvent effacé au profit du personnage-enfant, s'en rend bien compte : "Les enfants fleurissent dans les parterres au gré des saisons, dans le périmètre des jardins, sous le soleil ou la neige. Les parents l'oublient, ils sont bêtes. Ils enferment les enfants dans les cuisines $\rangle^{2}$. Rappelons que Detrez place ce premier récit " halluciné » sous le signe de l'imagination infantile. L'épigraphe rimbaldienne inspire le jeu antithétique de cette fiction narrative de soi : les enfants en deuil et les merveilleuses images de Ludo, la maison claustrale, aquatique et maternelle et l'évasion vers le jardin imaginaire. Le narrateur fournit une réélaboration personnelle de l'image de Rimbaud, celle de la fascination de l'enfant cloitré à l'égard des pouvoirs du dehors : " Je scrutais le pays des eaux, les prés, les jardins ondoyant comme des algues au fond d'un aquarium $»^{3}$.

\subsection{Rupture de ton et entremise mythologique}

Une autre stratégie récurrente de mise en scène de soi par la fiction dans l'écriture detrézienne consiste à imprégner

\footnotetext{
${ }^{1}$ Ibid., p. 49-50.

${ }^{2}$ Ibid., p. 47.

${ }^{3}$ Ibid., p. 141.
} 
la banalité du récit d'une " extase mystique » et à la sacrer d'une « charge odieuse ou comique ». Aussi l'«autobiographie hallucinée» nourrit-elle constamment ce statut équivoque et instable faisant alterner sans crier gare la panique et le ton comique, le tragique et le picaresque, le sacré et le profane, la solennité liturgique et le chaos carnavalesque. L'écriture autofictionnelle revendique ici aussi son caractère mitoyen et oxymorique. Jacques Bauduin considère ce procédé un « effet de brouillage » narratif induit par l'hallucination, la mémoire et le fantasme ${ }^{2}$. À ce titre, Detrez n'est pas seulement « frère de Tijl Ulenspiegel $»^{3}$. Il renoue avec une tradition marginalisée de l'écriture qui trouve de bonnes racines chez François Rabelais (ou Charles De Coster), voire dans le théâtre populaire médiéval. En fait, les épithètes se pressent pour qualifier l'irrégularité à l'œuvre dans cette trilogie autofictionnelle. Jean-Louis Lippert, partant de sa lecture de Les Plumes du coq, lance « gothique » pour rendre compte de « (...) l'inscription de ce livre dans un projet traversé par une même veine épique et démesurée - plus baroque encore : gothique $»^{4}$.

Nous retiendrons surtout l'oscillation jouissive et très maitrisée entre le « grotesque », le « baroque » et le sacré, voire l'épiphanique, le tragicomique et le burlesque. La poétique hallucinée de Detrez est forgée par et dans un pays d'entre-deux, une contrée foncièrement frontalière. Elle associe la saveur des parlers wallons, la glaise hesbignonne aux carillons et brumes des villes flamandes. Chez Detrez, la critique parisienne croit renouer avec le filon des clichés littéraires, " activés par le fantasme $»^{5}$ dont elle a souvent affublé les lettres belges : alliance de langue française et de

\footnotetext{
${ }^{1}$ Préface de Jean-Louis Lippert à Les Plumes du coq, p. 10.

${ }^{2}$ André-Joseph Dubois considère ce procédé un « effet de brouillage » narratif induit par l'hallucination, la mémoire et le fantasme. Lecture de Ludo, p. 168.

${ }^{3}$ Préface de Jean-Louis Lippert à Les Plumes du coq, p. 8.

${ }^{4}$ Idem.

${ }^{5}$ Lecture de Ludo, p. 171.
} 
thématique germanique, notamment l'atmosphère nordique, brumeuse et grise ${ }^{1}$. Jacques Franck souligne également ces apparentes ruptures de ton et de style comme étant le fait d'une écriture de frontière : « (...) un mélange original et fascinant de vérité profonde et de vision fantastique $»^{2}$ que consolide l'alliage germanique et " manuélin $\|^{3}$ où la question de la quête subjective fait corps avec la maitrise de la langue. Dans Ludo, récit chaotique d'une hystérie villageoise collective, en pleine Seconde Guerre mondiale, les avions de chasse allemands déchirent le ciel, lâchent leurs bombes, s'effondrent parfois. Le Geer est sorti de son lit, alimenté par des pluies diluviennes. L'eau envahit tous les espaces du quotidien : les cuisines, les basses-cours, les jardins potagers, les poulaillers. Les gens se terrent chez eux, éprouvés par le manque d'aliments et les rationnements. Les hommes s'absentent, résistent. Les soupçons, les ouï-dire et les délations sont monnaie courante. Les femmes se replient sur leurs maisons, s'affolent, prient, invoquent les saints, le Bon Dieu. Elles connaissent la guerre et l'eau, devisent avec elles, interrogent le ciel. Elles élèvent leurs enfants, les raisonnent, sermonnent, nouent une amitié complice et interdite. Le narrateur (cinq ans) et son voisin (six ans) transforment ce chaos hystérique en univers ludique, en espace évasif et initiatique. Ce cadre fournit un " univers barbare, trivial et halluciné $»^{4}$, mais « tour à tour baroque, cocasse et poétique, toujours émouvant $»^{5}$.

L'univers consolidé dans les deux autres volets de l'« autobiographie hallucinée » engendre des « images fortes et violentes » que Jacques Franck n'hésite pas à rapprocher de la peinture flamande, notamment de l'expressionnisme de

${ }^{1}$ Idem.

2 Jacques Franck, « L'individu dans l'Histoire : Pierre Mertens et Conrad Detrez », La Libre Belgique, 27 septembre 1978.

${ }^{3}$ Pierre Mertens, «Detrez à la croisée des chemins ? », Le Soir, 10 février 1981.

4 Jacques Franck, «L'individu dans l'Histoire : Pierre Mertens et Conrad Detrez », La Libre Belgique, 27 septembre 1978.

${ }^{5}$ Idem. 
Permeke ${ }^{1}$. Dans cette " fiction en prose », l'intervention narrative et discursive des deux enfants, axée sur des séquences anecdotiques, concourt à désamorcer, et par là même à mettre en relief l'atmosphère panique généralisée du texte. Les saynètes enfantines, ou le regard que les deux gosses portent sur le monde adulte, contribuent à la rupture burlesque et bouffonne d'un récit dans lequel, autrement, domineraient le sérieux et le tragique. Elles procurent une lecture tragicomique de la guerre et des inondations. Elles inversent la gravité de l'histoire, la ridiculisent, la déréalisent, voire l'annulent. De ce fait, le langage opère un « brouillage » de l'histoire dans le récit, mais aussi des stratégies autofictionnelles de ce récit où prime l'évocation de " fureurs mystérieuses et affections passionnées $»^{2}$. En témoigne ce souvenir fictionnalisé de Detrez où la mère affolée enjoint à son fiston de l'accompagner dans la récitation du chapelet. La prière est censée se substituer à la nage : «On prie! Quand on ne sait pas nager, on prie ! », et ses fruits sont attendus de manière tout à fait superstitieuse et mécanique. Prier devrait faire automatiquement baisser le niveau des eaux : « Est-ce que ça monte ? Prie, gamin ! Je vous salue, je vous salue, je vous salue, je vous salue, je vous salue $(. ..) \gg{ }^{4}$. Au milieu de cet acte pieux déjà si malmené, le môme éprouve une soif urgente : «Elle prend à nouveau la bouteille, boit une gorgée. Elle signe les lèvres avec le goulot. Je n'aime pas l'eau bénite, je voudrais du lait. - Du bénit Bois, ça te fera du bien $»^{5}$.

Les Plumes du coq, deuxième volet de la trilogie autobiographique hallucinée de Detrez, reprend non plus l'enfance mais l'adolescence d'un narrateur homodiégétique depuis son entrée au séminaire de Saint-Trudon. Le nouvel interne est immédiatement confronté à l'atmosphère étrange,

\footnotetext{
${ }^{1}$ Préface de Jacques Bauduin, Ludo, p. 7.

${ }^{2}$ Conrad Detrez, Ludo, quatrième de couverture.

${ }^{3}$ Conrad Detrez, Ludo, p. 58.

${ }^{4}$ Idem.

${ }^{5}$ Ibid., p. 59.
} 
inhospitalière et lourde qui règne dans la bâtisse, ainsi qu'au régime autoritaire, brutal, voire sadique qui y est en vigueur. On y apprend en effet à se mortifier, à se soumettre aux diktats d'un dieu invisible quoiqu'omniprésent, un véritable Big Brother lascif, efféminé et multiforme, régnant en maître sur la psychologie religieuse des jeunes pensionnaires : L'Époux : « Mon Époux ? Ça doit vouloir dire autre chose... enfin... je ne sais pas : Mon Époux, je vous jure... Ça me tracasse $(. ..) »^{1}$, «Car, vocifère-t-il [le supérieur], l’Époux est jaloux. Sachez-le : l'Époux est toujours près de vous, Il vous suit, Il vous aime, Il écoute derrière vos oreilles, Il s'assied sur vos mains $(\ldots) »^{2}$.

Les vecteurs d'une " autobiographie hallucinée » sont nettement dégagés : « Mon Époux, je vous jure... J'ai treize ans, mon Époux. Si je m'attendais à ce que vous m'habitiez le soir même de mon arrivée ! $»^{3}$. Tout comme celui de Ludo, le narrateur de Les Plumes du coq aime à braver naïvement les interdits. La fugue, l'exploration de l'extérieur sont autant de désirs irrépressibles mais violemment réprimés dans l'enceinte de l'internat. Et tout comme celui de Ludo, ce narrateur - adolescent cette fois - se trouve un complice, un autre fascinant et exotique. Le voisin de dortoir de Conrad s'appelle Victor. Le corps enseignant du lugubre internat affecte ses pupilles à des tâches ingrates et brutales. Dans le poulailler du collège Saint-Trudon, les séminaristes doivent accomplir leur « besogne $»^{4}$. Leur tâche consiste à tailler le plumage des poules, et surtout la fascinante parure des coqs : «Le coq privé de sa parure, humilié, court dans tous les sens, battant ce qui lui reste d'ailes, se précipitant contre la clôture $»^{5}$. Le poulailler est de surcroît le théâtre de perversions dont le narrateur, en fugueur curieux, en apprenti

\footnotetext{
${ }^{1}$ Conrad Detrez, Les Plumes du coq, p. 23.

${ }^{2}$ Ibid., p. 39.

${ }^{3}$ Ibid., p. 24.

${ }^{4}$ Ibid., p. 29.

${ }^{5}$ Ibid., p. 31.
} 
voyeur $^{1}$, a pris connaissance en suivant le supérieur dans sa randonnée zoophile nocturne.

Dans une atmosphère non moins hystérique que celle de Ludo, et qui plus est malsaine, éclate la Question Royale belge autour de l'éventuel retour de Léopold III après la Libération. Poussé par le culte de l'Époux, le collège SaintTrudon se veut le bastion et du catholicisme, et de la monarchie en ces contrées limitrophes (le Pays de Liège), dès lors politiquement susceptibles à plus d'un titre. Aux jeunes internes, le supérieur enjoint d'aller coller les oui favorables au retour du roi sur les murs plutôt hostiles de Liège la laïque, la païenne, la socialiste, où les non régnaient en maitres. Fuir ne consiste plus à quitter son jardin vers le jardin d'en face, mais faire le mur vers les champs de betteraves des alentours, ou s'initier à l'étrangeté et à la promiscuité de la ville. Mais le climat tendu, austère, sporadiquement fantastique du récit n'est pas à l'abri d'une rupture de ton. Ici encore le burlesque envahit le contenu diégétique et le déstabilise. Alors qu'il s'agit de prendre parti à un moment crucial de l'histoire belge, la tâche des partisans adolescents est tournée en dérision par leur inaptitude et leur amateurisme. Cet épisode burlesque entend rappeler au narrataire, si besoin était, que l'histoire ne joue ici qu'un rôle allusif, que son statut n'est pas aussi sérieux qu'il ne le laisse entendre : « La palissade offre à la contemplation de ceux qui passeraient une longue tapisserie de OIU, de OIN, de ONI posés comme des flotteurs sur les eaux de la Meuse quand le vent du nord fait des vagues $»^{2}$. La croisade politique s'avère tragicomique mais toujours émouvante dans sa bouffonnerie.

Pareil procédé de carnavalisation du texte et de discrédit burlesque en guise de rupture de ton narratif est également mis à l'épreuve dans le dernier volet du triptyque halluciné, L'Herbe à brûler. Ce dernier récit commence par la reconstruction fictive de l'entrée du jeune adolescent dans

\footnotetext{
${ }^{1}$ Cf. Conrad Detrez, La Mélancolie du voyeur, p. 13.

${ }^{2}$ Conrad Detrez, Les Plumes du coq, p. 102.
} 
l'univers du séminaire, dont il offre en somme une deuxième version tout aussi hallucinée. Le voisin de chambrée n'est plus Victor, mais un certain Leopoldus. Il n'est plus blanc aux cheveux d'ange, mais d'origine africaine.

Le narrateur homodiégétique connaitra Louvain (la vieille, la flamande et " la-merde $\rangle^{1}$ ) à une époque où le « Walen buiten » bat son plein, où le Royaume unitaire de Belgique approche de sa mutation. Mais la fugue prend cette fois une dimension internationale. Influencé par les récits et l'expérience des étudiants de théologie sud-américains, le narrateur, par le biais duquel Detrez se met en scène, part pour le Brésil où il tente de vivre en « missionnaire laïc » au service des favelas et des ouvriers démunis. Le durcissement de la dictature brésilienne, associé à la découverte de sa bisexualité, l'amène à reconsidérer le sens de son combat et de sa vie, lesquels se joueront de plus en plus sur le plan politique. Le personnage principal devient militant clandestin, guérillero urbain. Trahi par sa propre organisation, il est renvoyé en Belgique, non sans d'abord passer par Paris, où éclate le mouvement anarchiste de Mai 68. Enthousiaste d'abord, déçu plus tard, le Detrez fictif se retrouvera à Bruxelles-Brussel avant de rentrer dans la maison natale et matricielle, celle de Ludo, abandonnée, polysémique, où reposent les souvenirs qui serviront de ressort à la fiction.

À nouveau, Detrez, en bon compatriote de De Coster, en frère d'écriture de Rabelais, et surtout en " écrivain de langage $\rangle^{2}$, sans préjudice d'une quête subjective patente, insiste à introduire le comique et le bouffon au milieu d'un récit marqué par la gravité des événements historiques comme par la douleur due à l'évolution toujours problématique et initiatique du personnage. Le ton burlesque de certains épisodes fictifs vient déstabiliser la prévisibilité

${ }^{1}$ Conrad Detrez, L'Herbe à brûler, p. 65.

${ }^{2} C f$. à ce propos ce que l'on peut en lire dans Michel Zumkir, « La langue belge et la belge écriture de Patrick Roegiers », Le Carnet et les Instants, $\mathrm{n}^{\circ} 127$, 15 mars -15 mai 2003, p. 2-5. 
lyrique du récit. Il en va ainsi de l'ambiance vécue à Louvain lors du « Walen buiten ». Les manifestations de rue et les échauffourées prennent surtout l'apparence d'une bataille de tartes à la crème ou de guerre picrocholine. La Dyle devient le réceptacle de cette colère ridiculisée par le récit. On y jette à tour de rôle et avec la même conviction la culture française et la peinture flamande, c'est-à-dire le mythe identitaire : " Comme ils francisaient les noms des peintres [Flamands, s'entend] les activistes les ont jetés dans la Dyle (...). Les élèves se sont lancés au cri de 'Vive la culture française !' sur les premiers Flamands qui passaient et les ont à leur tour culbutés dans la rivière $» 1$.

La contamination grotesque et bouffonne est renforcée par l'inclusion disséminée dans le récit de détails mordants et satiriques, dignes du ton farcesque et truculent des légendes flamandes. Ainsi le professeur de « jurisprudence civile ecclésiastique " a perdu son beau chapeau dans les échauffourées linguistiques et communautaires louvanistes. Mais ce qui contribue à la dérision narrative, c'est le statut et le registre anecdotique, burlesque de cette perte :

(...) le chapeau s'était détaché de son crâne et, porté par le vent, s'était mis à planer, telle une feuille, au-dessus de la rivière (...). La coiffure se précipiterait avec les flots de la Dyle dans le Rupel puis bientôt dans les eaux grasses et grises de l'Escaut. Avant la fin de la journée le joli feutre neuf du professeur flotterait, ballotté, crasseux, imbibé de mazout, entre les navires quittant le port d'Anvers².

Mais l'heureux brouillage du récit halluciné et autofictionnel detrézien est surtout le fait d'une perspicace et spontanée introduction du mythe et du sacré dans le banal et le profane. Jean-Luc Lippert l'a pertinemment souligné : l'écriture detrézienne opère dans un même texte la mythification et la réhabilitation du bas et du profane ainsi

${ }^{1}$ Conrad Detrez, L'Herbe à brûler, p. 87.

${ }^{2}$ Ibid., p. 88. On trouvait pareil procédé, mais attribué à une conscience infantile cette fois, dans Ludo, p. 117. 
que la sécularisation du mythique et du sacré. Dans Ludo volet autofictionnel consacré à la prime enfance de Conrad Detrez et objet d'une maitrise narrative toute particulière en vue de la restitution la plus fidèle possible de ce stade, et de la libre reconstruction mémorielle - plusieurs séquences narratives indépendantes peuvent être lues comme la mise en œuvre d'un effet de déstabilisation du texte dans sa linéarité et homogénéité par le biais d'une lecture religieuse, mythique, biblique, voire cosmogonique du contenu diégétique dont le résultat réfère à plusieurs soucis narratifs. Il s'agit bien évidemment, pour une part, de rendre compte d'une piété infantile encline à l'interprétation magique et mythique du quotidien. Mais d'autre part, ce procédé concourt à un effet de rupture dans le discours du récit et à sa magnétisation transitoire, permettant au banal et au profane d'accéder à une aura textuelle inespérée et dès lors surprenante.

Le Geer, petit ruisseau et affluent de la Meuse, connait une montée impressionnante de ses eaux d'un point de vue infantile, d'autant plus que la rivière longe le jardin de la maison natale du petit Conrad. Cet « événement » marquant dans la mémoire du môme acquiert une dimension mythologique pour le roman qu'accentuent le phrasé bref et la panique de la séquence. L'inondation persistante, associée à la guerre punitive qui traverse les cieux, renvoie à un « déluge » eschatologique : « Le village flotte sur la rivière (...). Il pleut. Les eaux montent ${ }^{1}$. La montée des eaux, tout comme le déluge biblique du temps de Noé, façonne le cosmos, instaure un avant et un après ces inondations. Le présent atemporel et général appuie ce sentiment. Cette impression est renforcée par l'atmosphère chaotique et mythique pour l'enfant, qui règne sur le village : « Le feu et l'eau m'épargnaient. Toutes les secondes ma mère me sauvait la vie $»^{2}$. Le récit de $L u d o$ commence d'ailleurs par

${ }^{1}$ Conrad Detrez, Ludo, p. 18.

${ }^{2}$ Ibid., p. 19. 
cet hymne laudatif en clin d'œil à l'histoire sainte où Moïse est le " sauvé des eaux ». La dimension sotériologique est détournée par l'ironie et par le burlesque de la scène vers un salut plus prosaïque que Rabelais ne démentirait pas : « Tu m'as repêché, ma mère, je le sais, tu m'as sauvé des eaux » ${ }^{1}$.

Dans le même registre détourné et dérisoire, le narrateur place son petit voisin, Ludo, au centre d'un improbable combat mythologique et épique, car : «Maintenant le voici condamné à subir, dans son jardin, l'épreuve de l'eau et du feu $»^{2}$. Petit enfant très pieux, Detrez a dû assimiler plusieurs fresques bibliques, plusieurs épisodes évangéliques marquants au cours du catéchisme. Le serveur du café des colombophiles s'apparente à la figure de Zachée, personnage de l'Évangile. Comme lui, il s'agit d'un " petit homme ». Lorsque les soldats arrivent, cet homme adopte la stratégie de Zachée : « (...) il court se cacher dans des troncs d'arbre $»^{3}$ d'où il peut mieux voir, étant donné sa petite taille, mais sans être vu. De même, un épisode aussi prosaïque que la tentative « épique » de la récupération d'un œuf issu du poulailler et flottant dans la cuisine inondée, est porté à un statut cosmogonique inattendu. Dans ce décor, l'œuf renvoie à la totipotence de la vie, l'origine de toute chose en proie aux aléas du cosmos et de ses éléments.

L'œuf est le précieux Graal, l'inestimable prix d'une quête affolée, essentielle, cruciale : " L'œuf ballotte. Des forces opposées le font aller, venir. Il finit par tourner sur luimême. L'œuf fait la toupie. Ma mère rame tant qu'elle peut, déplace des litres d'eau, creuse le liquide entre elle et l'œuf dans l'espoir de l'attirer mais l'œuf recule $»^{4}$. Le thème du jardin, central dans $L u d o$, mais très prégnant dans les deux autres récits de l'« autobiographie hallucinée », fait lui aussi l'objet d'une lecture ambigüe dont l'effet consiste à mythifier et brouiller transitoirement la réception du récit. Dans Ludo la

\footnotetext{
${ }^{1}$ Ibid., p. 17.

2 Ibid., p. 25.

${ }^{3}$ Ibid., p. 144.

${ }^{4}$ Ibid., p. 136-137.
} 
guerre et les crues du Geer contraignent les habitants de Roclenge à se terrer hystériquement chez eux, à descendre dans les caves lors des bombardements, à se refermer un peu plus encore en tant que communauté close, matriarcale, toujours sur la défensive. Au petit narrateur, il est strictement défendu de sortir, de se rendre chez Ludo, dans le jardin de Ludo, espace magique et édénique, d'autant plus précieux qu'il subit l'influence néfaste des calamités : « Le jardin a rétréci $»^{1}$. Espace enclin à l'évaluation spatiale, animiste et merveilleuse de l'enfant, le jardin procure un milieu ludique infini : « Le jardin, la cour étaient secs. Nous pouvions partir en expédition $»^{2}$. Enneigé, il s'apparente à une page blanche offerte à l'imagination et créativité des deux gosses : « Le cerisier pousse au milieu de la salle à dessin $»^{3}$, d'où l'intervention obsédante des mères dans le sens de défendre son accès aux enfants. Les mères voisines font les troublefêtes et les trouble-jeux : «Elle ne supporte plus de me voir jouer dans le jardin $»^{4}$. De par les interdits qui l'entourent ou le concernent, le jardin gagne en polysémie. Il est l'espace de fugue vis-à-vis du domus maternel où règnent l'hystérie et la peur. Il encaisse les conséquences des crues et des bombardements : «Le jardin, on ne le retrouvera plus $»^{5}$. Il recèle de richesses imaginaires et inépuisables : « Le jardin de Ludo est un alignement de guirlandes poudrées de bronze $»^{6}$.

Il procure à l'enfant un espace mental et onirique fabuleux dont la prégnance s'affirme durant son sommeil : « Le jardin s'est logé dans ma tête mais ma mère ne le sait pas $\gg^{7}$. Son image perdure la nuit, nourrit son imagination et produit toutes sortes de conjectures puériles : « Le jardin, la nuit, est-ce encore un jardin ? C'est peut-être un trou et l'eau

\footnotetext{
${ }^{1}$ Ibid., p. 21.

2 Ibid., p. 34.

${ }^{3}$ Ibid., p. 49.

${ }^{4}$ Ibid., p. 48.

5 Ibid., p. 75.

${ }^{6}$ Ibid., p. 99.

${ }^{7}$ Ibid., p. 100.
} 
tombe dans le trou et, le matin, le trou est bouché $»^{1}$. Aire de plaisir et d'innocence, le jardin se rapproche du jardin mythique de la Genèse. Y demeurer est une grâce; en être chassé ou exclu, une malédiction et un châtiment : « La dernière fois que je suis allé dans le jardin de Ludo, il y avait des âmes [nuages considérés d'un point de vue animiste]. Ce sont elles qui nous en ont chassés, ce ne sont pas les eaux $»^{2}$.

Les champs de betteraves de Les Plumes du coq configurent un puissant et original relai du jardin édénique puisque leur rôle est plus emblématique que mythique. Par contre, L'Herbe à brûler voit renaître l'« âme de jardinier » de Conrad Detrez, qui se confond fictivement avec le narrateur. Ce métier sert de camouflage à un moment crucial de la résistance au Brésil alors que Detrez se cache derrière le faux nom de " Domingues » et s'apprête à être dénoncé, torturé et chassé vers l'insipide Belgique. En tant que fonctionnaire de la voierie de Rio, le faux Domingues renoue avec son « enfance et adolescence villageoise $»^{3}$. Dans le jardin botanique, Detrez se sent comme un poisson dans l'eau. Cet espace procure un havre de beauté et de paix à un guérillero belge éprouvé mais émerveillé, "dévoré » par l'Amérique latine. Le jardin sert même de cadre à l'élaboration d'une première vocation littéraire : « Ce roman, je l'intitulerais Les Mémoires d'un Jardinier $»^{4}$. Son ambiance change le soir venu, "Dans cette zone tout un monde de filles et d'hommes, de garçons et de travestis s'évaluaient du regard (...) $»^{5}$, d'autant plus que la végétation se prête à la drague. Aussi depuis Ludo, le thème du jardin homologue-t-il un lieu narratif où peut se consumer « une passion sacrilège $»^{6}$. L'ambigüité du jardin édénique,

${ }^{1}$ Ibid., p. 107.

${ }^{2}$ Ibid., p. 102.

${ }^{3}$ Conrad Detrez, L'Herbe à brûler, p. 178.

${ }^{4}$ Ibid., p. 203.

${ }^{5}$ Ibid., p. 178.

6 Jacques Franck, « L'individu dans l'Histoire : Pierre Mertens et Conrad Detrez », La Libre Belgique, 27 septembre 1978. 
oscillant entre innocence et culpabilité, naïveté et vice, chasteté et lascivité s'avère une stratégie de « brouillage » du récit et un des moyens de provoquer des effets de lecture plurielle. Rappelons à cet égard qu'un roman aussi « chaste » et naï que Le Dragueur de Dieu, dont un détail du triptyque de Jérôme Bosch (Le Jardin des délices) illustre la couverture, réélabore dans sa quête des rapports subtils qu'entretiennent religion et sexualité avec le thème polysémique du jardin, tantôt paradisiaque, tantôt lubrique ou grotesque. Ce texte met en scène la quête initiatique du narrateur (Lucien) centrée sur un certain Victor, à certains égards alter ego de Detrez : jeune séminariste, mystique, dévot des Saints-Anges ${ }^{1}$ qui quitte Paris sans prévenir.

Si le jardin du séminaire était déjà le théâtre de théophanies angéliques, c'est désormais dans les jardins parisiens chargés d'ambigüités que le narrateur tâchera de trouver son compagnon et la mystique angélique. Dans ce roman « chaste $»^{2}$, le narrateur fait la connaissance d'autres figurations angéliques et dès lors, pour respecter l'étymologie, " messagères » d'un désir infini : des guérilleros, des travestis, des homosexuels, des strip-teaseurs peuplent un univers fantasmatique urbain qui transforme en sensualité et en drague toute élévation mystique et ascétique. Mais c'est dans les jardins publics que ces théophanies mystico-sensuelles se produisent. Ainsi les « combattants du Christ ", guérilleros et militants chrétiens, conseillent à Lucien de chercher son camarade séminariste dans ces lieux d'échanges polysémiques : « Les jardins, n'oubliez pas : tous les jardins... Bonne promenade ! $»^{3}$. Dans les jardins, dissimulé par la végétation, le naïf et chaste narrateur Lucien (ou Detrez) s'initie à l'observation des dérives de « l'ange Amour », nom pompeux de l'Ange que Victor affirme contacter lors de ses extases. Lucien se fait « voyeur » à son

${ }^{1}$ Conrad Detrez, Le Dragueur de Dieu, p. 18.

${ }^{2}$ Cf. Pierre Mertens, « Detrez à la croisée des chemins ? », Le Soir, 10 février 1981.

${ }^{3}$ Conrad Detrez, Le Dragueur de Dieu, p. 70. 
corps défendant, une des facettes majeures des personnages principaux des romans detréziens et stade esthétique que Detrez assigne à son attente dans l'antichambre de la mort ${ }^{1}$.

La Lutte finale (1980) accorde également une importance mythique, initiatique et rituelle à un thème intimement associé au jardin : l'arbre dans la bananeraie. Le récit narre les aventures picaresques de deux amis habitant un bidonville sud-américain (brésilien, très probablement). Populo et Mambo, « manchot des deux bras » ainsi que leur quartier, reçoivent la visite d'étudiants et militants gauchistes venus les initier à la révolution et les sortir de la liénation dans laquelle ils sont censés croupir. Pour ce, les apprentis révolutionnaires doivent s'attaquer à la lecture et à l'assimilation des deux bibles de la modernité et du soupçon : Que faire? et La Révolution sexuelle. Une affaire grotesque de vol de soutien-gorge provoque une émeute, l'intervention de l'armée, qui découvre de la sorte les activités illicites du bidonville. Les deux personnages principaux et quelques camarades se voient arrêtés et torturés, puis relâchés. Une fois sortis de prison, ils décident de reprendre la « lutte finale » dérisoire, plus côté sexe que politique. Extradés en Algérie, ils s'efforcent de convertir des intellectuelles françaises à cette version burlesque du combat idéologique. Or pour Populo, et depuis sa tendre enfance, l'arbre (manguier) acquiert une valeur sacrée, un peu à l'image de « l'arbre sacré » dont Mircea Eliade analyse l'importance dans certaines tribus primitives. L'arbre ou le poteau sacré est au centre d'épreuves initiatiques d'ascension ${ }^{2}$ et procure une médiation « entre les divinités et les dieux, [ou peut-être] l'incarnation de la divinité $\gg{ }^{3}$.

Dans La Lutte finale, le manguier au milieu de la bananeraie offre un espace d'initiation sexuelle : « Dans mon

${ }^{1}$ Cf. Conrad Detrez, La Mélancolie du voyeur, p. 12.

${ }^{2}$ Cf. Mircea Eliade, Initiation, rites, sociétés secrètes, naissances mystiques.

Essai sur quelques types d'initiation, Paris, Gallimard, 1959, p. 144.

${ }^{3}$ Ibid., p. 165. 



\section{IMAGES OBSEDANTES : TRANSCRIPTIONS THEMATIQUES ET SCHEMATIQUES}

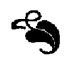

Du point de vue du lecteur, l'« autobiographie hallucinée » de Conrad Detrez réfère à un état équivoque et paradoxal du texte narratif à mi-chemin entre fiction et autobiographie. L'antinomie manifeste de cette proposition rejoint l'approche théorique de l'autofiction en tant que pacte oxymorique alliant simultanément dans un même texte un souci autoréférentiel et une attestation de fictionnalité. En effet, l'autobiographie implique une capacité narrative de contrôle mémoriel du vécu alors que l'adjectif « hallucinée » renvoie plutôt à un travail de sape ou de fluctuation du subconscient sur cette même référence vécue. Dès lors, le titre de la trilogie autofictionnelle detrézienne acte l'incapacité ou l'incompétence du sujet à mettre sa vie en récit. Autrement dit, ce titre assume son intention de dire l'indicible par négation, en creux. L'autofiction en tant qu'autobiographie fictive, " fictionnalisée » tient forcément un discours, voire adopte une démarche psychanalytique comme donnée tacite de l'écriture de soi sous forme romanesque. En fait, l'autofiction detrézienne s'apparente à une autobiographie qui ne voudrait pas dire son nom, mais qui se sait consciente de ses mécanismes de défense, de mensonge à soi. Si l'autobiographie permet de se cacher derrière un je fluctuant, 
l'autofiction induite par l'hallucination fait en sorte que l'autobiographe n'hésite pas à endosser le pacte romanesque. Une lecture plus consonante ou dissonante par rapport à la véracité de l'autoréférence mise en texte ne dépendra que de la décision du lecteur et de sa crédulité déjà mise à l'épreuve par les multiples ruptures de ton et de registre dont nous parlions plus haut.

Du point de vue de Conrad Detrez, c'est-à-dire de l'intention autobiographique, l'écriture romanesque essaie de comprendre les raisons d'un triple échec :

Dieu, l'amour, la révolution s'étaient retournés contre moi (ou m'avaient lâché) (...). Je me retrouvais seul. Aux échecs politiques s'ajoutait l'échec amoureux. J'ai eu le sentiment d'avoir tout raté. J'ai cherché à connaitre les causes de ces faillites, à mettre à nu les racines de mes révoltes.

Mais Detrez va plus loin et explicite la portée et la nature de son projet scriptural : " J'ai lu Freud et j'ai commencé, la plume à la main, à me livrer à une sorte d'analyse $»^{1}$. Toute trace de discours ou de catégories psychanalytiques doit dès lors être perçue comme étant le résultat d'une intention et non comme le repérage d'un nondit ou d'images inconscientes. Non seulement Detrez a lu Freud comme il s'en sert sciemment pour se mettre en scène. Cette stratégie n'invalide pas pour autant un réel et douloureux souci de se connaître, de se révolter et d'exorciser ses démons.

Toutefois, un écart fictif et est toujours à craindre ou à escompter. C'est à ce titre que le triptyque detrézien rejoint ce que la critique littéraire nomme depuis les années soixante-dix « autofiction ». Certains écrivains ont en effet choisi le genre romanesque comme moyen de mettre à nu certaines contradictions de leur vie, qu'ils auraient difficilement abordées dans le genre autobiographique canonique. C'est dans ce nouveau contexte qu'il nous faut

${ }^{1}$ Conrad Detrez, « Le jardin de la vie », p. 198. 
rappeler quelques apports théoriques et critiques utiles à la compréhension de la démarche fictionnelle detrézienne. Pour Pierre Mertens, Conrad Detrez distribue textuellement " les figures dominantes d'une mythologie [personnelle] » qui évitent trois écueils : " la redite, l'exotisme (à bon marché), la complaisance envers lui-même $\rangle^{1}$. Il représente l'un des exemples les plus évidents du " retour à l'autobiographie » dans les lettres belges de langue française, mais dont le rendu se bâtit sur le mode « conjecturel $»^{2}:$ « Si aveu il y a, il n'aurait guère de portée que dans la mesure où il découle d'un débat noué avec la langue elle-même $»^{3}$.

Pour Bruno Blanckeman, Detrez - tout comme Hervé Guibert, d'ailleurs - met en scène "l'autre du moi, la dimension imaginaire d'une identité $»^{4}$, faisant de la sorte coïncider « le retour au sujet narratif » avec « une reconsidération du sujet psychique $»^{5}$. Le rapprochement de l'œuvre de Conrad Detrez de celle d'Hervé Guibert trouverait également des arguments théoriques dans l'approche que Sémir Badir fait du retour à une « veine autobiographique $»^{6}$ dans la littérature contemporaine, qu'il désigne de " postmoderne ", c'est-à-dire comme « troisième degré » critique :

Dans le [tri]ptyque, le je qui s'énonce est, sans aucune mise à distance, à la fois héros, narrateur et écrivain ; les règles de la représentation classique sont outrepassées ainsi que le cadre dans lequel la modernité les dénonçait : en effet, il ne s'agit ici ni de faire illusion sur ce rapprochement du narrateur et de l'auteur ni d'en dénoncer le leurre, mais au contraire d'affirmer ce rapprochement sans la moindre équivoque ${ }^{7}$.

\footnotetext{
${ }^{1}$ Pierre Mertens, « Detrez à la croisée des chemins ? », Le Soir, 10 février 1981.

2 Pierre Mertens « Du retour à l'autobiographie », Revue de l'Institut de Sociologie, Bruxelles, ULB, 1990 / 91, p. 62.

${ }^{3}$ Idem.

${ }^{4}$ Bruno Blanckeman, Les Récits indécidables, p. 21.

${ }^{5}$ Idem.

${ }^{6}$ Sémir Badir, « Vers la postmodernité. Retour à Baudelaire ? », p. 15.

${ }^{7}$ Idem.
} 
est arrivée (...) $\gg^{1}$. Qui plus est, la mère est (trop) expressément castratrice. En trouble-fêtes, ce genre de mères veille à ce que les garnements s'évitent, ne jouent pas ensemble le jeu du jet d'urine, s'éloignent l'un de l'autre : «Elle s'empare de mon sexe, le serre, elle va me le couper, c'est fini $(. ..) »^{2}$. Detrez, qui « a lu Freud », la place au centre d'un conflit œdipien exemplaire, peut-être trop explicite.

Une dispute avec Ludo suscite un câlin maternel, un repli sur l'univers maternel, une fusion qui tue symboliquement le père : "Ma mère dit qu'on restera ensemble, qu'on s'occupera des poules et du jardin. J'aurai vite grandi, je ferai comme mon père, mieux que mon père (...). Pourtant ... non, ça ne se dit pas, je ne dois pas le lui dire que ce n'est pas avec elle que je veux me marier $»^{3}$. Le lit maternel - dont le père s'est absenté - procure un lieu privilégié à ce fantasme fusionnel, à ce report du sevrage. La suggestion symbolique est claire: « Je cherchais mon bois de réglisse dans le lit de ma mère $»^{4}$. Dans L'Herbe à brûlerrécit circulaire dans sa géographie symbolique - le narrateur dédoublé par " [s]on âme » quitte la maison, les fleurs et la chambre maternelles, ensemble matriciel symbolique dont il s'arrache, pour se lancer dans le voyage et le récit. Le retour du Brésil, la lassitude et la déception le restitueront à cet espace utérin. Le narrateur a vingt-huit ans. Il sait que « Dieu est mort, la révolution broyeuse des hommes qui la font, l'amour impossible $»^{5}$. Il ne lui reste plus qu'à retrouver « une glaise et une eau aussi nécessaires à ce paysage que le sable et le soleil au désert $»^{6}$, extension maternelle d'un lit où, enfant, il pouvait « s'endormir en paix $»^{7}$.

\footnotetext{
${ }^{1}$ Ibid., p. 22.

${ }^{2}$ Ibid., p. 51.

${ }^{3}$ Ibid., p. 106.

${ }^{4}$ Ibid., p. 78.

${ }^{5}$ Conrad Detrez, L'Herbe à brûler, p. 231.

${ }^{6}$ Ibid., p. 230.

${ }^{7}$ Ibid., p. 231.
} 
Le narrateur homodiégétique de La Guerre blanche lui aussi « monté » de ses Ardennes (françaises) natales à Paris - essaie cette fois d'entamer une carrière d'écrivain mais, n'y parvenant pas, finit par rejoindre, déçu, son village natal nordique, si proche de la frontière franco-belge. À nouveau, c'est la glaise matricielle, que le texte associe sans transition au lit maternel, qui opère ce fantasme fusionnel : «Quelque chose d'indéfinissable et de serein s'installait en moi. Mon lien à la terre (...). Une force ancestrale et douce me ramenait à mes origines (...). Tous les soirs je me glisserai dans le lit de ma mère $(. ..) »^{1}$. Tout comme le narrateur désabusé de L'Herbe à brûler, celui de La Guerre blanche n'aspire qu'à mourir chez lui, dans la maison maternelle déserte, qu'à rejoindre nu, comme pour mieux insinuer l'inceste, la mère dans sa mort, dans son lit mortuaire : " Je me suis mis nu et j'ai glissé, comme pour mourir, dans le lit de ma mère $»^{2}$. Le complexe œedipien est d'autant plus prégnant que les récits detréziens s'acharnent à évacuer la figure paternelle. Dans Ludo, le père, ou sa disparition, fait l'objet de plusieurs conjectures de la part du gamin, élevé uniquement par sa mère hystérique et névrosée. C'est aussi le cas de L'Herbe à brûler où la mère se montre évasive à ce sujet : « Il paraît que mon père est parti comme je devais le faire : sans avertir. Ma mère refusait de parler de sa disparition $»^{3}$.

Plusieurs facteurs et circonstances le gardent à l'écart de la maison maternelle. Son métier - jamais explicitement nommé - est à fuir, comme la plupart des occupations des hommes du village : « ils [les garçons] profitent du passage à la caserne pour fuir à jamais le travail du père (...), les interdits de la mère $»^{4}$. On le dit dans la résistance, exilé 5 , distrait : « Elle [la mère] appelle mon père. Il ne répond

\footnotetext{
${ }^{1}$ Conrad Detrez, La Guerre blanche, Paris, Calmann-Lévy, 1982, p. 152-153.

${ }^{2}$ Ibid., p. 175.

${ }^{3}$ Conrad Detrez, L'Herbe à brûler, p. 19.

${ }^{4}$ Cf. Ibid., p. 60.

${ }^{5}$ Conrad Detrez, Ludo, p. 35.
} 
pas » ${ }^{1}$, absent : « Je ne sais pas pour quelle raison il s'en est allé $(. ..) »^{2}$, en fuite, déserteur ou raté : « Mon père, son

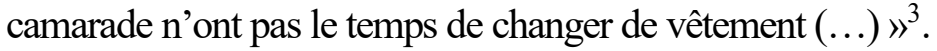
Dans Le Dragueur de Dieu, le narrateur fournit une version réélaborée de l'absence du père. Cette fois, la répulsion du métier du père fait en sorte que Victor fuie définitivement sa présence et éprouve sa première extase en contemplant l'image des Saints-Anges dans son église paroissiale, et se lance dans une mystique ambigüe. Le cryptage symbolique freudien, mais aussi l'agencement autofictionnel gagnent en évidence quand cette fièvre religieuse finit par se muer en drague homosexuelle à Paris. Detrez semble vouloir forcer, voire parodier, les lieux communs de l'analyse. Un père absent, au métier cruel (boucher) pour un jeune homme si pieux : «La vue des dépouilles, les peaux de vache, les cœurs, les estomacs, les têtes pendues aux crocs, tout cela le répugnait $\gg{ }^{4}$, évoque celui du narrateur que la guerre écarte définitivement du foyer au profit d'une relation exclusive et jalouse avec la mère : « Tombée veuve (j'avais un an, c'était la fin de la guerre, mon père n'en est pas revenu) $(\ldots) \gg\rangle^{5}$.

De même, les deux autres volets romanesques de l'«autobiographie hallucinée » omettent la figure paternelle dans la tendre enfance du petit Conrad. C'est la mère et le curé de Roclenge qui conduiront le jeune homme au séminaire dans L'Herbe à brûler, alors que dans Les Plumes $d u \operatorname{coq}$ il n'est fait mention que d'une visite sans cesse reportée ou annulée du père et de la tante du narrateur.

Le fantasme de l'enlisement constitue un autre poncif psychanalytique récurrent dont Conrad Detrez se sert sciemment pour le travail d'autofiction de son passé et qu'il offre en clin d'œil au décryptage complice du lecteur. S'enliser, c'est mourir un peu, c'est subir l'épreuve des

\footnotetext{
${ }^{1}$ Ibid., p. 43.

${ }^{2}$ Ibid., p. 89.

${ }^{3}$ Ibid., p. 90.

${ }^{4}$ Conrad Detrez, Le Dragueur de Dieu, p. 17.

${ }^{5}$ Ibid., p. 33.
} 
espaces funéraires, les expériences sexuelles et initiatiques aussi. Mais Detrez sait subtilement associer ce thème à celui davantage géographique, climatologique, voire sismologique (Nicaragua) - de l'attachement à la terre, au terroir et au pays. Dès lors, l'enlisement assume un statut allégorique, métaphorique que les textes detréziens traduisent par le retour final, funéraire en Belgique, dans cette Wallonie rurale pluvieuse, dont la glaise / glaire fertile, féconde tous les fantasmes et active une expérience physique, sensuelle avec l'espace labouré de l'ici, ses coordonnées, sa prégnance symbolique. Il fonctionne donc comme un rappel poétique et onirique à l'ordre et aux racines pour un personnage enclin à l'égarement extatique, exotique, érotique ou politique.

Dans Ludo, ce sont surtout les crues du Geer à Roclenge qui offrent un cadre d'engloutissement et de noyade, suractivé par la psychologie infantile du narrateur et ses phobies non exprimées. Le fait que les eaux montent induit une peur hystérique généralisée que le village ne finisse englouti. Mais c'est l'enfant qui transforme le plus profondément cette phobie en fantasme : «Tu m'as repêché, ma mère, je le sais, tu m'as sauvé des eaux $\rangle^{1}$. Le risque permanent de noyade dans les eaux du Geer alimente une peur mythique des pouvoirs de la rivière : «L'eau coule, inépuisable. La noyade est un danger permanent $»^{2}$. La puissance du cours des eaux du Geer engendre également chez l'enfant un fantasme d'emportement, de dérive ironique :

Nous sommes entraînés vers l'immensité des eaux de la cour, vers le Geer qui bouillonne, impatient, qui file vers la Meuse, aspiré par elle, attiré vers Maastricht, vers la Hollande, et bientôt livré aux tourbillons de la mer et la mer du Nord, en hiver, est glaciale; on y meurt de froid ${ }^{3}$.

${ }^{1}$ Conrad Detrez, Ludo, p. 17.

${ }^{2}$ Ibid., p. 54.

${ }^{3}$ Ibid., p. 117. La figure de l'enlisement est également retenue dans les vers que William Cliff lui dédie. Cf. William Cliff, Conrad Detrez, Paris, Le Dilettante, 1990, p. 14-15. 
L'Herbe à brûler reprendra le récit du premier voyage à vélo de Conrad jusqu'au collège de Saint-Rémy - entendons par là le collège de Saint-Trudon de Les Plumes du coq. Un même cadre provoque le même enlisement, le même embourbement paralysant, le même retour mortel ou régénérateur dans la glaise / glaire maternelle et wallonne. Le récit de ce trajet insiste sur la fusion avec la mère dans l'épreuve régressive de l'enlisement et sur la connotation climatique du décor : "Les roues de nos bicyclettes s'enfonçaient. La mienne soudain pénétra dans la boue jusqu'aux moyeux. La pluie tombait à verse (...). J'ai à nouveau appelé, levé les bras, j'ai hurlé. Je m'enfonçais (...) $»^{1}$. À nouveau la mère se montre sous un jour rédempteur, salvateur. Elle rejoint le garçon dans son engluement imminent, mais l'en sauve : « (...) nous descendions tous deux à la même vitesse dans le puits de glaise lorsqu'elle s'est penchée vers moi, extirpant ses mains du sol. Je les ai agrippées. Ma mère, m'attirant vers elle, m'a étreint $\rangle^{2}$. La scène finale ne pouvait être plus symbolique. Alors que le risque d'enlisement n'est pas encore tout à fait écarté et prend même un tour allusif plus sensuel, « Mais nous nous enlisions avec lenteur $\rangle^{3}$, mère et fils parachèvent une image fusionnelle et incestueuse : « Noués l'un à l'autre pareils à un couple modelé dans une seule masse d'argile (...) $»^{4}$. La bâtisse de Saint Trudon dans Les Plumes du coq, suppôt emblématique d'une société figée, close et cruelle au centre de laquelle elle trône, ne vit que de la machination perverse de supplices, comme ces noyades rituelles et sadiques dans l'énorme bassin où les novices sont censés laver la vaisselle : " C'est tout juste si nous arrivons à mouvoir le torse. Le garçon qui redoute la noyade se met à pleurer, une tasse collée sur la bouche, une autre sur la tempe

\footnotetext{
${ }^{1}$ Conrad Detrez, L'Herbe à brûler, p. 23. C'est nous qui soulignons.

${ }^{2}$ Ibid., p. 24. C'est nous qui soulignons.

${ }^{3}$ Idem. C'est nous qui soulignons.

${ }^{4}$ Idem. C'est nous qui soulignons.
} 
telles des ventouses $»^{1}$. Par ailleurs, toute tentation ou tentative de fugue en dehors de l'espace claustral du séminaire est freinée par le risque d'embourbement dans la glaise des champs de betteraves des alentours. L'incroyable instabilité du terrain procure également des cachettes glaiseuses au narrateur et à son complice, Victor : « Je me suis laissé prendre, m'en suis détourné cependant que l'enlisement se poursuivait, que la terre entre les betteraves mollissait, fondait sous son corps brûlant de toutes les fièvres réunies, tel un bloc de glace $»^{2}$.

Dans les textes detréziens par rapport auxquels l'auteur ne revendique aucune mise en fiction «hallucinée », le thème polysémique de l'enlisement persiste qui appelle un décryptage tout aussi convenu que dans la trilogie autofictionnelle. Le récit des déboires politiques de Populo dans son bidonville, probablement carioca, s'ouvre sur l'association fantasmatique de la chute et de l'expérience funéraire mise en relief par le cadre sordide et dégradant de la favela et de ses dépotoirs d'ordures : « Me voilà plongeant dans une fosse. Mes ongles ont griffé la paroi. Elle est molle et grasse. Mon visage a frotté contre la glaise, a noirci $»^{3}$. Paumé, Populo reçoit ce nouvel habitacle comme un don, comme un espace funéraire où se replier, s'endormir, s'assoupir : " Je me recroqueville dans un coin de la tombe $\gg{ }^{4}$. Populo et Mambo, le manchot, reviendront ensemble dans cette décharge à la recherche d'une clocharde pour « vidanger » le pauvre handicapé. À nouveau, cette quête n'est pas exempte d'épreuves périlleuses, mais l'ironie grotesque permet une allusion sexuelle : « Mon ami et moi on a cherché, on s'est enlisé. Finalement on a déniché l'antre de la vieille $»^{5}$. Même recours trop évident au thème funéraire de l'ensevelissement au début du récit de $L e$

\footnotetext{
${ }^{1}$ Conrad Detrez, Les Plumes du coq, p. 34.

${ }^{2}$ Ibid., p. 50. C'est nous qui soulignons.

${ }^{3}$ Conrad Detrez, La Lutte finale, p. 11. C'est nous qui soulignons.

${ }^{4}$ Ibid., p. 12. C'est nous qui soulignons.

${ }^{5}$ Ibid., p. 28.
} 
viril, dominateur, mais hypocrite. Dans le bidonville de $L a$ Lutte finale, « Les coqs [y] exercent leurs fonctions de coq. Ils se battent, hérissant leur crête, plantent leur bec dans le cou des pondeuses. Les coqs couvrent les poules $\rangle^{1}$. Le coq, du fait de sa « lubricité $»^{2}$, nargue les mours chrétiennes du pays et scandalise les femmes. Aussi est-ce avec suspicion que le clergé voit la tenue de combats de coqs, sport emblématique au Nicaragua, et dont les femmes sont absolument exclues. Alvaro et son coq en sortent souvent vainqueurs et $\mathrm{y}$ réaffirment leur virilité. Par contre, son frère Abel, une fois dévoilée son homosexualité honteuse, en est catégoriquement exclu et réduit à un statut féminin. À nouveau, lors des combats, les coqs confirment les rôles et assignent les statuts sociaux : « Sa mère et sa sœur versaient enfin leur dîme à l'église. Et son père et son frère dépensaient le reste au bordel. Les coqs étaient beaux avec leurs plumes vertes et brunes $(\ldots) »^{3}$.

Par ailleurs, le thème récurrent de l'Époux mérite également que l'on s'y attarde. Il dérive bien évidemment d'une tradition mystique chrétienne ancrée dans le Nouveau Testament dans laquelle la figure parousiaque du Christ est conçue comme celle d'un Époux attendu de longue date en vue des noces mystiques, des retrouvailles eschatologiques où l'Église fait souvent figure de fiancée. La mystique chrétienne s'est emparée de cette image très suggestive et très productive du point de vue spirituel. Dans Les Plumes du coq, l'allusion au thème de l'Époux renvoie, d'une part, à cet usage - conventionnel dans le séminaire Saint-Trudon - de l'image mystique, à même de catalyser toutes les ressources religieuses du jeune séminariste et de lui imposer un ordre hiérarchique strict et viril (« Mon Époux, je vous jure... J'ai treize ans, mon Époux. Si je m'attendais à ce que vous m'habitiez le soir même de mon arrivée ! $»^{4}$ ), mais d'autre

\footnotetext{
${ }^{1}$ Conrad Detrez, La Lutte finale, p. 52.

${ }^{2}$ Idem.

${ }^{3}$ Ibid., p. 39.

${ }^{4}$ Conrad Detrez, Les Plumes du coq, p. 24.
} 
part, au fait que le jeune âge du séminariste et sa psychologie religieuse propre ne sont pas capables de saisir la signification mystique de cette formule et de cette figure qu'il s'agit de révérer et de respecter. Il n'en comprend la portée spirituelle ni sur lui, ni sur l'ensemble de l'établissement : «Mon Époux ? Ça doit vouloir dire autre chose...»».

Cette brèche conceptuelle ouvre la voie à toutes sortes de dérives que le contexte historique de la diégèse ne cesse de reformuler. L'Époux sera tantôt un dieu tout-puissant et redoutable, une instance légitimante du régime sadique et claustral de la lugubre bâtisse : " 'Car, vocifère-t-il, l'Époux est jaloux. Sachez-le : l'Époux est toujours près de vous, Il vous suit, l'Époux est jaloux' ${ }^{2}$, tantôt le précurseur d'un culte hystérique et mortifiant, doloriste et malsain : «L'Époux saigne, son cœur a mal, il faut réparer » ${ }^{3}$, tantôt une excroissance des perversions voyeuristes, zoophiles et pédophiles du supérieur du collège : " L'Époux est partout : sous mon lit, dans les corridors, dans la salle de douches, dans le poulailler (...). Il dort en même temps dans le lit du supérieur et dans le lit de Marien ${ }^{4}$.

En tous cas, l'image de l'Époux est toujours instable, passible d'innombrables interprétations au gré des hallucinations du jeune narrateur dans la bâtisse et des événements extérieurs. Le rapprochement de l'Époux de la figure du Christ crucifié accroîtra le caractère lascif et lubrique de cet être énigmatique, produit hallucinatoire du narrateur et fil conducteur du récit. Son "ventre et [ses] cuisses nues » retiennent l'attention d'un narrateur déconcerté : «L'Époux a pris les vêtements d'une femme $(..) »^{5}$. Conrad Detrez reviendra d'ailleurs sur le glissement permanent des jeunes séminaristes vers une perception lascive de cette image christique : «Qu'on interroge (...) des séminaristes (pour

\footnotetext{
${ }^{1}$ Ibid., p. 23.

${ }^{2}$ Ibid., p. 39.

${ }^{3}$ Ibid., p. 40.

${ }^{4}$ Ibid., p. 44.

${ }^{5}$ Ibid., p. 87-89.
} 
l'émoi surtout et pour l'allégresse), encore qu'en matière de lascivité les novices livrés à l'Époux $(. ..) »^{1}$. Le statut foncièrement hallucinatoire du thème de l'Époux explique son puissant et obsédant travail onirique. En effet, certaines apparitions ne trouvent d'autre raison d'être que celle d'une réélaboration nocturne et onirique, fécondée par les perversions internes et les soucis hystériques externes. Rappelons qu'à l'intérieur du pensionnat deux phénomènes apparemment autonomes attirent l'attention du narrateur, voire l'impliquent directement. D'une part, le jour, la taille des plumes des gallinacés pour les empêcher de fuir le poulailler; d'autre part, la nuit, la perversion zoophile du supérieur sur les pondeuses. Ces scènes diurnes et nocturnes font l'objet d'un intense travail onirique qui se traduit par l'apparition de l'Époux sous forme de coq, véritable divinité païenne et idolâtrique : « (...) une crête d'or apparait. L'Époux, me dis-je instinctivement $»^{2}$.

À l'extérieur, c'est la Question Royale qui contamine l'hallucination du narrateur. Du fait du camp politique qu'il s'est choisi - royaliste et catholique - l'Époux renvoie quelque part à la figure du Roi absent dont on attend le retour imminent en Belgique pour des « épousailles », des noces hystériques. Ainsi la vacuité du pays se redouble-t-elle d'une nubilité, voire d'une viduité maladives et irrationnelles : « Aller au-devant de l'ennemi, bras ouverts, délesté de mes tracts, entamer la discussion sur les relations de la monarchie et de l'Époux $(\ldots) »^{3}$, telles sont les consignes du collège pour le combat que les jeunes recrues ont à mener à Liège, la laïque et la socialiste, ennemie de l'Époux. Mais la convocation par Conrad Detrez du thème de l'Époux - sujet mystique s'il en est - permet aussi d'évoquer subtilement la mystique flamande et de faire circuler dans le texte un certain nombre de clichés littéraires flamands et nordiques tels que

\footnotetext{
${ }^{1}$ Conrad Detrez, La Mélancolie du voyeur, p. 109.

${ }^{2}$ Conrad Detrez, Les Plumes du coq, p. 71-72.

${ }^{3}$ Ibid., p. 103-104.
} 
les a véhiculés depuis deux siècles la production littéraire francophone de Belgique, notamment pour donner une image de sa spécificité.

Le Dragueur de Dieu - récit dont le propos n'est ni autofictionnel, ni halluciné - entend mettre en fiction les rapports étroits et subtils entre religion et sexualité. La figure de l'Époux et des noces mystiques, bien dans le goût de la tradition mystique flamande, s'y retrouve dans plusieurs allusions dont le but premier est, somme toute, de provoquer l'ironie et le brouillage. Rappelons que l'action de ce roman se déroule quelque part entre un couvent de Saint-Amand, aux confins de la frontière franco-belge, dans un nord absolu et mythique, presque anhistorique, et Paris, ville perverse et ambigüe, où les signes religieux ne peuvent être interprétés qu'à partir d'une ironie entendue et à travers un personnage d'une totale naïveté. Dans ce pays innommé, des femmes se retirent, une fois veuves, "dans un béguinage ${ }^{1}$. Les familles y sont pieuses et dévouées, et fournissent à l'Église une foule de religieuses, notamment à « l'ordre du DivinÉpoux $»^{2}$. Par ailleurs, les références spirituelles de Lucien, en quête de Victor - soi-disant consolé par l'apparition des Saints-Anges, mais en vérité inséré dans les milieux gays parisiens - remontent à un patrimoine facilement reconnaissable. S'y croisent Ruysbroek l'Admirable, auteur de Les Noces mystiques (traduit par Maeterlinck) ${ }^{3}$, où les noces spirituelles visent introduire les « amants dans les bras de l'Époux $»^{4}$, Sainte Hadwige et ses baisers mystiques sur la bouche de l'« Époux $»^{5}$, mais aussi des ouvrages plus fictifs, mais tout aussi révélateurs du ton nordique qu'il s'agit d'imprégner à ce récit énigmatique. Parmi eux, on trouve cet

${ }^{1}$ Conrad Detrez, Le Dragueur de Dieu, p. 30.

${ }^{2}$ Idem.

${ }^{3}$ Cf. Maurice Maeterlinck, L'Ornement des noces spirituelles de Ruysbroeck l'Admirable, traduit du flamand, Bruxelles, Les Éperonniers, 1990. Conrad Detrez, Le Dragueur de Dieu, p. 104.

${ }^{4}$ Ibid., p. 104-105.

${ }^{5}$ Ibid., p. 174. 
ouvrage improbable : Les secrets de l'Époux ${ }^{1}$.

D'autres thèmes obsédants pourraient figurer dans notre analyse. Le thème du jardin et celui de l'ange nous semblent ressortir à ce souci detrézien de mettre à profit une lecture freudienne, souvent superficielle ou amatrice, dans un projet d'autoanalyse par la fiction. Toutes ces figures thématiques semblent avant tout appartenir à un répertoire fantasmatique intime défini, mûri par les épreuves de la vie et pressé de se trouver un espace romanesque où le poète peut s'émouvoir : « Tel champ m'inspire. J'y logerais des histoires d'amour, d'élévation, d'enlisement (...). Dans une plantation de betteraves prendraient place telle solitaire aventure, un commerce avec les anges, des épousailles, le nom de Dieu, des épiphanies $»^{2}$.

Outre ces thèmes axiaux dans l'élaboration de la mythologie personnelle, il nous faut aussi considérer les structures plutôt schématiques du récit qui, par leur récurrence et leur réseau complexe, constituent un outil puissant dans l'écriture romanesque du moi. Il s'agit de structures thématiques plus complexes, étayées sur des attitudes et des rapports plus complexes.

\subsection{Traits schématiques}

Un premier trait schématique, fantasmatique et narratif de l'écriture autofictionnelle de Conrad Detrez se retrouve dans l'ensemble de la trilogie hallucinée et même ailleurs. Il s'agit de la médiation et de l'initiation de l'ami, un ami qui est toujours porteur d'une extranéité. André-Joseph Dubois y voit une veine voltairienne à l'œuvre dans l'imaginaire detrézien : "C'est qu'il y a du Candide dans le héros detrézien, à qui il faut un Pangloss pour le jeter sur les routes $»^{3}$. Dans $L u d o$, c'est le petit voisin de six ans du tout

\footnotetext{
${ }^{1}$ Ibid., p. 171.

${ }^{2}$ Conrad Detrez, La Mélancolie du voyeur, p. 150.

${ }^{3}$ Lecture d'André-Joseph Dubois, Ludo, p. 168.
} 
petit narrateur de cinq ans qui le fascine et polarise le récit. C'est lui aussi qui le convoque dans ses jeux, son jardin, sa maison. Il est le complice inséparable du narrateur, celui que le gosse veut absolument rejoindre chez lui, sur son « île » : « Mon camarade est aussi dans son île ${ }^{1}$, un projet dont le refus catégorique de la part de la mère s'apparente à un interdit injustifiable pour le petit enfant à la pensée animiste et merveilleuse : « Si je veux sortir elle appelle la guerre qui me brûlera vif avant que je n'arrive dans l'eau $\rangle^{2}$. De telles menaces illustrent bien la rigueur avec laquelle les mères s'obstinent à séparer leurs fistons du danger représenté par l'autre : "Lui chez lui, toi chez toi ! »" Les sentences maternelles sont sans appel et ne font aucun cas de la complicité des deux gosses : « On vous séparera! Gamin de merde ! Et toi, tu ne sortiras plus ! On les séparera ! » ${ }^{4}$.

Le schème de la médiation de l'ami prend ici surtout la forme d'une initiation à l'autre et au monde des adultes par le truchement du jeu et du chaos. Aussi l'altérité de Ludo estelle surtout le fait des préjugés des adultes, mais trouve-t-elle une traduction animiste et merveilleuse chez le narrateur : « La mère de Ludo est née à Maastricht. Son père est né de l'autre côté des peupliers. Et Ludo ? Ludo est né dans le jardin $»^{5}$. Ludo est avant tout le complice du jeu. Il procure au narrateur un personnage ludique proprement dit, mais dont les dérives ludiques sont autant d'indices d'une recherche autoanalytique rétroactive en vue d'une compréhension du destin de l'auteur. L'envoûtement panique du récit ne doit pas nous faire perdre de vue que nous avons ici affaire, au dire de l'auteur lui-même, à une lecture et à une application personnelles des acquis freudiens sur un vécu d'enfance. L'auteur y cherche ou y met en scène des pistes enfouies qui permettraient d'éclairer des échecs et des comportements

\footnotetext{
${ }^{1}$ Conrad Detrez, Ludo, p. 20.

${ }^{2}$ Idem.

${ }^{3}$ Ibid., p. 21.

${ }^{4}$ Ibid., p. 25.

${ }^{5}$ Idem.
} 
présents. C'est à cette aune qu'il faudrait lire la hantise du jeu du jet d'urine. Ludo se trouve être le premier ami, mais aussi quelque part le premier amant du narrateur. C'est avec lui qu'il découvre son corps, les plaisirs vagues et difficilement assimilables qu'il procure : « Ludo vient à ma rescousse, la [la verge] saisit. Mes pieds gèlent sur place, le vent me pique à l'entrejambe. Ludo manœuvre avec le sérieux d'un horticulteur, le membre se raidit, je m'échauffe, mes pieds dégèlent $\gg{ }^{1}$.

Après le désir de fusion avec l'instance maternelle, c'est une aspiration à rejoindre l'ami qu'expriment ces fugues incessantes, le caractère sensuel et festif des retrouvailles ou des projets enfantins, marqués par le brouillage des perceptions sentimentales, affectives et cognitives de la tendre enfance : «Mon camarade se prend pour son père, je suis le mien. Il m'appelle mais moi je joue avec le soleil ! Et puis, les papas ne se marient pas avec des papas $»^{2}$. À cet égard, une approche interprétative libre de la portée onomastique de ce premier « ami », de ce premier impact de l'extranéité acte un propos d'inscription d'un filon autofictionnel fécond dans ce texte. Ludo - variante onomastique de Louis, Ludovic, Clovis - procure une empreinte germanique et franque à un récit « frontalier » à plus d'un titre. Ce nom constitue également une réalisation emblématique de l'univers ludique du texte et des deux personnages enfantins. Il opère un dédoublement fictionnel, mais aussi psychologique du narrateur en dépit de la distance hétérodiégétique qu'il instaure par rapport au narrateur qui balbutie dans ce texte.

Dans Les Plumes du coq, la médiation et initiation de l'ami sont assurées par Victor, le camarade de chambrée du narrateur au collège Saint-Trudon. Tout comme Ludo, Victor marque le narrateur par son aspect exotique : « Il a l'air d'un

\footnotetext{
${ }^{1}$ Ibid., p. 50.

${ }^{2}$ Ibid., p. 32.
} 
étranger, ses cheveux sont d'un noir (...) $»^{1}$. Cet aspect particulier de la chevelure de Victor opère un rapprochement sensuel ambigu que l'auteur sait subtilement mettre à profit dans son souci autofictionnel : « Victor a des cheveux doux comme des fils de soie, on dirait des cheveux d'ange (...) $»^{2}$. À nouveau, le narrateur se sent fasciné, envoûté par un personnage à la physionomie exotique et qui l'entraîne dans ses fugues. C'est Victor que le jeune narrateur retrouvera, enlisé dans les champs de betteraves, lors de ses randonnées nocturnes. C'est grâce à lui qu'il s'initie à l'amour lors de séances de baisers ${ }^{3}$. C'est avec lui enfin qu'il jurera, à la suite du scandale pédophile de l'établissement, n'aimer que «l'Amour $)^{4}$.

À nouveau, l'ami forme avec le narrateur les deux pôles majeurs du récit. Il lui permet de modeler son comportement, de manifester sa fascination devant la nouveauté d'un monde inconnu qui s'obstine à s'insinuer à l'intérieur de la bâtisse claustrale. Mais pour l'heure, il représente la solidarité et la complicité dans l'état de réclusion auquel le collège voue ses internes. C'est Victor que le jeune narrateur retrouvera purgeant une peine d'exclusion et d'errance, voire d'enlisement dans les champs de betteraves avoisinants : « (...) le crâne de Victor ressemble à s'y méprendre, avec ses taches beiges et roses, à la partie supérieure d'une betterave (...). L'enterré [Victor] ne répond pas $»^{5}$.

L'Herbe à brûler offre un doublon de cette amitié initiatrice et médiatrice dans la figure de Leopoldus, le jeune noir, camarade de chambrée de Conrad dans le séminaire de Saint-Rémy. Du fait de sa différence raciale, Leopoldus induit chez le personnage principal, de plus en plus autodiégétique, une prise de conscience, d'une part de la réalité extérieure marquée par la différence, voire l'exotisme

\footnotetext{
${ }^{1}$ Conrad Detrez, Les Plumes du coq, p. 30.

${ }^{2}$ Ibid., p. 37.

${ }^{3}$ Cf. Ibid., p. 82.

${ }^{4}$ Ibid., p. 198.

${ }^{5}$ Ibid., p. 52.
} 
envoûtant : « Je songe à sa peau couleur d'argile, à ses mains ; je revois ses dents, ses yeux $(. .).\rangle^{1}$, mais d'autre part, de sa condition nationale propre, inavouée : « Je suis Belge, fais-je, étonné de m'entendre décliner pour la première fois ma citoyenneté $»^{2}$. Par ailleurs, Leopoldus initie le naïf Conrad à l'art de l'amour avec les jeunes vachères du village, une expérience qui pour le narrateur tourne au fiasco : « Il restera au collège tant que j'y serai et il va tâcher de me trouver une fille qui m'embrassera moi aussi (...) $\rangle^{3}$. Il est le promoteur des nombreuses évasions et infractions aux règles strictes de l'enseignement du collège de Saint-Rémy. Le jeune noir fait volontiers le mur pour rejoindre les élèves de la section agricole. Cette vocation plus « jardinière » et « buissonnière » éclaire celle de Conrad, de moins en moins attiré par la culture livresque et humaniste de sa section, de plus en plus fasciné par l' « extériorité » et la liberté des études agricoles en plein air, représentées par l'exotisme nonconformiste et rusé de Leopoldus : " Pourtant là-bas, en Afrique, il lisait mais un seul volume à la fois et entre deux randonnées dans la brousse $\gg$.

Outre l'amitié de Leopoldus, L'Herbe à brûler fournit d'autres variantes du schème de l'ami initiateur et médiateur. Une fois inscrit en théologie à l'Université Catholique de Louvain, Conrad fait la connaissance de Rodrigo, étudiant et novice brésilien dont l'influence s'avérera capitale dans l'évolution politique et religieuse du futur « missionnaire laïc ». D’une part, Rodrigo initie Conrad à la nouveauté de la réalité tropicale et latino-américaine. Il introduit dans la conscience de Conrad la complexité de la situation brésilienne dans les années soixante, la militance et l'ébullition de la mouvance gauchiste de l'Église ; il incarne l'engagement du narrateur wallon : « Car pour Rodrigo il est dérisoire, l'enjeu. Comme sont dérisoires les autres querelles

\footnotetext{
${ }^{1}$ Conrad Detrez, L'Herbe à brûler, p. 30.

${ }^{2}$ Idem.

${ }^{3}$ Ibid., p. 41.

${ }^{4}$ Ibid., p. 31.
} 
des évêques et des théologiens des Églises d'Europe $»^{1}$. Par ailleurs - nous le disions - l'étudiant brésilien préfigure de par son comportement si peu chaste les épreuves qui attendent le narrateur au Brésil, son initiation à la vie sexuelle, son dépucelage ${ }^{2}$ : «Que répondre ? J'établissais un lien trop confus, trop neuf, entre les frémissements et la nudité des jeunes gens, je m'y perdais. L'idée que l'amour fit mal me désorientait $»^{3}$.

D'une certaine façon, à Rio, le noir Fernando avec qui Conrad s'initiera à l'amour homosexuel poursuit le travail d'intégration de Detrez dans l'univers exotique, envoûtant et déréglé du Brésil :

Nous sommes tombés à genoux l'un devant l'autre, toujours enlacés, mouillés, baignant dans sa puissante odeur de nègre, et on s'est regardé. Une sensation inconnue, un bien-être, un bonheur indicible s'est installé en $\mathrm{moi}^{4}$.

Dès lors, le récit perd l'exclusivité de cette figure schématique (l'ami médiateur) et devient multipolaire tandis que le narrateur abandonne sa facette d'éternel initié au profit d'une posture de protagoniste et militant politique : « Mes lectures et l'étude des principes de la Plate-forme, ajoutées à mon expérience (...) avaient fait de moi un militant $(..) »^{5}$.

Une deuxième figure schématique de la trilogie hallucinée de Conrad Detrez a trait à la tentative de fugue, désir d'évasion du narrateur et personnage principal de l'univers carcéral où il est contraint de vivre, vers un extérieur fascinant par la différence et la découverte qu'il permet. Dans Ludo, ce schème d'évasion et d'exploration de l'extérieur prend les traits animistes de la conception du monde externe du petit narrateur, âgé de cinq ans. Pour lui, la maison et le jardin de Ludo, son voisin, constituent un

\footnotetext{
${ }^{1}$ Ibid., p. 60.

${ }^{2}$ Cf. Ibid., p. 105.

${ }^{3}$ Ibid., p. 86.

${ }^{4}$ Ibid., p. 122.

${ }^{5}$ Ibid., p. 151.
} 
univers infini, un espace magique et attirant qu'il s'agit avant tout de rejoindre au prix de plusieurs infractions à la logique séparatiste des mères. L'inscription si précoce du thème de la fuite dans l'œuvre detrézienne vise précisément à souligner la provenance et la construction infantiles de cette hantise solidement ancrée dans sa mémoire. Fuir à cet âge-là suppose avant tout le départ de la maison claustrale et carcérale où règne l'hystérie maternelle pour gagner la maison, et surtout le jardin de l'autre, de l'ami : «Qu'elle complote, la mère ! J'ai mon plan, je passerai de l'autre côté. Je jetterai une passerelle entre ma maison et le jardin $\gg{ }^{1}$. Car pour ces gosses inventifs, partir, c'est jouer un peu, c'est transformer l'espace domestique du voisin en plaine de jeu, en espace ludique et chaotique, c'est abolir la logique et l'agencement spatial de la maison des adultes, c'est instaurer un nouvel ordre, ludique cette fois : « Les enfants fleurissent dans les parterres au gré des saisons, dans le périmètre du jardin, sous le soleil ou la neige. Les parents l'oublient, ils sont bêtes $\gg{ }^{2}$. Les enfants mettent à mal, miment ou dérèglent la conception du monde des adultes. Les vêtements des parents de Ludo font l'objet de cette fête mimétique : « Ludo retire son bras de la braguette, y enfile sa tête, gonfle ses joues. Le soleil repart $\iota^{3}$.

Mais outre la maison, c'est surtout le jardin édénique de Ludo qui retient toute l'attention du narrateur et qui s'inscrit dans son esprit animiste et magique comme une référence obsessionnelle. Pour l'heure, les fugueurs n'entendent pas s'aventurer au-delà de cet espace considéré immense, récréatif et irrésistible : « Le jardin colle à la plante de mes pieds. Le souvenir du jardin m'irrite à la jointure des doigts $\gg{ }^{4}$. La conception merveilleuse et magique de l'espace concourt à une vision infinie de ce lieu, pourtant envahi par les eaux et remodelé par les bombardements : « Nous

\footnotetext{
${ }^{1}$ Conrad Detrez, Ludo, p. 100. C'est nous qui soulignons.

${ }^{2}$ Ibid., p. 47.

${ }^{3}$ Ibid., p. 31.

${ }^{4}$ Ibid., p. 100.
} 
arrachons les voiles, filons vers la haute mer du jardin $»{ }^{1}$. Les Plumes du coq devait dilater la dimension de l'exil et de la fugue du narrateur. La structure schématique de l'espace claustral et carcéral et de la fugue irrépressible trouve ici une variante plus nette parce que non soumise à une logique animiste. Cette fois, le narrateur quitte la maison maternelle de Roclenge pour se rendre à Visé, plus précisément au séminaire Saint-Trudon. Ce déplacement - apparemment insignifiant si l'on considère la distance parcourue - prend cependant des allures de périple du fait des difficultés de la marche jusqu'à l'établissement clérical : « De ma vie je n'ai avancé sur un sol aussi gras. De ma vie je n'ai contemplé bâtisse plus massive, plus uniformément brune $\rangle^{2}$. Cette fois, la version de l'arrivée à Saint-Rémy procure un récit plus minutieux du départ de la maison maternelle. Conrad explicitement nommé - quitte son village natal du pays de Liège accompagné de sa mère et du curé de sa paroisse. Le trajet se montre ici plus pénible, rendu plus ardu par les conditions météorologiques et la spécificité du sol wallon : « Ma mère à ce moment avait de la boue jusqu'à la ceinture ; nous descendions tous deux à la même vitesse dans le puits de glaise $(. ..) \gg)^{3}$.

Arrivé tantôt à Saint-Trudon (Les Plumes du coq), tantôt à Saint-Rémy (L'Herbe à brûler), le narrateur de plus en plus autodiégétique est confronté à un nouvel espace claustral et carcéral dont il éprouvera rapidement le besoin ou l'envie de fuir, et dont il souligne surtout le caractère lugubre, inhospitalier et austère. Dans Les Plumes du coq, le jeune séminariste survit tant bien que mal dans un édifice marqué par l'hystérie collective et les perversions multiples du supérieur de l'établissement, métaphore paternelle royale et légale : « La bâtisse domine comme un château fort les terres à perte de vue ${ }^{4}$. Dans $L$ 'Herbe à brûler, le collège de

\footnotetext{
${ }^{1}$ Ibid., p. 70.

${ }^{2}$ Conrad Detrez, Les Plumes du coq, p. 21.

${ }^{3}$ Conrad Detrez, L'Herbe à brûler, p. 24.

${ }^{4}$ Conrad Detrez, Les Plumes du coq, p. 46. C'est nous qui soulignons.
} 
Saint-Rémy apparaît affublé des mêmes caractéristiques carcérales et phalliques que la bâtisse de Visé. À nouveau, l'édifice s'avère imposant, menaçant et intimidant : " $\mathrm{Ce}$ collège se dressait dans un parc à l'entrée du bourg de SaintRémy qu'on gagnait, à travers la campagne, en une heure de vélo» ${ }^{1}$.

Dorénavant, c'est de ce lieu lugubre que le narrateur aura envie de s'évader afin de découvrir toute la nouveauté du dehors. Sous l'impulsion de son amitié avec Victor, le jeune séminariste de Saint-Trudon fera souvent le mur. L'évasion lui permet de mieux prendre la mesure de la place imposante occupée par le bâtiment dans son contexte champêtre, notamment dans le paysage marqué par la prégnance des champs de betterave : «La lumière découvre l'immensité du champ de betteraves $»^{2}$. Le dehors du pensionnat se montre alors sous un jour ambigu et éclaire les perversions latentes du collège. C'est le cas des pratiques inavouables du supérieur de Saint-Trudon dans le poulailler, mises à jour à la faveur des escapades du narrateur planqué dans le champs de betteraves: " La masse s'engage dans le carré de betteraves, stoppe, reprend sa marche, stoppe à nouveau, fait quelques tours sur elle-même, reflue vers la limite du champ $»^{3}$.

Nous le soulignions plus haut, la médiation de l'ami est cruciale, aussi bien dans la concrétisation de la fugue que dans la perception de ses enjeux. Victor - puni et temporairement expulsé du séminaire - est rejoint par le narrateur dans sa cachette atypique : « Victor ressemble à s'y méprendre, avec ses taches beiges et roses, à la partie supérieure d'une betterave privée de ses feuilles $»^{4}$. Leopoldus, le camarade africain de Conrad à Saint-Rémy, initie le narrateur à faire le mur et à explorer les potentialités séduisantes du dehors. L'évasion signifie l'abandon

\footnotetext{
${ }^{1}$ Conrad Detrez, L'Herbe à brûler, p. 21. C'est nous qui soulignons.

${ }^{2}$ Conrad Detrez, Les Plumes du coq, p. 46. C'est nous qui soulignons.

${ }^{3}$ Ibid., p. 47.

${ }^{4}$ Ibid., p. 52.
} 
sporadique des études humanistes, côté jardin. Alors la tentation est grande de rejoindre cet éden réservé à quelques privilégiés : " [lls] font le mur et cherchent à traverser le domaine mais se font presque tous arrêter dans le potager ou le verger, se font capturer par les agricoles avant d'atteindre la grille du collège $»{ }^{1}$.

En outre, le récit de L'Herbe à brûler élargit encore d'un cran la dimension de la séparation à l'égard de son village natal. La médiation d'un ami brésilien, Rodrigo - comme lui étudiant en théologie à Louvain - opère une évolution décisive dans les certitudes politiques et religieuses du novice. L'exposition à la fois déconcertante et fascinante de la réalité sociopolitique latino-américaine éveille chez Conrad un désir irrépressible de rallier cette zone troublée du monde et de s'y engager à part entière : " Pour moi [Conrad], ce terrain est encore neuf $\rangle^{2}$. Dès lors, une fois sa décision prise, le départ semble incoercible et libérateur : "J'ai quitté Louvain comme on quitte, recru d'air vicié, un W.- C. public $»^{3}$. Le schème de la fugue-découverte ne constitue en aucun cas une figure isolée de l'écriture autofictionnelle detrézienne. Il implique l'imbrication d'autres traits thématiques et schématiques qui en soulignent la signification et l'enjeu. D'une part, tout départ ou évasion s'avère le fait d'une complicité et d'une médiation de l'autre. C'est le jardin de Ludo que le narrateur convoite, c'est à cause de Victor que l'extérieur de Saint-Trudon semble si fascinant, même au risque d'en devenir effrayant, c'est Leopoldus qui initie Conrad à l'art de la fugue, et c'est lui qui lui inculque le sens d'un ailleurs exotique inscrit dans sa propre physionomie. Par ailleurs, c'est Rodrigo qui, par son comportement et son discours, promeut la lente, mais radicale évolution psychologique de Conrad. D'autre part, tout désir d'évasion apparaît toujours lié à une fascination envers l'altérité d'un

${ }^{1}$ Conrad Detrez, L'Herbe à brûler, p. 34.

2 Ibid., p. 61.

${ }^{3}$ Ibid., p. 95. 
ailleurs inscrite quelque part dans l'aspect physique de l'ami. Ludo fascine le narrateur non seulement par son jardin, mais aussi par le côté énigmatique de son origine : "La mère de Ludo est née à Maastricht. Son père est né de l'autre côté des peupliers ${ }^{1}$. Qui plus est, les cheveux de Victor (Les Plumes $d u$ coq), le fugueur, rappellent ceux des " turcos $»^{2}$. Leopoldus, lui, introduit un exotisme africain dans l'univers restreint à plus d'un titre du jeune Wallon : " C'est la première fois que je dors à proximité d'un Noir (...) » ${ }^{3}$. Le départ de Conrad pour le Brésil est surtout le fruit d'un subtil envoûtement qui ne récuse pas la médiation du côté physique, exotique, voire érotique de l'ami lui-même : « La maigreur de Rodrigo m'a frappé ainsi que l'abondance et la noirceur des poils qui lui couvraient le ventre, les cuisses $»^{4}$. Aussi l'appel de l'ailleurs est-il étayé par un désir de l'autre.

Un troisième trait schématique récurrent consiste dans l'oscillation entre l'ordre et le chaos, entre la logique et la tentation carnavalesque et festive. Dans l'univers merveilleux des gamins de Ludo, la tension entre loi et infraction festive est dictée, d'une part par les contraintes de la guerre, des crues et de l'hystérie que ces deux facteurs provoquent chez les femmes du village et, d'autre part par l'irrépressible appel du jeu. Pris entre ces deux pôles difficilement conciliables, les gosses seront souvent victimes des remontrances des mères : " J'essaie de sortir une deuxième fois. C'est alors qu'elle [la mère] s'écrie : - La guerre ! Ah ! La guerre ! Tu la veux, la guerre ? Tu l'auras! $\rangle^{5}$. Dans ce récit, les éléments apparemment adverses de la guerre et des inondations sont aux yeux des deux garçons des alliés considérables. La guerre et les eaux montantes opèrent une transformation chaotique et radicale des choses et des biens. L'inondation fonctionne en tant que

\footnotetext{
${ }^{1}$ Conrad Detrez, Ludo, p. 25.

${ }^{2}$ Conrad Detrez, Les Plumes du coq, p. 30.

${ }^{3}$ Conrad Detrez, L'Herbe à brûler, p. 30.

${ }^{4}$ Ibid., p. 86.

${ }^{5}$ Conrad Detrez, Ludo, p. 22.
} 
désorganisation festive et carnavalesque du monde à la faveur de laquelle les objets changent de statut, s'exilent et se mêlent. La sensibilité enfantine est la plus à même de capter ces dérèglements et d'en faire une source de jouissance. Raison pour laquelle le narrateur de Ludo n'hésite pas à appeler un désastre de ses vœux :

Bon Dieu, faites que la rivière entre par la cuisine. Elle peut bien noyer le garde-manger, la cave, la resserre aux échalotes (...). Faites que la rivière sorte le lit de Ludo par la fenêtre qui donne sur le verger, le transporte (...). Qu'elle emmène celui de ses parents le plus loin possible, en Hollande ${ }^{1}$.

L'invasion de l'eau reformule l'agencement précaire des propriétés des terres, des biens : « La rivière coule entre les maisons, les eaux séparent les jardins ». L'invitation au jeu, « loin des regards $\rangle^{2}$ des mères et dans le domaine magique du jardin de Ludo comporte dès lors un renversement chaotique de l'univers ordonné des adultes. L'invasion de la chambre des parents de Ludo offre l'occasion d'un désordre festif et « ludique » intense. Le linge des parents fait l'objet d'un chaos jouissif, vindicatif et mimétique :

Ludo le [le vêtement] saisit par un bout, monte sur une chaise. Le vêtement se déplie, les pointes effleurent le plancher. La braguette, énorme, descend jusqu'au point médian de l'entrejambe. Ludo l'ouvre, introduit son bras ${ }^{3}$.

À cette pratique ludique ininterrompue, les crues et la guerre s'allient activement. Elles contribuent à un surplus de chaos dont le narrateur ne cache pas la fascination. Alors que la mère lui enjoint de prier afin d'éviter la montée des eaux, le narrateur avoue préférer contempler l'ampleur du désastre : « Ma mère prie. Je regarde l'eau. Prie! Je ne prie pas, je

\footnotetext{
${ }^{1}$ Ibid., p. 18.

2 Ibid., p. 35.

${ }^{3}$ Ibid., p. 31.
} 
regarde l'eau $\rangle^{1}$. Le spectacle est en effet trop beau pour être évité et le nouvel ordre trop tentant pour ne pas être accueilli : « Tout chavire, lentement, irrésistiblement ». À cet égard, le petit narrateur résume à merveille le nouveau régime en vigueur dans la commune de Roclenge : « Le sol n'est plus le sol. Les éléments s'ordonnent à l'envers $»^{2}$.

Dans Les Plumes du coq, l'ambiance chaotique ou carnavalesque se produit avant tout à la faveur des événements historiques mis en fiction et dont l'écho se trouve amplifié par l'hystérie collective du séminaire Saint-Trudon. Il s'agit - rappelons-le - de la Question Royale et de l'éventuel retour de Léopold III dans la foulée de la Libération. Or le narrateur choisit de rendre de façon carnavalesque ces événements somme toute capitaux de l'Histoire de la Belgique. En effet, Detrez tourne en dérision cette « histoire » dont la gravité factuelle est ridiculisée et relativisée. C'est ainsi que les lettres des « oui » et des « non » que les jeunes séminaristes sont censés coller sur les murs hostiles de Liège se mêlent et s'annulent dans une dérisoire interchangeabilité selon la fantaisie ou l'inaptitude des séminaristes aux combats politiques : « La palissade offre à la contemplation de ceux qui passeraient une longue tapisserie de OIU, de ONI, posés comme des flotteurs sur les eaux de la Meuse $(. ..) »^{3}$.

À Rio, Conrad - le narrateur autodiégétique de L'Herbe à brûler - connaîtra le carnaval proprement dit, avec ses excès, ses dérèglements, sa sensualité et sa mise entre parenthèses des bonnes intentions et des projets moraux. Là, le « missionnaire laïc » entendait mettre en œuvre tout un programme alliant ascèse et action, une « règle » élaborée par « un mystique d'un genre nouveau » ${ }^{4}$. Mais c'est au carnaval sensuel et païen et à ses propres démons qu'il aura à se confronter. L'obédience religieuse donne lieu à un

\footnotetext{
${ }^{1}$ Ibid., p. 57.

${ }^{2}$ Ibid., p. 41.

${ }^{3}$ Conrad Detrez, Les Plumes du coq, p. 102.

${ }^{4}$ Conrad Detrez, L'Herbe à brûler, p. 110.
} 
dérèglement radical et douloureux du narrateur, un baptême lubrique et (homo)sexuel dans la chaude et accueillante mixité du Brésil, administré par le Nègre Fernando : « La prière et le sperme, le sang, la douleur, cette douleur atroce entre les cuisses $(\ldots) »^{1}$. La récurrence du schème de l'introduction du chaos et du jeu dans un contexte régi par la gravité des événements historiques, par l'humeur des adultes ou par la fermeté apparente des résolutions vocationnelles traduit surtout la prégnance d'un trait autobiographique que Conrad Detrez fictionnalise : l'oscillation, chez un être perméable à toutes sortes d'influences, entre obéissance et infraction, entre faute et culpabilité.

Ces deux derniers schèmes, très présents dans la trilogie autofictionnelle detrézienne, méritent que l'on s'y attarde car ils éclairent, malgré l'écran fictif et au risque de tomber dans le cliché, une personnalité complexe, instable, en proie à l'autoanalyse. D'une lecture guidée par le souci de repérage autobiographique du triptyque halluciné, il appert que Conrad Detrez n'est décidément pas un bâtisseur de mondes, de morales. Il n'est pas un leader ou un stratège. Il n'a jamais vraiment pris une part active à ces fonctions de pouvoir. Son parcours et son vécu fictionnalisés dans l'« autobiographie hallucinée » font plutôt état d'une passivité exemplaire à suivre le cours du siècle dans son recyclage, de la vocation religieuse à l'engagement et militance politiques à gauche, jusqu'à la grisante expérience de l'amour affranchi des préjugés dont il avait, sans le savoir, tellement soif.

Dans Ludo, la domination hystérique de la mère, accentuée par l'absence du père se traduit en menaces, remontrances et châtiments. Mais les constantes fugues du gamin dans le jardin de Ludo ne procurent qu'une mince variante de cette même domination. En effet, le gosse vit on ne le dira jamais assez - « subjugué » par l'altérité de Ludo, par le caractère imposant de sa maison et par sa puissance au jeu. Les joutes de jet d'urine illustrent l'emprise

${ }^{1}$ Ibid., p. 124. 
psychologique de Ludo sur son voisin, d'un an son cadet. L'inaptitude à produire un jet copieux assigne au narrateur un statut d' « impuissant ». Le jet abondant et artistique de Ludo l'intimide et l'inhibe : « Ma feuille est gâchée, devant moi ce n'est que gribouillis, déchirures jaunâtres, formes qui ne ressemblent à rien $»$.

De même, le narrateur de Les Plumes du coq est un personnage foncièrement passif, soumis aux diktats des supérieurs de Saint-Trudon. Contrairement à Victor dont l'altérité exotique le fascine et maintient sous le charme, le narrateur se soumet sans grincher aux impositions sadiques du pensionnat. L'image faussement tutélaire de l'Époux le hante et l'impressionne jusqu'à l'hallucination. Par ailleurs, ses fugues nocturnes en font avant tout un apprenti voyeur, spectateur déconcerté et effrayé et, plus tard, victime des tendances pédophiles du supérieur.

L'Herbe à brûler met en scène l'évolution d'un narrateur, Conrad, dont les traits psychologiques s'identifient de plus en plus avec ceux de l'auteur homonyme. Au collège de Saint-Rémy, Conrad se signale par sa passivité et sa timidité. Leopoldus, le camarade africain de Conrad, exerce sur celui-ci une fascination qui tient aussi bien à sa différence raciale qu'à sa supériorité, habilité et astuce. À cet égard, il est déconcertant de voir le Congolais conquérir très facilement les cœurs des vachères blanches du village alors que le Belge se montre timide et gauche dans son initiation amoureuse. C'est même Alphonsine qui doit prendre l'initiative lors du premier baiser du naif Conrad : «Alphonsine alors a voulu qu'on se recouche, que je caresse sa poitrine et me remette à lui sucer la langue (...). Mais [gêné] je n'ai plus sucé $»^{2}$. À Louvain, Conrad, le jeune novice, végète dans la plus stricte obédience à l'égard d'une Église et d'une société conservatrices et dominatrices. Contrairement à son collègue brésilien, engagé dans le

${ }^{1}$ Conrad Detrez, Ludo, p. 50.

${ }^{2}$ Conrad Detrez, L'Herbe à brûler, p. 46. 
l'amour dans leur chambre de Louvain qui déclenche la conscience d'un monde inconnu et fascinant, édénique, antérieur à la notion peccamineuse de la sexualité honteuse et de la nudité obscène : " J'ai fermé la porte, ai regardé, incapable d'articuler un mot, ces deux corps qui ne semblaient avoir aucune honte de leur nudité $\gg{ }^{1}$.

Mais c'est l'exubérance et la mixité magiques et exotiques du Brésil qui viendront à bout d'un ethos ancré dans le schème mécanique du péché-expiation. En éternel « voyeur», et alors qu'il élabore son programme missionnaire et apostolique, Conrad se voit confronté à une scène déconcertante eu égard à la fermeté de ses principes moraux. Il devient de plus en plus évident que le ver est dans le fruit. À São Vicente, où l'évêque l'envoie pour se remettre d'un premier échec moral et pour peaufiner sa règle en vue d'un nouvel apostolat laï, Conrad est le témoin d'un épisode troublant, mais qui le fascine dans son for intérieur. Deux soldats, l'un noir, l'autre blanc, nagent nus dans l'océan, puis regagnent la plage : «Ensuite le blanc s'est tourné vers le Noir, s'en est rapproché, leurs jambes se sont mêlées, leurs poitrines touchées $»^{2}$. La fascination devant cette scène païenne et aberrante trahit une homosexualité latente qui n'ose pas encore s'assumer, mais que le Brésil, dans sa folie exubérante, se chargera de mettre à nu. Reste que cette vision entraîne, pour l'heure, une culpabilité malsaine. Conrad s'en veut d'avoir été là, d'avoir vu, de ne pas avoir été dégoûté ou scandalisé :

Quelque chose d'imprécis et de violent dans ces mouvements me fascinait. Dieu me pardonne, mon devoir était de fuir, d'aller me jeter à plat ventre sur le sol de la chapelle et de prier, marteler de mon front le pavé, me flageller, jeûner ${ }^{3}$.

\footnotetext{
${ }^{1}$ Conrad Detrez, L'Herbe à brûler, p. 86.

${ }^{2}$ Ibid., p. 112.

${ }^{3}$ Idem.
} 
Le carnaval de Rio, de par ses excentricités sensuelles et son inversion des valeurs morales et religieuses, procurera lui aussi la jouissance d'un univers et d'un temps libérés de tout sentiment de culpabilité, livré à un chaos festif et innocent : « ce que tu veux, pendant le carnaval on fait ce qu'on veut $»^{1}$. Cet état d'impunité, de grâce et de suspension de tout jugement moral, le narrateur en fera l'expérience à son corps défendant. Absorbé et envoûté par les rythmes cariocas, Conrad est happé par une fille qui, soudain, le suce et le fait jouir. D'autres femmes s'emparent de sa naïveté et le conduisent vers les orgies de la plage de Copacabana. Grisé par une sexualité qu'il voulait jusqu'alors ignorer et forclore, Conrad se retrouve nu sur cette plage paradisiaque, mais déjà accablé par l'ampleur de son péché originel : « (...) j'étais nu. Honteux, j'ai rabattu mes mains sur mes parties $\gg{ }^{2}$.

Mais le narrateur, dans son état adamique, n'était pas au bout de ses peines, ni de son plaisir. $\mathrm{Si}$ « le remords me tenaillait, mon âme se tordait. J'ai pensé courir vers une église, me confesser, expier $»^{3}$, la vue de Fernando, son camarade et apôtre laïc, décomplexé, dans un bal gay, l'amène à rejoindre une orgie homosexuelle dont il ne soupçonnait jusque-là ni le besoin, ni l'urgence. L'assomption de son homosexualité avec Fernando, le Noir, entraîne l'urgence d'un inutile et inefficace mercredi des Cendres. Les amants vivent dès lors dans le schème névrosé et mécanique du péché-confession:

La prière et le sperme, le sang, la douleur, cette douleur atroce entre les cuisses, les disputes et les mots d'amour puis ces confessions, ces pénitences, ces saintes communions et de nouveau le péché, l'étreinte, les larmes, les excréments. Puis encore la contrition et, six jours plus tard, épuisés, battus, et plus passionnément amoureux que jamais l'imprécation et le blasphème... ${ }^{4}$

\footnotetext{
${ }^{1}$ Ibid., p. 115.

${ }^{2}$ Ibid., p. 119.

${ }^{3}$ Ibid., p. 120.

${ }^{4}$ Ibid., p. 125-126.
} 
En fait, le sentiment de culpabilité après la chute trahit les oscillations d'un désir plus profond, un désir d'absolu dont nous accompagnerons l'évolution tragique dans le chapitre suivant. 


\section{VARIATIONS D'UN DESIR D’ABSOLU}

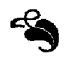

Conrad Detrez a clairement énoncé les raisons profondes et personnelles de son entrée en (auto)fiction avec Ludo en 1974. Il s'agissait pour lui de comprendre le cours qu'avaient pris plus de vingt ans de sa vie, ceux qui se sont écoulés entre sa naissance à Roclenge-sur-Geer (Wallonie), son entrée au séminaire à Visé, son passage à l'université de Louvain, son départ pour le Brésil, la militance maoïste et la guérilla urbaine, l'arrestation, la torture, l'assomption de sa bisexualité et le retour en Belgique. Ces événements, en principe " privés ", tissent des liens complexes et puissants avec l'Histoire à laquelle ils se rattachent d'une façon ou d'une autre. L'« autobiographe halluciné » conçoit la littérature sur le mode récapitulatif et analeptique. Detrez s'y est d'ailleurs mis relativement tard. En effet, selon lui, plusieurs raisons expliquent le recours à l'écriture autofictionnelle : " ma naissance, l'amour de Dieu, l'amour tout court et la politique $»^{1}$. À ce titre, Detrez est un enfant du XXe siècle. Il a incarné toutes les grandes métamorphoses du siècle révolu. Toute une génération " militante » n'aura guère de mal à se reconnaître dans cette œuvre au ton nostalgique. Detrez a prématurément quitté une fin de siècle désabusée et

\footnotetext{
${ }^{1}$ Conrad Detrez, « Le jardin de la vie », repris dans Ludo, p. 126.
} 
excessivement consensuelle. Le ton récapitulatif et confidentiel de l'ensemble de l'œuvre romanesque gagne une urgence inédite dans son témoignage posthume, La Mélancolie du voyeur, comme l'a bien pressenti l'un de ses derniers amis, Hector Bianciotti :

Je ne saurais jamais pourquoi, Conrad Detrez se mit à récapituler sa vie, comme s'il y avait urgence à le faire - et pour moi seul. Depuis les champs de betteraves à proximité desquels il était né, près de Liège, jusqu'à la conscience de la mort qui l'habitait et dont il parlait comme d'une loterie' ${ }^{\text {. }}$

Il confirme le rôle sotériologique, quasi théologique, que l'auteur assigne à l'écriture et qui le contraint à une « rigueur monacale $»^{2}$. À Colette Braeckman, journaliste au journal Le Soir, spécialiste du Tiers-Monde et amie de longue date, Detrez confiait son désabusement vis-à-vis du journalisme, jugé trop « immédiat », incapable de renouer avec le caractère presque épique de son parcours personnel : «(...) cette quête incessante du quotidien ne calmait pas ses nostalgies. Il avait envie de liquider son passé $»^{3}$. Raison pour laquelle à la suite du « sentiment d'avoir tout raté » ${ }^{4}$, il a sondé les raisons de ces faillites multiples et successives : « J'ai lu Freud et j'ai commencé, la plume à la main, à me livrer à une sorte d'analyse. Ainsi est né mon premier roman $\rangle^{5}$. Ainsi est donc née l'« autobiographie hallucinée » dans laquelle il inscrit un rythme ternaire obsédant. D'abord, l'écriture entend expliquer les raisons d'un triple échec : « Une crise morale, intellectuelle, affective me tourmentait $»^{6}$.

Elle s'étale dans le temps, sur une trilogie - Ludo (1974), Les Plumes du coq (1975) et L'Herbe à brûler

\footnotetext{
${ }^{1}$ Conrad Detrez, La Mélancolie du voyeur, p. 10.

${ }^{2}$ Colette Braeckman, « Les iguanes bavards de la cathédrale en ruine », Le Soir, 13 février 1985.

${ }^{3}$ Idem.

${ }^{4}$ Conrad Detrez, « Le jardin de la vie », repris dans Ludo, p. 198.

${ }^{5}$ Idem.

${ }^{6}$ Idem.
} 
(1978) - dont la diégèse autofictionnelle s'emploie à dilater par trois reprises un trajet, un départ, une fugue qui devaient amener cet « étonné perpétuel » au jardin de Ludo, à Visé, à Louvain, avec un excursus brésilien, qui s'avérera crucial dans l'évolution du narrateur, avant de se clore par un repli sur sa maison natale, le pays de son enfance. Marc Baronheid a très bien résumé ce cheminement jusqu'au « désenchantement pacifique ${ }^{1}$.

L'autofiction dégage et travaille trois $^{2}$ domaines thématiques majeurs, quoique sans souci de compartimentage : Dieu, la politique - surtout dans sa version révolutionnaire, celle qui aura profondément marqué le XXe siècle - et l'amour, dont l'expression n'exclut aucune modalité. Pierre Mertens voit dans ces trois thèmes principaux « les frontières d'un univers romanesque », les «figures dominantes d'une mythologie $»^{3}$ que les trois romans font souvent coexister dans leur univers propre. À cet égard, André-Joseph Dubois attire l'attention sur la piste de lecture offerte par l'épigraphe de chaque roman de l'hallucination romanesque. Trois perpétuels étonnés, révoltés ou briseurs d'idoles parrainent cette entreprise. Le seuil péritextuel de $L u d o$, récit de l'enfance, renvoie à Illuminations de Rimbaud dont le poème "Après le déluge » évoque une inondation purificatrice et l'ambiance apaisée, sereine qui lui succède. La critique n'a jamais été unanime à interpréter le sens de cette accalmie, mais Detrez sait la mettre à profit pour rendre l'atmosphère de sa prime enfance marquée par la Seconde Guerre mondiale et les crues successives du Geer. L'image d'« enfants en deuil » regardant « les merveilleuses images » après un déluge annonce bien l'univers de Ludo, où le dehors

1 Marc Baronheid, «Conrad Detrez repose parmi les idoles brisées », $L a$ Wallonie, 2 novembre 1986.

${ }^{2}$ Même si dans son entretien avec Christian Panier, Detrez ajoute le thème somme toute vague du « rapport à la nature et aux éléments ». Christian Panier, « Du Brésil à Paris et détours : entretien avec Conrad Detrez », p. 203.

${ }^{3}$ Pierre Mertens, « Detrez à la croisée des chemins ? », Le Soir, 10 février 1981. 
humide et chaotique suscite l'envoûtement des enfants cloîtrés chez eux, mais attentifs aux moindres signes extérieurs.

L'écriture de Les Plumes du coq signale, tout en l'illustrant, l'abandon d'un idéal chrétien et ecclésiastique au profit d'une plus ample acception de l'amour et de ses causes : « Ensemble nous avons juré d'aimer l'Amour »'. Dans le péritexte, Detrez annonce qu'il entend marcher sur les pas palinodiques de Nietzsche - maître du soupçon s'il en est - et connaître à son tour un « dieu inconnu ». Detrez est " pour la dernière fois " aux prises avec un dieu " insaisissable ", mais d'autres appels plus urgents le contraignent à « tourner [ses] yeux vers l'avenir ». L'Herbe à brûler devait concrétiser le lieu de ce conflit douloureux et de ce « désenchantement paisible ». L'épigraphe de ce troisième et dernier tome évoque l'un des personnages les plus " révoltés " de l'histoire biblique, Job, le Juste durement éprouvé par Yahvé, sûr de son équité et de sa bonne conscience, mais qu'amis et circonstances s'acharnent à incriminer.

Une lecture attentive de ces trois exergues dessine trois thèmes faisant écran à la vision de la Beauté ${ }^{2}$ dont il éprouve le besoin serein au « voisinage de la mort », et forment en fait « trois pôles imbriqués $»^{3}$, comme on le verra dans l'analyse de chacune de ces figures, et non pas trois moments successifs. Elles apparaissent imbriquées dans chacun des trois romans, mais s'avèrent surtout enchevêtrées aussi bien dans l'évolution historique et sociétale du siècle passé que dans le cheminement de l'auteur lui-même. À cet égard, l'«autobiographie hallucinée » se propose d'éclairer la prégnance de ces trois pôles changeants dans la poursuite d'une certaine idée d'Absolu qui n'aura jamais quitté son auteur. Il suffit pour s'en convaincre de lire les premières

${ }^{1}$ Conrad Detrez, Les Plumes du coq, p. 198.

${ }^{2}$ Conrad Detrez, La Mélancolie du voyeur, p. 13.

3 Jacques Franck, « La pavane de Conrad Detrez pour les révolutions défuntes », La Libre Belgique, 19 septembre 1984. 
pages de La Mélancolie du voyeur. Detrez y déclare sa « faim d'autre chose ", ce qui laisse entendre que, malgré tout, demeure quelque part un souci métaphysique et religieux après la chute de toutes les idoles. Mais c'est à l'écriture romanesque ultérieure - davantage « fictionnelle » et moins «hallucinée »- qu'il reviendra de mettre en lumière les rapports subtils et les « emprunts et renvois » ${ }^{1}$ constants liant les trois figures axiales de l'œuvre detrézienne. À nouveau, il s'agit ici aussi d'un projet d'écriture sciemment mis en œuvre ${ }^{2}$.

La Lutte finale joue sur les équivoques produites par le rapprochement des discours politique et religieux, tandis que Le Dragueur de Dieu met en exergue - notamment par le truchement de la métaphore de l'Ange - les liens et les emprunts unissant l'univers religieux au domaine de la sexualité (et de l'homosexualité). Ce corpus fictionnel ne faisant qu'indirectement partie de notre propos, nous y reviendrons succinctement après l'approche de l'impact autofictionnel des trois figures dominant le triptyque detrézien.

\section{1. «Quelque chose » appelé Dieu}

Conrad Detrez est revenu sur son expérience enfantine de Dieu dans le témoignage autobiographique qu'il livre dans un entretien intitulé « Le jardin de la vie ». Le petit garçon très pieux ${ }^{3}$ de Roclenge s'est senti dégoûté par la profession cruelle et sanglante du père, boucher habitué aux abattoirs. La religiosité enfantine offre une réponse et un bien-être spirituels à ce gosse à qui la violence répugnait. Conrad - tout comme Victor dans Le Dragueur de Dieu - a fui « le métier du père " pour se consacrer à la mystique des anges.

\footnotetext{
${ }^{1}$ Christian Panier, « Du Brésil à Paris et détours », p. 200-201.

${ }^{2}$ Cf. Idem.

${ }^{3}$ Cf. « Roclenge : la plaque du pont Conrad Detrez... », La Meuse, 21 mai 1987 (éditorial).
} 
Reprise dans L'Herbe à brûler sans toutefois se répéter, l'expérience de l'entrée et l'existence dans le collège de Saint-Rémy valide le sentiment d'une pratique religieuse acritique caractérisée par l'obédience et la gestion mécanique d'une conscience tourmentée par la culpabilité. Le baiser à Alphonsine entraîne la nécessité du confesseur : « Le prêtre insistait, fouillait mon âme (...). Et il était grand mon péché ; c'était comme une bête à plusieurs têtes et tentacules $(. ..) »^{1}$. À Saint-Rémy, établissement confessionnel s'il en est, l'enseignement humaniste transmet surtout une culture mécanique plus proche de celle de Gargantua que de Pantagruel. Une vision conservatrice et autoritaire de l'Église s'y consolide à force de mémorisation irréfléchie : «J'apprenais par cœur des livres entiers, connaissait sur le bout des doigts la liste des papes depuis saint Pierre jusqu'à Pie XII et les principales dates de l'histoire de l'Église $»^{2}$. Par ailleurs, la piété populaire se trouve surtout sous l'emprise des préjugés religieux et politiques comme sous celle de la politique coloniale du Royaume : "Je priais pour la conversion des athées [communistes], des juifs et des Congolais $»^{3}$. À Louvain, la rencontre avec Rodrigo et les étudiants sud-américains est l'occasion d'une confrontation entre une conception ecclésiale progressiste et prophétique du christianisme et celle de Conrad, un débat qui à l'époque se tient aussi au sein du concile Vatican II. Aussi pour Rodrigo, l'enjeu liturgique semble-t-il bien dérisoire, « comme sont dérisoires les autres querelles des évêques et des théologiens des Églises d'Europe $»^{4}$.

L'impact de la réalité sud-américaine et l'assomption de son (homo)sexualité devaient venir à bout d'une tentative d'« apostolat laïc » qui tentait de concilier ce qui s'avère de moins en moins conciliables : un appel à la militance, à l'engagement sociopolitique et la tentative désespérée de se

\footnotetext{
${ }^{1}$ Conrad Detrez, L'Herbe à brûler, p. 48.

2 Ibid., p. 49.

${ }^{3}$ Idem.

${ }^{4}$ Ibid., p. 60.
} 
maintenir lié à une vision conservatrice, hiérarchique et autoritaire, culminant dans la chasteté. À São-Vicente, Conrad rêve encore d'une mystique « d'un genre nouveau » ${ }^{1}$. Il a vingt-deux ans et se dit « ivre de Dieu $\rangle^{2}$ et exalté. Il se croit le digne successeur des mystiques fondateurs de règles et de communautés religieuses. Il se sent l'instrument d'un plan providentiel en vue de l'érection d'une communauté ecclésiale inédite : « La communauté des travailleurs chastes et mystiques que je réunirais en vivant au milieu des hommes $\|^{3}$. En fait, Conrad est en train de se leurrer doublement. Dans sa naïveté congénitale, il ne tient pas compte de l'expérience accumulée par les mouvances gauchistes de l'Église brésilienne, notamment les Communautés Ecclésiales de Base (CEBs) et le rôle qu'y joue une personnalité aussi charismatique que Frei Betto. De lui, Detrez dira dans Les Noms de la tribu que « La mystique l'attire plus que tout mais il ne peut se résoudre à taire les exigences de sa conscience politique $\gg^{4}$. Conrad ne peut donc revendiquer le caractère novateur et inédit de sa démarche. Par ailleurs, la révélation de son homosexualité, refoulée jusque-là, mettra fin à ces projets chastes : « La souffrance et le plaisir sont venus à bout de la religion $»^{5}$. Il ne renie pas vraiment le christianisme où il a sans cesse cherché des ponts avec une vision évolutive du monde. Rappelons ses lectures et ses traductions de Teilhard de Chardin, de Maritain ou de Mounier. Sa fascination à l'égard de l'adhésion de toute une intelligentsia chrétienne brésilienne à « un épanouissement intégral : spirituel, social, culturel $\rangle^{6}$ prélude à une réévaluation de son propre rapport au christianisme. Désormais, Detrez trouvera ses modalités d'engagement dans la militance politique, et plus tard dans la guérilla urbaine. Par

\footnotetext{
${ }^{1}$ Ibid., p. 110.

${ }^{2}$ Ibid., p. 111.

${ }^{3}$ Idem.

${ }^{4}$ Conrad Detrez, Les Noms de la tribu, p. 73.

${ }^{5}$ Conrad Detrez, L'Herbe à brûler, p. 125.

${ }^{6}$ Conrad Detrez, Les Noms de la tribu, p. 76.
} 
ailleurs, il devait faire face au pouvoir incontrôlable de la passion et du sexe qui s'insinuait de plus en plus en lui et minait une existence étayée sur le vœu de chasteté, mais surtout sur le refoulement. L'exubérance et le carnaval brésiliens mettraient à mal la posture « cléricale $\rangle^{1}$ et vierge $\mathrm{du}$ jeune Européen. En prenant conscience de sa " déchéance » et de sa défaite lors de ses déboires amoureux à Rio, il acte la péremption de son rapport d'obédience à l'égard du catholicisme : " J'avais pourri en vingt-quatre heures aussi profondément, intimement, que d'autres dans toute une vie $»^{2}$.

$\mathrm{Au}$ « voisinage de la mort », Detrez - qui fait profession de foi en la «Beauté » - ne renie pas tout à fait Dieu. Une lecture plus attentive de son bilan posthume trahit sa déception d'une certaine idée usée et instrumentale : « À présent on l'étale, telle une marchandise, sur un bout de comptoir $»^{3}$. Detrez regrette que Dieu soit « devenu une denrée idéologique $»^{4}$, mais confirme la prégnance de cette première étape et de cette première défaite de son existence. Il témoigne aussi d'un profond respect vis-à-vis du Dieu de son enfance, si étroitement lié aux souvenirs persistants de cette période de sa vie : «Par exemple, il y eut Dieu. Lui, je l'ai cru beau, un temps, j'ai cru l'avoir trouvé et j'ai vécu dans sa compagnie. Mais il m'a déçu, il est usé, ce pauvre Dieu, il ne croit plus dans ses pouvoirs, il s'est laissé circonvenir $»^{5}$.

\subsection{Le lumpen et la Révolution}

L'Herbe à brûler fictionnalise la douloureuse transition de la fidélité envers Dieu et l'Église vers la militance

\footnotetext{
${ }^{1}$ Conrad Detrez, La Mélancolie du voyeur, p. 59.

${ }^{2}$ Conrad Detrez, L'Herbe à brûler, p. 120.

${ }^{3}$ Conrad Detrez, La Mélancolie du voyeur, p. 13.

${ }^{4}$ Idem.

${ }^{5}$ Idem.
} 
politique, clandestine et parfois armée. L'intimité avec Fernando n'a pas seulement opéré la prise de conscience du refoulé sexuel de Conrad, elle a aussi fait s'ouvrir le projet d'apostolat laïc à la militance syndicale et politique : « La direction nationale des T. C. s'inquiéta, les âmes des travailleurs on les oubliait, Fernando d'apôtre devenait politicien $\rangle^{1}$. Detrez lui emboîtera le pas quelques jours plus tard, encouragé par l'ambiance de plus en plus houleuse et conflictuelle causée par le coup d'État militaire et le passage dans la clandestinité d'une bonne partie de l'opposition de gauche, toutes mouvances confondues. De nouveaux maitres à penser (Che Guevara, Fidel Castro, Mao, Marighela) et de nouveaux ouvrages, bannis aussi bien à Visé qu'à Louvain, lui servent désormais de modèles. Il aura beau souligner a posteriori une certaine cohérence dans sa démarche intellectuelle dans la foulée de ses lectures de Mounier et de Chardin; il aura beau plaider dans les bidonvilles « les avantages d'un supposé socialisme latin $»^{2}$ dont la révolution cubaine offrait une version " personnaliste $»^{3}$, le jeune séminariste idéaliste ne peut en toute franchise qu'entériner son irréversible évolution :

Un jeune homme était mort en moi, qui naturellement n'avait pas survécu à son Dieu ; un autre jeune homme était né, qui parlait une langue différente, ne priait plus, aimait son corps et voulait établir le ciel sur la terre ${ }^{4}$.

Toutefois, le narrateur n'hésite pas à associer, voire à faire dériver ce nouveau credo et cet engagement sociopolitique de son apostolat chrétien antérieur. À cet égard, Detrez est assurément le produit de son siècle. Avec une lucidité précoce, il prend conscience des liens étroits et des affinités des catégories chrétiennes unissant malgré les

\footnotetext{
${ }^{1}$ Conrad Detrez, L'Herbe à brûler, p. 126.

${ }^{2}$ Conrad Detrez, Les Noms de la tribu, p. 28.

${ }^{3}$ Idem.

${ }^{4}$ Conrad Detrez, L'Herbe à brûler, p. 159.
} 
malentendus le christianisme et les projets modernes mis en œuvre au XXe siècle et qui ne seraient mis en lumière qu'avec la crise du marxisme. En effet, le narrateur signale que cette évolution répond avant tout à une variation, à un glissement d'un désir profond d'amour et d'engagement qu'il avait jusque-là éprouvé dans son état clérical et à partir de la vieille Europe : «Ce jeune homme se sentait porté par une force aussi puissante que l'ancienne mais plus vraie, palpable et mesurable (...) » ${ }^{1}$. En somme, et par l'ironie du sort, Detrez aura finalement et à son corps défendant mis sur pied son programme de « mission laïque » et sa « mystique d'un genre nouveau ». Les repères sociopolitiques n'étaient pas totalement absents des deux premiers thèmes de l'« autobiographie hallucinée ». Tout comme dans L'Herbe à brûler, leur inscription ne constitue aucunement une thématique exclusive, mais résulte d'une intéressante imbrication narrative et mémorielle. Cependant, dans les deux premiers volets, le narrateur se montre acritique, passif, incapable, du fait de son âge comme de l'état léthargique du pays, de prendre réellement part aux événements et aux débats sociaux du moment.

Dans Ludo, le point de vue animiste de l'enfant ou le procédé descriptif frôlant çà et là l'ethnographie ne permettent pas d'appréhender avec un minimum de réalisme, et surtout d'implication sociale, les enjeux du conflit en cours. De son côté, Les Plumes du coq a beau fictionnaliser l'un des événements les plus marquants de l'histoire belge (la Question Royale), l'état d'obédience et de minorisation politique, allié à l'hystérie conservatrice de Saint-Trudon, ne promeut pas une conscientisation sociale des faits, et encore moins de la part du jeune narrateur. Au contraire, l'ironie et le fantasme de l'Époux annulent toute la gravité factuelle de l'histoire, rendant le récit quasiment anhistorique.

La conscientisation politique de Detrez n'aurait pu se produire autrement que dans un pays comme le Brésil des

${ }^{1}$ Idem. C'est nous qui soulignons. 
années soixante. La rencontre avec Rodrigo à Louvain l'y avait préparé, mais la réalité brésilienne lui a permis de se mettre dans le bain. Une fois passée la crise religieuse, Conrad est introduit au sein de l'organisation politique maoïste fondée par Marighela. Rompant avec un passé et environnement acritiques et passifs, l'auteur souligne l'initiative de son intense engagement de néophyte gauchiste : « Nous [Conrad et Sónia] avons milité ensemble, collé des affiches, peint des inscriptions, distribué dans les bidonvilles des sacs de lait en poudre pillés dans une cargaison amenée par un bateau de la marine américaine $»^{1}$. L'expulsion de Detrez et son arrivée à Paris en plein Mai 68 sont l'occasion d'un premier infléchissement et d'une première prise de distance par rapport à la militance politique. À Paris, au printemps 1968, on reportait « des rumeurs de grève, de troubles et même de révolution $»^{2}$. À côté des soucis urgents et violents du Brésil, les tracas parisiens semblent bien dérisoires : « (..) car un jour, brutalement, la France m'a lancé au visage qu'elle avait cessé de s'ennuyer $»^{3}$. Pour le narrateur, cette époque constitue un " temps de reflux $»^{4}$ où des sciences humaines moins « dialectiques », relayées par les universités françaises, attirent de plus en plus l'attention des anciens guérilleros. Detrez « découvre la psychanalyse » et l'applique à un projet d'écriture 5 . Un temps séduit par l'« a-nar-chis[me] » parisien $^{6}$, il finit par s'en écarter, déçu, mais aussi méfiant envers les causes sud-américaines que l'anarchisme feignait d'ignorer, tout comme il ignorait ses acteurs anonymes auxquels il se sentait encore fortement attaché (Sónia), ou en tous cas redevable.

\footnotetext{
${ }^{1}$ Ibid., p. 165.

${ }^{2}$ Conrad Detrez, Les Noms de la tribu, p. 205.

${ }^{3}$ Ibid., p. 206.

${ }^{4}$ Ibid., p. 116.

${ }^{5}$ Idem.

${ }^{6}$ Cf. Conrad Detrez, L'Herbe à brûler, p. 208.
} 
Le troisième récit autofictionnel ne se réfère pas à la Révolution portugaise des CEillets de 1974. Il se clôt plus tôt, avec le retour quasi fusionnel de Conrad dans son village natal, Roclenge. Entre-temps, il est correspondant à Lisbonne dans l'après 25 avril 1974 et couvre pour la RTB la période trouble du lent et incertain retour démocratique au Portugal après la dictature salazariste et la tentative de coup d'État marxiste. À Lisbonne - qui sent l'empire et la saudade Detrez rédige Les Plumes du coq et consolide une attitude assagie et lucide des luttes révolutionnaires dont il éprouve un profond écœurement. Bruxelles se plaint de plus en plus de ses reportages trop fades : « mes confrères, là-haut (...) meurent d'envie (...). Ils sont excités, mes braves gauchistes belges $\rangle^{1}$. Les gauchistes de tous bords en mal de révolution suivent avec une passion toute sportive et hypocritement détachée le cours des événements au Portugal. Detrez raille ces touristes politiques de gauche qui en voudraient davantage, mais qui devront se contenter d'un coup d'État plutôt policé. $\mathrm{Si}$ « pour la gauche européenne, ce pays était devenu un point d'attraction $»^{2}$, pour Detrez, il signale surtout un moment de bascule idéologique : « J'ai reçu à Lisbonne, des mois durant, une magistrale leçon de léninisme, non plus théorique mais pratique. J'ai palpé le mal totalitaire qu'il peut engendrer $\iota^{3}$. À l'instar de toute une intelligentsia marxiste européenne et de ses anciens compagnons de route et de malheur brésiliens, qu'il ne reconnaît plus tout à fait lors de son retour au Brésil, après la restauration d'un régime démocratique et son amnistie personnelle, il « se recycle, (...) essaie de rajeunir les vieux schémas, les vieilles analyses $»^{4}$. On fait comme tout le monde. On se dit désormais " social-démocrate $»^{5}$ et on avoue s'intéresser au Tiers-Monde et militer dans les droits

\footnotetext{
${ }^{1}$ Conrad Detrez, La Mélancolie du voyeur, p. 111.

${ }^{2}$ Conrad Detrez, Les Noms de la tribu, p. 122.

${ }^{3}$ Ibid., p. 128.

${ }^{4}$ Ibid., p. 72.

${ }^{5}$ Ibid., p. 128.
} 
de l'homme. Vaste et vague programme! Les dernières lignes de L'Herbe à brûler accusent ce désenchantement doux-amer et cette deuxième et cinglante défaite personnelle : «Mon âme avait tout appris. Elle savait à son tour que Dieu est mort, la révolution broyeuse des hommes qui la font, l'amour impossible $»^{1}$.

\subsection{L'amour «qui fait mal »}

L'« amour » est un mot trop vague et trop grand pour rendre compte de ce que Conrad Detrez reconnait être sa troisième défaite et son troisième échec. Il peut en effet référer à l'amour de Dieu dont nous avons vu combien il a fini par s'éloigner. En fait, Detrez parle du « sexe » comme n'étant qu'un « autre Dieu, dévalué encore à force d'en user $»^{2}$. La lecture des trois récits autofictionnels met certes en scène une initiation, un apprentissage de l'affectivité dont toute une éducation religieuse décrite dans Les Plumes $d u$ $\operatorname{coq}$ l'avait dramatiquement privé. Chez le narrateur de plus en plus autodiégétique de l'" autobiographie hallucinée », la sexualité a été vécue comme étant du domaine du refoulé. Le contact avec le Brésil, son carnaval, son exubérance et son métissage intrinsèques opère une prise de conscience de sa bisexualité inexplicable et irrépressible. L'autofiction affective et sexuelle de cet auteur a très tôt suggéré à la critique littéraire que ce romancier contemporain s'inscrivait sous la rubrique confortable du « roman homosexuel $»^{3}$ où l'on place par exemple Guy Hocquenghem, et dans lequel l'homosexualité est recherchée ou décrite pour elle-même.

Toutefois, Detrez se défend bien d'avoir jamais entrepris pareille démarche d'écriture : « Je n'ai pas voulu qu'on me

\footnotetext{
${ }^{1}$ Conrad Detrez, L'Herbe à brûler, p. 231.

${ }^{2}$ Conrad Detrez, La Mélancolie du voyeur, p. 13.

3 Cf. Joël Schmidt, "Éclatements du roman français », Romans français contemporain, Paris, Ministère des Affaires Etrangères, Sous-Direction du Livre et de l'Écrit, 1997, p. 148.
} 
colle une étiquette - vite posée - de romancier homosexuel : elle est aujourd'hui à la mode et je ne veux pas de cette image de marque $\rangle^{1}$. En fait, il n'entend rien illustrer. Il dit en passant, avec ironie et avec un détachement rusé. Ceux qui s'attendaient à y lire une écriture homosexuelle, dont notre époque est friande, en seront pour leurs frais. Il ne livre que " des romans chastes $\|^{2}$ où la description des scènes amoureuses ne confine jamais à la pornographie, mais implique toujours une certaine pudeur ou retenue. Le poète William Cliff a mis en vers ses souvenirs d'un « turbulent fils » de retour dans une Belgique morose et ingrate ${ }^{3}$. Cliff aura le soin de préciser qu'ils ne furent pas amants ${ }^{4}$. Dans son dernier témoignage, foudroyé par le sida, Detrez voudra en finir avec toutes ces spéculations critiques et cliniques: « ça me dépasse, ces choses cliniques. J'ai couché, c'est tout $»^{5}$. L'écriture se veut ici surtout allusive. À cet égard, cette retenue narrative illustre une tendance formelle $\mathrm{du}$ roman contemporain que Sémir Badir analyse dans le contexte catégoriel et esthétique de la postmodernité.

Tout comme Hervé Guibert, Detrez « se fai[ $t$ ] raconter par le roman, contaminer sa propre identité par sa mise en fiction $(\ldots) »^{6}$. Très concrètement, et toujours à l'instar d'Hervé Guibert, « (...) l'homosexualité, qui pourrait être le sujet de son œuvre, n'est pas rendue comme tel, elle est présente, sans ostentation, parce qu'elle est inhérente au personnage, inévitable (...) $\gg^{7}$. Pour Detrez, l'homosexualité ne constitue jamais un thème unique, exclusif et explicite. Il

${ }^{1}$ Pierre Mertens, «Detrez à la croisée des chemins ? », Le Soir, 10 février 1981.

${ }^{2}$ Idem.

${ }^{3}$ Cf. William Cliff, Conrad Detrez, p. 14.

${ }^{4}$ Cf. « William Cliff : la vie comment ça rime », entretien avec Carmelo Virone, Le Carnet et les Instants, n ${ }^{\circ}$ 77, 15 mars-15 mai 1993, p. 7.

${ }^{5}$ Conrad Detrez, La Mélancolie du voyeur, p. 80.

${ }^{6}$ Sémir Badir, « Vers la postmodernité. Retour à Baudelaire ? », Écritures, $n^{\circ} 5$, « Le Dépli. Littérature et postmodernité », automne 1993, p. 1.

${ }^{7}$ Laurent Demoulin, « Pour un roman sans manifeste », Écritures, ${ }^{\circ} 1$, « Fin de millénaire », automne 1991, p. 17. 
s'agit plutôt de « l'inscrire dans un univers plus vaste $»^{1}$ où les autres domaines thématiques sont eux aussi imbriqués dans une même quête. Force est de reconnaître que la complexité de l'entreprise autofictionnelle de Detrez ne met pas l'écriture à l'abri du cliché. On remarquera une relation fusionnelle et exclusive avec la mère ainsi qu'un père absent et violent. Toutefois, les trois récits autofictionnels distillent, au gré d'une mémoire sûre, des moments cruciaux de l'enfance ou des détails décisifs issus du subconscient. Isolé, chaque détail ne permet pas une lecture de la quête d'une trame cohérente qui éclairerait l'homosexualité de l'auteur narrateur-personnage principal dans son état de latence et de refoulement, raison pour laquelle nous suivrons le cheminement narratif de ces détails immenses.

Dans Ludo, il nous est loisible de lire plusieurs traits mémoriels comme autant de pistes enfouies ou d'indices latents d'une homosexualité refoulée, mais que l'animisme et le ludisme enfantins cryptent et rendent énigmatiques. Un souci d'approcher l'homosexualité assumée du narrateur de L'Herbe à brûler apporte un éclairage rétrospectif sur certains épisodes fictionnalisés de l'enfance, et tout d'abord sur la fascination profondément sensuelle envers l'autre petit garçon, Ludo, dont la chevelure fonctionne comme objet de désir : « Ses cheveux se défont, je les peigne du bout des doigts, les arrange $»^{2}$. Entre Ludo et le petit narrateur s'établissent de complexes rapports de complicité et de pudeur à la faveur du jeu et du contexte difficile du récit : « (...) pourquoi me regarde-t-il [Ludo] comme ça, comme quelqu'un qui $n^{\prime}$ a jamais vu un garçon? $»^{3}$. Par ailleurs, le penchant ludique du récit - « loin des regards » des parents est le lieu d'un apprentissage rudimentaire et latent des interdits sociaux des adultes confrontés à l'irrépressible pouvoir du jeu, à l'implosion d'un désir sans nom : « Mon

\footnotetext{
${ }^{1}$ Christian Panier, « Du Brésil à Paris et détours », p. 203.

${ }^{2}$ Conrad Detrez, Ludo, p. 103.

${ }^{3}$ Ibid., p. 122. C'est nous qui soulignons.
} 
camarade se prend pour son père, je suis le mien. Il m'appelle mais moi je joue avec le soleil. Et puis, les papas ne se marient pas avec des papas $»^{1}$. Mais ce sont les concours de jet d'urine qui, de par l'exhibitionnisme qu'ils impliquent, suscitent la complicité la plus réprimée par les mères. Le petit narrateur - à la fois exhibitionniste et voyeur - ne cache pas sa fascination pour la puissance du pénis de Ludo, capable de fournir un jet copieux et continu d'urine. Il regrette sa propre impuissance tout en soulignant le penchant sensuel de ce jeu fait d'attouchements : « Ludo la [la verge du narrateur] saisit, le membre se raidit, je m'échauffe, mes pieds dégèlent $»^{2}$.

Au séminaire Saint-Trudon, la fascination amoureuse et sensuelle porte sur la chevelure de Victor, son camarade de chambrée : «Ma main s'abandonne, se laisse porter. Je lisse des boucles dans un paradis que je ne connais pas $»^{3}$. Dans l'univers répressif et exclusivement masculin du collège, l'apprentissage de l'amour se fait forcément entre garçons, accoutrés d'habits féminins : " D'ailleurs un garçon qui embrasse un autre [Marien], ça ne compte pas (...) $»^{4}$, s'insurge le narrateur tout en adhérant au jeu initiatique. L'Époux, lui aussi, tout comme Marien, active un rapport ambigu à l'image du Christ - homme nu et, sur certaines images pieuses, affublé d'une tunique très féminine : «L'Époux a pris les vêtements d'une femme, on dirait Marien $\gg$.

Les pratiques perverses du supérieur dans le poulailler suscitent la méfiance, la surveillance et surtout une fascination voyeuriste du narrateur qui culminera dans $L a$ Mélancolie du voyeur. En effet, c'est en apprenti voyeur que le jeune narrateur de Les Plumes du coq suit, caché dans les champs de betteraves, l'évolution sinistre du supérieur et ses

\footnotetext{
${ }^{1}$ Ibid., p. 32. C'est nous qui soulignons.

${ }^{2}$ Ibid., p. 50. C'est nous qui soulignons.

${ }^{3}$ Conrad Detrez, Les Plumes du coq, p. 37.

${ }^{4}$ Ibid., p. 83.

${ }^{5}$ Ibid., p. 87.
} 
Lucien se montre incapable d'y lire autre chose qu'un pèlerinage spirituel dans la capitale française.

La dérision, l'ironie et l'humour s'insinuent dans le récit promouvant de la sorte une " théologie profane » indécidable ${ }^{1}$, comme dans cette scène de strip-tease gay que Lucien ne saisit pas : «Après cette parade j'ai vu l'Ange. Il correspondait aux descriptions que donne l'histoire sainte (...) : l'Ange, sous sa robe était nu $»^{2}$. À la faveur de la figure métaphorique de l'Ange, le discours religieux prête ses images, ses métaphores et sa sainteté à la sexualité, et lui confère une dimension spirituelle et mythologique dont on la prive habituellement. Ce roman met ainsi en scène l'une des leçons à la fois libératrices et douloureuses de la vie de Detrez : la prise de conscience de «la frontière oh combien ténue du péché et de l'innocence $»^{3}$.

\subsection{La Beauté comme épilogue}

Après Dieu, la révolution et le sexe, Detrez, aux portes de la mort, prétend être parvenu au stade esthétique et sage du « regard ». Un regard en amont et halluciné portant sur son enfance à Roclenge, son séjour au collège de Visé, ses études de théologie à Louvain, son départ pour le Brésil, son retour en Belgique, son poste de correspondant à Lisbonne, sa naturalisation française liée à son départ pour le Nicaragua comme attaché culturel sous l'ère mitterrandienne, son hospitalisation, sa mort qu'il sent proche, mais sereine. Un regard essentiel et métaphysique enfin, car « ce qui compte c'est ce qu'il y a dedans, ce qu'il faut garder, sauver jusqu'à la mort (et au-delà ?) : l'inclassable, le diamant, la nourriture profonde, toujours reconstituée : cela qu'on a $v u »^{4}$.

Detrez renoue avec son enfance wallonne, avec le temps

\footnotetext{
${ }^{1}$ Christian Panier, « Du Brésil à Paris et détours », p. 199.

${ }^{2}$ Conrad Detrez, Le Dragueur de Dieu, p. 100.

${ }^{3}$ Christian Panier, « Du Brésil à Paris et détours », p. 199.

${ }^{4}$ Conrad Detrez, La Mélancolie du voyeur, p. 16-17.
} 
du regard ébloui et émerveillé ${ }^{1}$ des champs de betteraves à perte de vue. Il se réconcilie avec le « voyeurisme » de sa jeunesse, celui de sa transition d'un monde chaste et pieux vers les initiations à l'amour tous azimuts : « Le regard est une métaphysique. L'essence du regard est voyeuse $»^{2}$. Une fois écroulés les trois écrans qui l'empêchaient de voir et dont le XXe siècle nous aura appris à faire le deuil, une fois pressenti le voisinage de la mort, il s'emploie à se remémorer tout ce qu'il a vu, à profiter de tout ce qui lui reste à voir. Ironie du sort : il y a chez lui une foi qui reste quand tout semble discrédité. L'ex-séminariste, ex-militant, ex-amant se fait soudain mystique au sens le plus spirituel du terme : « on se rapproche de l'éternité " ${ }^{3}$. Il choisit la «meilleure part », pour reprendre l'expression évangélique, et devient un contemplatif d'un genre nouveau. Le guérillero tire sa révérence : " Pour le reste, finis les combats (et de toute nature), finie l'action - ô dérisoire action ! -, finis les discours ! (...). Désormais je serai, je ne veux plus être qu'un regard. Et le regard chasse. Ma mission m'est assignée, définitive : la beauté. Je serai chasseur de beauté » ${ }^{4}$.

\footnotetext{
${ }^{1}$ Idem.

${ }^{2}$ Idem.

${ }^{3}$ Ibid., p. 13.

${ }^{4}$ Idem.
} 


\section{L'INSCRIPTION DE L'ICI : ENTRE ALLUSION, REFRACTION ET DERISION}

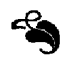

Le débat de la belgitude ${ }^{1}$ coïncide grosso modo avec l'entrée en autofiction de Conrad Detrez. L'œuvre qui s'annonce suscite bien des espoirs du côté des tenants de cette polémique cruciale puisque cet auteur - tout comme Mertens auquel on l'associe de plus en plus - entreprend le renouvellement de la fiction narrative alliant paradoxalement un souci d'immersion internationaliste avec un ancrage dans la concrétude de l'ici. Chez lui, la critique a tôt signalé une inscription tout sauf honteuse du cadre géographique et historique de la Belgique. En effet, à l'instar d'autres romanciers de sa génération, très à l'aise dans les milieux internationalistes ou dans l'avant-garde parisienne (Mertens, Verheggen, Otte), Detrez fait partie de ce groupe d'écrivains qui « (...) ont cessé de pratiquer le gommage des origines $»^{2}$.

Jacques de Decker salue chez lui un digne représentant de la belgitude dont l'œuvre emboîte le pas de celle de Pierre Mertens. Ludo représenterait l'équivalent du roman mertensien de l'enfance (L'Inde ou l'Amérique), Les Plumes du coq serait la version detrézienne de La Fête des anciens tandis

${ }^{1}$ Cf. José Domingues de Almeida, De la belgitude à la belgité. Un débat qui fit date. Bruxelles: P.I.E. Peter Lang, 2013.

2 Jean-Marie Klinkenberg, « La production littéraire en Belgique francophone. Esquisse d'une sociologie historique », Littérature, $n^{\circ}$ 44, décembre 1981, p. 48. 
que L'Herbe à brûler correspondrait au projet de roman politique entrepris par Mertens dans Les Bons Offices. Chez ces deux auteurs, " hérauts de la belgitude $»^{1}$, les mythes belges et l'histoire du Royaume sont pris à bras le corps, même si dans le tournant des années quatre-vingt Marc Quaghebeur peut encore regretter qu'une synthèse entre le pôle de l'engagement internationaliste et le souci de dire ce pays dans ses contradictions n'ait pas encore été produite chez eux. Entre " ici et partout ", ces deux romanciers préfèrent souvent revendiquer un statut somme toute « commode »d'《 apatride mental », de Belges « inavouables » ${ }^{2}$. À cet égard, force est de souligner le caractère foncièrement initiatique (bildungroman) de l' «autobiographie hallucinée », associé à l'intuition qu'a le lecteur d'être en présence d'une écriture d'un impossible aboutissement, d'une improbable synthèse et d'une douloureuse déception de l'auteur-narrateur aussi bien face à sa militance sud-américaine qu'à son vécu wallon de l'enfance et de l'adolescence. Comme l'a bien remarqué Rita Olivieri-Godet, le passage à l'écriture après (ou à cause de) l'expérience brésilienne se conçoit comme une quête ou une fuite vers un ailleurs qui n'est ni l'ici, ni vraiment le là-bas, mais plutôt l'écriture elle-même en tant qu'ailleurs ${ }^{3}$. Quoi qu'il en soit, cette écriture autofictionnelle qui succède à l'épreuve brésilienne n'évite pas l'ancrage dans la glaise wallonne où elle s'obstine à s'enliser. La critique parisienne surtout - escomptait de ce guérillero une fresque au goût du jour de la militance gauchiste. La révolution portugaise de 1974 en faisait rêver plus d'un et procurait une raison d'être à toute la gauche européenne qui la faisait ainsi par procuration ${ }^{4}$.

\footnotetext{
${ }^{1}$ Nous reproduisons à ce stade la pensée de Marc Quaghebeur dans Lettres françaises de Belgique. Mutations, p. 91.

${ }^{2}$ Cf. la préface de Jean-Louis Lippert à Les Plumes du coq, p. 9.

${ }^{3}$ Rita Olivieri-Godet, «Conrad Detrez : genèse d'une écriture », Textyles, ${ }^{\circ}$ 13, «Lettres du jour » (I), p. 70. On lira avec profit cet article pour ce qui est de l'impact du Brésil sur l'œuvre detrézienne.

${ }^{4} C f$. la lecture d'André-Joseph Dubois à Ludo, p. 166.
} 
Or Detrez fait son entrée dans la fiction narrative par Roclenge, son village natal, et ses souvenirs d'enfance de la guerre. Qui plus est, il récidive dans Les Plumes du coq et dans la première partie de L'Herbe à brûler. Ainsi, son écriture inscrit malgré tout le discours et l'hallucination dans le cadre de l'ici. Nous nous proposons dès lors d'en faire l'inventaire aussi bien au niveau du traitement des données historiques de ce pays que de certains repères directs ou allusifs. Nous soulignerons par la suite la distance prise par le narrateur vis-à-vis de cette réalité - ce qui se traduit le plus souvent par une fascination de l'autre et du là-bas. Nous évoquerons finalement l'attachement critique et exigeant de l'auteur wallon à la complexité de son pays natal.

\subsection{Dérision sur fond d'Histoire}

Le brouillage animiste de Ludo fait quelque peu écran à une lecture historique des événements auxquels il fait allusion. Mais quelques détails, parfois de nature ethnographique, ainsi que les contributions paratextuelles de l'auteur, permettent de situer le récit dans le contexte de la Seconde Guerre mondiale et des inondations qui sévirent en ces années critiques. Le narrateur de cinq ans est le témoin presque amusé d'une guerre aérienne frappant un pays frontalier et interstitiel, mais dont la panique n'affecte que les adultes. S'il est vrai que « les oiseaux peuvent s'arrêter audessus de chez nous au moment où l'on s'y attend le moins (...) $»^{1}$, le fait est que cette guerre se déplace : « Là, du côté de la mer, du côté de la frontière, en France... $»^{2}$. La guerre coïncide avec de terribles crues des affluents de la Meuse, notamment du Geer, ce qui place le récit entre ces deux coordonnées et éléments historiques axiaux pour l'enfant, l'eau et le feu : « La guerre se démène à longueur de jours et

${ }^{1}$ Conrad Detrez, Ludo, p. 113.

${ }^{2}$ Idem. 
de nuits entre lac et ciel $»^{1}$. On sait combien chez Conrad Detrez le recours permanent au présent de l'indicatif pour restituer une mémoire enfantine et une ambiance hystérique promeut l'anhistoricité du récit. Ce procédé narratif n'invalide pas pour autant la dissémination de détails, parfois piquants, d'une époque troublée dont l'ensemble ébauche une espèce d'ethnographie du pays de Liège à cette époque. Nous découvrons ainsi les habitudes religieuses et populaires de l'époque, comme ces prières et ces expressions de piété populaire en faveur de la fin de la guerre : « Il a demandé qu'on récite au moins un chapelet $(. ..) »^{2}$ ou cette coutume dévotionnelle funéraire sur le cadavre de bonne-maman : « Ma mère frottait les joues de la morte avec un peu d'eau bénite $»^{3}$.

Au reste, il est fait sporadiquement allusion à plusieurs vicissitudes de l'existence paysanne en temps de guerre. Les bombardements allemands contraignent les gens à descendre dans les caves où ils se terrent et se tassent en attendant la fin du passage des « oiseaux de fer » et de leurs « œufs de feu ». Tout signe avant-coureur de cette arrivée funeste se traduit par cette descente collective et hystérique : « Mon père nous jette à la cave (...). Ludo, sa mère, d'autres femmes nous rejoignent au sous-sol $»^{4}$. Par ailleurs, durant ces années de guerre, les populations sont durement éprouvées par le manque de nourriture et par les rationnements. Ces difficultés ne sont pas comprises par le gamin, mais font néanmoins l'objet de descriptions distanciées de la part du narrateur : « Ma mère ouvre la sacoche, les femmes se répartissent les pommes de terre $»^{5}$, ou encore: "C'est elle [la mère de Ludo] qui nous rapporte le pain auquel nous avons droit tous les deux jours $\rangle^{6}$. Finalement, le petit narrateur signale, sans

\footnotetext{
${ }^{1}$ Ibid., p. 136. C'est nous qui soulignons.

${ }^{2}$ Ibid., p. 57.

${ }^{3}$ Ibid., p. 86.

${ }^{4}$ Ibid., p. 60.

5 Ibid., p. 65.

${ }^{6}$ Ibid., p. 127. C'est nous qui soulignons.
} 
en comprendre la portée, plusieurs aléas et vicissitudes d'une époque de résistance et de clandestinité : « Les hommes sont descendus dans la cave, ont trouvé la bicyclette (...). Les hommes l'examinaient, posaient des questions ${ }^{1}{ }^{1}$. Des perquisitions et des débandades se succèdent, les ruses stratégiques et les planques de la résistance aussi. L'enfant, incapable de suivre critiquement ces informations, essaie d'interpréter ces différents ouï-dire et rumeurs villageoises. Par exemple, « À Bourg-Léopold [caserne où le père du narrateur avait fait son service militaire] les patates avaient cramé, on n'avait pu rassembler la troupe, les trois quarts des hommes manquaient ${ }^{2}$. Le rôle du père du narrateur dans ce conflit n'est pas clairement restitué, mais il est évident qu'il participe, d'une façon ou d'une autre à la résistance dans la région : «Un homme est venu le chercher, il a dit que cette fois c'était pour de bon $\rangle^{3}$, ou encore ce souvenir marquant : «Un soldat a déchiré la photo de mariage en deux, a glissé dans sa poche la partie concernant le marié (...) : il le ramènerait, le cher mari $)^{4}$.

Le traitement historique de la Seconde Guerre mondiale est dès lors fonction du stade de développement infantile du narrateur et ne permet qu'un abordage allusif de l'ici en accord avec la vision d'une Belgique mythique, minuscule et frontalière, mais disposant d'une vaste excroissance coloniale africaine, source de clichés et d'imaginaire :

C'est comme ça au village, dans les champs, à Visé, à Liège. C'est comme ça en Ardenne, dans toute la Wallonie, en France, partout, sauf au Congo où il ne neige jamais puisque là-bas les gens sont noirs 5 .

Dans Les Plumes du coq, poules, coqs, champs de betteraves, l'exotisme de Victor, mais surtout les apparitions

\footnotetext{
${ }^{1}$ Ibid., p. 73.

${ }^{2}$ Ibid., p. 85.

${ }^{3}$ Ibid., p. 141.

${ }^{4}$ Ibid., p. 92.

5 Ibid., p. 45.
} 
spectrales et fantomatiques de l'Époux sont autant de figures privant le récit d'un abordage réellement factuel d'un événement aussi important dans l'histoire belge que la Question royale. L'ambiance sociopolitique autour de l'éventuel retour du roi Léopold III, le référendum, le retour en soi, les incidents de Grâce Berleur et l'abdication en faveur de Baudouin ne constituent pas vraiment le centre d'un récit, davantage axé sur l'ambiance sordide du séminaire SaintTrudon. Néanmoins, la Question royale y joue un rôle plus qu'allusif, tout comme les manifestations de rue d'ailleurs. Dans cette affaire, le culte de l'Époux et les supérieurs de Saint-Trudon, bastion du catholicisme et du royalisme, enflamment les pensionnaires et les amènent à militer pour le retour de Sa Majesté, retenue en territoire ennemi, et ce à l'opposé de l'opinion majoritaire à Liège, bastion socialiste et républicain.

Ce deuxième volet évoque dérisoirement ces événements excessifs et ces circonstances passionnelles. Il y fait une allusion hallucinée et obsessionnelle qui les rend subtilement irréels et anhistoriques. Aussi le titulaire d'histoire fustige-t-il ces adorateurs du coq wallon, tous socialistes et laïcs, adversaires du Roi, du Pape et de la Sainte Église : « Le culte du coq est un fléau sans cesse renaissant, poursuit l'historien $»^{1}$. Et ce véritable intégriste d'une Belgique atemporelle et unie de trouver des origines mythiques et glorieuses à son pays, alors au bord de l'implosion, et de les faire répéter à l'envi à ses élèves, enfants de l'Époux, et qui plus est en une langue moins encline à véhiculer les idéaux de gauche : « Fortissimi... ? Continuez!... sunt Belgaez (...)», « Leve God! Leve De Kerk ! ${ }^{2}$.

D'ailleurs, « le titulaire de français n'aime plus les Français $»^{3}$, l'heure étant aux phobies et aux emportements hystériques :

\footnotetext{
${ }^{1}$ Conrad Detrez, Les Plumes du coq, p. 65.

2 Ibid., p. 62-66.

${ }^{3}$ Ibid., p. 66.
} 
Le titulaire de français regarde le plafond quand il croise dans les couloirs, le titulaire de néerlandais qui, rapporte-t-il, enseigne en réalité le flamand que bredouillent les rongeurs de couenne de son canton natal ${ }^{1}$.

Un été chaud à plus d'un titre que celui-là : « Un pays menacé, un pays qui se cassait en deux. Le supérieur s'est épongé le front, il s'est expliqué : une moitié de ce pays, la plus belle, priait pour que $\mathrm{Sa}$ Majesté revienne se promener à la cour (...). Les villes du Sud, hélas ! s'y opposaient (...) $»^{2}$. Le collège s'apprête à engager ses recrues, au nom d'une Belgique unitaire, chrétienne, royaliste que l'on semble déjà regretter. Au nom de l'Époux contre le coq wallon et laïc :

Le supérieur s'excitait : nous avions un roi. Personne jusque-là n'en avait parlé. Le roi était un ami de l'Époux et son représentant, le seul après lui à faire monter vers la capitale et chanter, en chœur et dans une langue unique, le syndicat des marchands de crevettes d'Ostende, des wattmans et des forgerons borains ${ }^{3}$.

Il leur fallait coller les oui favorables au retour du roi, sur les murs hostiles et rebelles de la cité des Princes-Évêques devenue entre-temps païenne et laïque par un aléa de l'Histoire, où les non régnaient en maîtres. Ils se devaient de convertir : « (...) la cité la plus antiroyaliste du pays, la maçonne, la rouge, l'égorgeuse de princes et d'évêques, la dissidente : Liège à nouveau possédée par des démons du paganisme et de la république, Liège et sa turbulente banlieue, sa ceinture d'anarchistes et de libidineux $»^{4}$. Ils y évolueraient tels des missionnaires de l'Époux et de ses causes, entre elles celle du Roi : « Mais nous ramènerions le roi sur ses coussins, l'assiérions devant un paravent d'azalées, à droite de l'Époux, dans les velours de la cathédrale $»^{5}$,

\footnotetext{
${ }^{1}$ Ibid., p. 68.

${ }^{2}$ Ibid., p. 92.

${ }^{3}$ Ibid., p. 93.

${ }^{4}$ Ibid., p. 97.

5 Ibid., p. 95.
} 
quitte à se retrouver par un fầcheux hasard sur une « place de la République Française ».

Si les champs de betteraves au milieu desquels se dresse la bâtisse de l'Époux s'inscrivent dans un cadre culturel agricole répétitif et traditionnel, la ville et sa banlieue préludent à la rupture, à la conflictualité et à la révolution latente : «C'est ainsi qu'arrivés en vue des premières usines, nous butons contre une palissade surchargée de graffitis, de représentations de pénis rouges et noirs dressés comme des poings, de coqs installés sur des NON en fils de fer barbelés (...) $»^{1}$. Detrez reviendra plus tard, dans une contribution paratextuelle à caractère nettement politique, sur l'ambiance houleuse de cette ville rebelle à cette époque troublée, dans un article délibérément intitulé : " Une fureur de Wallon » : "Cette ville était Sodome, Gomorrhe, et Moscou réunies $»^{2}$. Voici les jeunes et naïs séminaristes pris entre deux feux : ceux qui crient « lieve God $»^{3}$ et ceux qui s'écrient "Rex à Nuremberg $»^{4}$. Toutefois, la tournure carnavalesque, picaresque, burlesque du récit ôte toute gravité factuelle aux événements de l'histoire belge auxquels il fait allusion. Les lettres des oui et des non se mêlent et s'annulent dans leur dérisoire interchangeabilité selon la fantaisie et l'inaptitude des séminaristes aux combats politiques : « La palissade offre à la contemplation de ceux qui passeraient une longue tapisserie de OIU, de OIN, de ONI posés comme des flotteurs sur les eaux de la Meuse quand le vent du nord fait des vagues $\rangle^{5}$, tout comme ces slogans tautologiques que l'on entend dans les manifestations : " La monarchie est le régime dans lequel notre chef est un monarque $»^{6}$. Entre-temps, les rumeurs, les menaces et conjectures vont bon train :

\footnotetext{
${ }^{1}$ Ibid., p. 97.

${ }^{2}$ Conrad Detrez, « Une fureur de Wallon », repris dans Ludo, p. 203.

${ }^{3}$ Conrad Detrez, Les Plumes du coq, p. 98.

${ }^{4}$ Ibid., p. 99.

${ }^{5}$ Ibid., p. 102.

${ }^{6}$ Ibid., p. 111.
} 
- Le roi rentrera en avion!

- Le roi n'est plus roi !

- Le roi écrit tous les jours des lettres au cardinal.

- Le cardinal est flamand, vive la Wallonie !

Les rivalités, les soupçons, les préjugés entre les deux communautés s'amoncellent et s'aiguisent avec le cours des événements : «Et la menace croissait dans la mesure ou les heureux devenaient malheureux : lorsque les votes flamands tendirent à surcharger les votes wallons $»^{2}$. Leur rendu narratif ne frôle toutefois jamais l'approche véritablement historiale, encore moins les caractéristiques génériques du roman historique. Une fois évoquée la tragédie de GrâceBerleur, une fois annoncées les tendances sociopolitiques en jeu, le récit regagne les murs austères du séminaire SaintTrudon et favorise un filtrage fantastique, fantomatique et onirique $^{3}$ des événements. En somme, le récit dessine un repli halluciné. Aussi la victoire douce-amère de l'Époux, celle, serrée et essentiellement flamande, des oui, le retour de Léopold III, son abdication en faveur de son fils aîné, Baudouin, « le fils de l'autre, le petit, regulum minimum sed crescendum $! »^{4}$, devaient-ils se répercuter sur le moral et l'humeur de Saint-Trudon. Le narrateur prétend recevoir de plus en plus souvent la visite spectrale de l'Époux : « Le lendemain l'Époux s'introduit par une autre fenêtre, avance, plumé sur toute la face antérieure du corps, se plante devant moi alors que je suis déjà sous mes couvertures $»^{5}$. C'est même l'Époux qui l'orientera et l'inspirera pour la thématique de sa rédaction, un choix prémonitoire au vu de ce qu'aura été l'existence de l'auteur:

L'Époux m'apparait, le même jour, à la salle d'études. J'ai terminé le plan de ma rédaction sur un des trois sujets suivants,

\footnotetext{
${ }^{1}$ Ibid., p. 112.

${ }^{2}$ Ibid., p. 123.

${ }^{3}$ Même si le récit frôle le reportage dans quelques rares paragraphes.

${ }^{4}$ Ibid., p. 140.

${ }^{5}$ Ibid., p. 143.
} 
au choix : Imaginez les conséquences de la mort subite d'un jeune homme impur. De la joie du garçon qui fait de la gymnastique. La pureté, le bonheur, et l'agonisant. J'ai choisi le troisième ${ }^{1}$.

À savoir substituer au culte sadomasochiste, paternel et légal de l'Époux celui, bien moins contraignant, de l'« Amour »: « Ensemble nous [le narrateur et Victor] avons juré d'aimer l'Amour $»^{2}$.

L'histoire récente de la Belgique est également présente dans L'Herbe à brûler où elle subit à nouveau une dévalorisation carnavalesque étant donné le traitement picaresque du récit. Conrad, le narrateur, débarque à Louvain à une époque troublée de l'histoire du Royaume. L'Université catholique se trouve en effet en pleine effervescence du Wallen buiten! (Les Wallons à la porte !), ce qui aboutira à son éclatement et préludera à la fin de la conception unitaire du Royaume de Belgique. Or ces événements cruciaux de l'histoire belge sont durement contrebalancés, d'une part par l'effet de contraste permanent engendré par la fréquentation des milieux sud-américains de Louvain, notamment Rodrigo, qui fonctionne comme stratégie de relativisation des querelles en cours. $\mathrm{Si}$, dans un premier temps, « La guerre scolaire (...) connaissait depuis la rentrée un regain de violence $\rangle^{3}$ avant d'être résolue à l'amiable entre les grandes familles politiques belges : « La guerre des écoles était terminée. Évêques et politiciens s'étaient rencontrés, sur un terrain neutre, pour constater qu'après deux années de troubles et d'excitation, les uns n'avaient pas avancé et les autres n'avaient pas reculé $»^{4}$, «(..) à Louvain s'étaient déclenchées de nouvelles hostilités, plus circonscrites : la guerre des langues $»^{5}$. Or cet épisode marquant de l'histoire belge récente se voit

\footnotetext{
${ }^{1}$ Ibid., p. 145.

${ }^{2}$ Ibid., p. 198.

${ }^{3}$ Conrad Detrez, L'Herbe à brûler, p. 71.

${ }^{4}$ Ibid., p. 80.

${ }^{5}$ Ibid., p. 81.
} 
dévalorisé dès lors qu'il est comparé avec les questions brûlantes de l'actualité latino-américaine. À ce propos, Rodrigo se montre catégorique : « Je veux dire chez nous, en Amérique du Sud. Là on se bat pour des questions décisives : pour le pain, pour la terre... $\rangle^{1}$. Mais d'autre part, la contamination picaresque intermittente du récit opère une déstabilisation et un brouillage bouffon de la diégèse, notamment dans ses implications factuelles. Les combats de rues entre les deux factions prennent l'allure bon enfant de combats carnavalesques de tartes à la crème. Le résultat ne pouvait être plus ridicule : «Avant la fin de la matinée la moitié de l'université barbotait dans la Dyle, y compris six chanoines : deux wallons et quatre flamands, de la faculté de Droit canon $»^{2}$.

Outre les querelles picrocholines belgo-belges, le récit fera une allusion à d'autres événements historiques de l'époque qui affectent décisivement les options et positionnements politiques et religieux du narrateur. Dans ce cas, le traitement narratif concède un peu plus de précision factuelle, et frise à certains moments le reportage. En effet, ce ne sont pas seulement les disputes louvanistes qui frappent la naïveté du narrateur. L'Église catholique, alors en plein concile, provoque des querelles théologiques et liturgiques dont le récit se fait l'écho amusé par les contrastes d'urgence et de souci qu'il évoque par rapport aux Églises sud-américaines. Si à Rome les Pères conciliaires se divisent sur le renouveau liturgique, à Louvain ces débats se répercutent sur les querelles internes de l'Université, notamment entre liturgistes : «C'est pour cela que dans les séminaires on ne vit plus que dans une ambiance de croisade $»^{3}$.

Or ces débats semblent bien insignifiants vus du Brésil. Conrad en fera l'expérience personnelle une fois sur place :

\footnotetext{
${ }^{1}$ Ibid., p. 83.

2 Ibid., p. 88.

${ }^{3}$ Ibid., p. 60.
} 
« Comme sont dérisoires les autres querelles des évêques et des théologiens des Églises d'Europe $»^{1}$. Au Brésil justement, l'histoire fera une violente irruption dans le récit avec la description très détaillée, presque documentaire, du coup d'État militaire et de l'organisation clandestine d'une milice gauchiste, d'une guérilla urbaine ${ }^{2}$. L'histoire prend ici un tour moins dérisoire, plus grave. Elle implique l'engagement concret et dangereux dans le contexte d'une sanglante dictature. À cet égard, le contraste avec les événements de Mai 68, dont témoignera Conrad lors de son retour en Europe, ne pouvait être plus flagrant. Les soucis parisiens ont un goût de trop peu pour l'ex-guérillero belge qui a tâché d'implanter la révolution ailleurs : « (...) mes yeux sont tombés sur ce titre imprimé à la une d'un quotidien passant pour le plus sérieux du pays : La FRANCE S'ENNUIE. Je me suis mis au lit, dérouté $»^{3}$. Cette histoire-ci ne mérite plus qu'on la prenne au sérieux.

Conrad Detrez a bel et bien écrit ses romans autofictionnels sur un solide fond historique puisé dans l'histoire récente de la Belgique dont il a témoigné et a vécu ou subi certains événements cruciaux. Detrez inscrit donc son récit dans l'ici, et n'est pas tenté de le délocaliser ou de le rendre irréel pour éviter d'affronter la concrétude de ce lieu. Néanmoins, les événements convoqués ne le sont que dérisoirement, par le trait bouffon, par simple allusion contextuelle, réfraction d'un autre, étranger, ramenant le débat aux enjeux essentiels. Dès lors, l'« autobiographie hallucinée » se présente comme une quête personnelle et identitaire de soi sur fond d'histoire et en référence à un pays inavouable, mais dont les récits disséminent des traces très parlantes.

${ }^{1}$ Idem.

${ }^{2}$ Cf. Ibid., p. 127ss

${ }^{3}$ Ibid., p. 200. 


\subsection{Inscriptions indicielles de l'ici}

Outre le fond historique présent dans la trilogie, il faut relever les indices, parfois subtils, de l'inscription de l'ici dans le récit halluciné. Une certaine image de la Belgique y est diffusée qui répond à certains clichés ou attentes que l'on pourrait entretenir sur ce lieu, ou à un certain attachement inavouable de l'auteur à son pays d'origine. Par exemple dans $L u d o$, deux vecteurs indiciels peuvent être aisément dégagés qui préfigurent une conscience subliminaire de la réalité nationale à l'œuvre dans ce texte : la Belgique se présente comme un pays d'entre-deux où le gris domine largement. La perception animiste du petit narrateur construit une vision mobile de la guerre dont le déplacement rapide dessine un pays frontalier, médian, lieu de transit militaire situé entre les grandes puissances belligérantes, territoire que l'on foule, dont on viole la neutralité pour se rendre ailleurs.

L'inscription géographique est nette. Le récit se penche sur l'enfance de Detrez à Roclenge-sur-Geer dans le pays de Liège, le pays d'Aubel à quelques kilomètres à peine de Maastricht ou de la frontière allemande, et qui plus est sur l'une des frontières linguistiques les plus polémiques qui soient en Belgique depuis la seconde moitié du XXe siècle, les Fourons. Aussi l'eau des crues a-t-elle emporté le lit de Ludo et de ses parents « le plus loin possible, en Hollande » ${ }^{1}$. En outre, on apprend que " l'abattoir de Tongres sert de caserne $»^{2}$. Cet endroit, le père du narrateur, boucher de métier, le connaît bien. Il s'y rend habituellement ou « à Visé $»^{3}$. Ce terroir n'est pas destitué de sa réalité idiosyncrasique propre. Le récit n'évite pas non plus la transcription de certaines expressions wallonnes « L'Hom'â rodj dînts » ou des tournures populaires belgisantes telles que «Y a pas de fleur, que je te dis $\rangle^{4}$ ou $"$ gamin de merde $»^{1}$.

\footnotetext{
${ }^{1}$ Conrad Detrez, Ludo, p. 18.

${ }^{2}$ Ibid., p. 110.

${ }^{3}$ Ibid., p. 112.

${ }^{4}$ Ibid., p. 46.
} 
La guerre se déplace dans l'esprit du narrateur selon les ouï-dire des adultes et des informations inintelligibles qui lui parviennent. Or ce déplacement est surtout le fait d'une exigüité territoriale, d'une conception frontalière du pays comme lieu de passage : " La guerre vivote, assez loin, dans les Flandres, disent les uns, en France, disent les autres $»^{2}$. Dès lors, l'univers personnel et ludique du narrateur ne se confine pas au jardin de Ludo. Il connaît des dérives oniriques qui constituent autant d'excroissances transfrontalières. Ainsi, être menacé de noyade dans les eaux du Geer peut signifier une dislocation ou une dérive de la Belgique elle-même. Le narrateur de Ludo a beau se dire " sauvé des eaux ", par une extension fantasmatique, c'est toute l'histoire d'un peuple qui s'engouffre métaphoriquement à l'instar du monument aux morts des deux guerres sur la place communale de Roclenge : « La crue s'accélère. Les gens racontent que le soldat dressé sur la place communale a perdu ses pieds. La liste des morts est engloutie, on ne voit plus le 14-18 $»^{3}$. Or les emportements de l'imagination fertile de l'enfant conçoivent un pays en dérive, un territoire-radeau happé par l'importance symbolique des frontières :

Nous sommes entraînés vers l'immensité des eaux de la cour ; vers le Geer qui bouillonne, impatient, qui file vers la Meuse, aspiré par elle, attiré vers Maastricht, vers la Hollande, et bientôt livré aux tourbillons de la mer et la mer du Nord, en hiver, est glaciale; on y meurt de froid ${ }^{4}$.

Le statut frontalier de la région se reflète sur l'évaluation imaginaire des dimensions du jardin de Ludo, ce vaste pays ludique qu'il s'agit de « retrouver de l'autre côté, dans l'autre pays $»^{5}$. Par ailleurs, ce territoire n'est pas seulement blafard.

\footnotetext{
${ }^{1}$ Ibid., p. 40.

${ }^{2}$ Ibid., p. 109.

${ }^{3}$ Ibid., p. 57.

${ }^{4}$ Ibid., p. 117.

5 Ibid., p. 37.
} 
Le gris y domine largement et il y pleut sans cesse. Le Geer déborde. Les jardins y deviennent ternes et fades à force de pluie. Revenant sur son enfance wallonne dans le livretémoignage La Mélancolie du voyeur, l'auteur dira : " C'est monotone, ces paysages. S'ils ont de la beauté, je ne la remarque pas, sauf en mai $»^{1}$. Ludo accumule ces cadres de décrépitude et de grisaille : « Le jardin, on ne le retrouvera plus. Les plantes ont pourri, les couleurs fondu comme des sucreries $»^{2}$, « Le ciel n'est jamais descendu si bas $»^{3}$. La pluie s'impose comme élément chaotique, perturbateur de la vie sociale et de la vie tout court : « Les eaux ruinent la vie des habitants, rongent les pieux fichés en terre, le bas des portes $(\ldots) »^{4}$. Le spectacle offert par ce paysage pluvieux est plutôt blême et insipide : "Les fenêtres donnent sur une même et unique nappe de liquide sans forme ni couleur $»^{5}$.

La restitution d'indices de la Belgique, même non historiques, se poursuit dans Les Plumes du coq. À nouveau, le récit dégage une géographie concrète (le pays de Liège) et une époque facilement repérable (les années cinquante). Quand le narrateur fait la connaissance de son camarade de chambrée de Saint-Trudon, Victor, il tâche désespérément de le situer dans le contexte vicinal de sa région natale : « Je n'ai jamais accompagné une personne ainsi nommée [Victor] au marché de Visé $)^{6}$.

Par ailleurs, on apprend que plusieurs garçons du séminaire Saint-Trudon proviennent « (...) de Roclenge, notre village commun $»^{7}$ alors que les grammaires en usage « sont imprimées dans des villes différentes : à Hasselt, à Tournai, aux Presses du Rupel et des deux Nèthes réunies $»^{8}$. Par le biais de ces indices, le récit instaure une subtile vision

\footnotetext{
${ }^{1}$ Conrad Detrez, La Mélancolie du voyeur, p. 102.

${ }^{2}$ Conrad Detrez, Ludo, p. 75.

${ }^{3}$ Ibid., p. 44.

${ }^{4}$ Ibid., p. 140.

${ }^{5}$ Ibid., p. 76.

${ }^{6}$ Conrad Detrez, Les Plumes du coq, p. 36.

${ }^{7}$ Ibid., p. 86

${ }^{8}$ Ibid., p. 62.
} 
dichotomique d'un pays en évolution et en ébullition. D'une part, un paysage de champs de betteraves au milieu duquel « la bâtisse [Saint-Trudon] domine comme un château fort » ${ }^{1}$ préfigure et métaphorise un monde rural pacifié, unifié où une logique conservatrice des structures sociales est en vigueur : " La lumière découvre l'immensité du champ de betteraves $\rangle^{2}$. Une image subliminaire de la collectivité rurale de ce pays idéalisé consolide cette logique sereine, close et vicinale : «L'instituteur du village a, un jour, averti le garde champêtre qui en [deux étrangers] a chassé deux du territoire de la commune $(. ..) »^{3}$. Ce pays mythifié dispose en plus d'un réservoir colonial, source d'imaginaire et d'exotisme pour ces contrées rurales refermées sur elles-mêmes. Dans la lointaine colonie, des missionnaires (pères blancs) s'affairent à établir la même civilisation chrétienne cautionnée par l'Époux « (...) aux protégés des Euvres euchérotrudonniennes étendues à Notre Congo $»^{4}$.

Cependant, Les Plumes du coq entérine la péremption latente de cette vision idyllique du Royaume. À cet effet, le récit n'hésite pas à restituer la complexité linguistique de cette région limitrophe et annonce les troubles communautaires futurs : « Le coq... Traduisez (...). - De haan, réponds-je tout fier $(\ldots) »^{5}$. Un pays déchiré, « un pays menacé, un pays qui se cassait en deux $»^{6} \mathrm{y}$ prend corps. À cet égard, la descente sur Liège la païenne par les jeunes troupes de l'Époux constitue une métaphore expressive de l'évolution sociale en cours et des factions en présence. Elle opère un passage d'une société rurale et conservatrice, associée au paysage champêtre et bucolique, vers la banlieue industrielle, sale et progressiste de Liège. Elle est par là

${ }^{1}$ Ibid., p. 46.

2 Idem.

${ }^{3}$ Ibid., p. 30.

${ }^{4}$ Ibid., p.64.

5 Ibid., p. 71. Une restitution des complexités linguistiques qui va jusqu'à signaler les variantes à l'intérieur de l'espace néerlandophone. $C f$. p. 86.

${ }^{6}$ Ibid., p. 92. 
même l'occasion d'une description détaillée de la ceinture industrielle liégeoise. Une fois passés les derniers jardins potagers, une transition vers l'hostilité urbaine s'opère. Les usines commencent à dominer et à enlaidir un paysage, et une mentalité marquée par l'assurance de la foi, des besognes et des rythmes agricoles s'impose : " C'est ainsi qu'arrivés en vue des premières usines, nous butons contre une palissade $(. ..) »^{1}$. La paisible et harmonieuse irrégularité de la campagne cède le pas à la lugubre régularité et uniformité des cités ouvrières: « les maisons construites l'une contre l'autre par la direction des houillères $»^{2}$.

Outre les épisodes historiques proprement dits - que le narrateur fictionnalise à son gré - L'Herbe à brûler disperse les traces d'une belgité intimement associée au statut frontalier de la région natale de Conrad, alias " Conradus ». Dans ce contexte spécifique, il est de coutume que les pensionnaires de Saint-Rémy latinisent leur nom lors de leur admission. Or le proviseur s'empresse d'expliquer au jeune séminariste l'étymologie de son nom : " Conradus... Conradus... oui, c'est cela : Kon'... de l'audace... Qu'elle vienne à propos !... Et rad ou rat ou rath avec un h, naturellement... c'est-à-dire le conseil, le bon conseil... $»^{3}$. De ce fait, le nom du narrateur, une fois latinisé, figure à lui seul la complexité linguistique et les clichés mythiques du pays à cheval entre la germanité du caractère et la latinité de l'expression. Le trajet de Roclenge à Louvain permet la reproduction de la complexité linguistique, d'autant plus que le voyage du narrateur suit plus ou moins la frontière linguistique et fait défiler une toponymie improbable, des «non-lieux » que l'auteur caractérisera plus tard sans complaisance ${ }^{4}$, et qui donnent au narrateur le sentiment de dépaysement : « Ensuite j'ai traversé des villes aux noms si différents : Grandville, Kumlich, Erps Kwerps, Moha... qu'à

\footnotetext{
${ }^{1}$ Ibid., p. 97.

${ }^{2}$ Ibid., p. 125.

${ }^{3}$ Conrad Detrez, L'Herbe à brûler, p. 28s.

${ }^{4}$ Cf. Conrad Detrez, « Une Belgique fabuleuse », repris dans Ludo, p. 194.
} 
chaque gare j'avais l'impression d'entrer dans un autre pays $\rangle^{1}$.

Par ailleurs, par sa forte présence africaine, Leopoldus l'ami de chambrée congolais de Conrad et allusion ludique au roi Léopold II (à qui le Royaume doit sa politique coloniale), incarne l'extension coloniale du Royaume belge au lendemain de l'indépendance. Une vision stéréotypée du Congo y est véhiculée : "Des Congolais, le collège en compte six, élevés par des missionnaires et envoyés par eux afin qu'ils poursuivent leurs études dans un des établissements qu'ils possèdent en métropole $»^{2}$. Mais de retour de cette ex-métropole coloniale, " son pays d'origine $\|^{3}$ après son aventure sud-américaine, Conrad retrouve un pays identifiable désormais à la redondance bilingue de sa capitale et de ses gares sur laquelle le narrateur insiste avec un dégoût sarcastique: « (...) deux fois transcrits, les mêmes mots, tels quels et inversés, confirmant que je me trouvais bien à BRUSSEL-BRUXELLES ou BRUXELLES-BRUSSEL $»^{4}$. Dans ce pays « qui ne [l']attendait pas $»^{5}$, le guérillero fatigué n'a plus rien à « declareeren $»^{6}$.

Le tarissement révolutionnaire de l'œuvre detrézienne n'empêche pas les textes ultérieurs de jouer avec des repères implicites ou brouillés d'une inavouable inscription indicielle dans l'ici. On peut très honnêtement y lire un infléchissement considérable et honteux quant à l'inscription narrative de l'ici, mais il devient évident que l'auteur s'éloigne symboliquement de la Belgique. C'est le cas de La Guerre blanche où un écrivain raté, correcteur dans une maison d'édition parisienne, essaie de produire son premier roman, attend un improbable succès et remet toujours son mariage à

\footnotetext{
${ }^{1}$ Conrad Detrez, L'Herbe à brûler, p. 51. C'est nous qui soulignons.

${ }^{2}$ Ibid., p. 30.

${ }^{3}$ Ibid., p. 218.

${ }^{4}$ Ibid., p. 219.

5 Idem.

${ }^{6}$ Idem.
} 
plus tard. Or dans ce récit plutôt ennuyeux, la Belgique apparaît comme une géographie en creux, in absentia, coïncidant le plus souvent avec une vision frontalière d'un nord français en opposition avec le pouvoir symbolique de la capitale. Le récit opère une subtile substitution de l'ici belge par un ersatz limitrophe français, et ce à une époque où l'auteur postule la nationalité française. La fiancée du narrateur, Polymnie, est originaire de Givet sur la Meuse, à quelques minutes de la frontière belge ${ }^{1}$. Le grand-père de la promise était « grand admirateur de la Belgique $»^{2}$. Cette région est décrite comme un lieu de passage pour les camionneurs, un trajet « qui va de Paris à Maubeuge et, de là, en Belgique $»^{3}$.

Incapable d'écrire son roman, le narrateur se voit contraint à un repli, une retraite dans son village natal « dans les Ardennes », région mosane que la France partage avec la Belgique. Dans son village ardennais, substitut « honteux » de Roclenge, sa tâche d'écrivain n'est pas rendue plus facile pour autant. Bien au contraire, "Au lever du jour des dizaines de voitures défilent devant ma maison et toutes prennent la direction de Givet, parfois de Charleville ou de Sedan $»^{4}$, c'est-à-dire de villes françaises explicitement frontalières par rapport à la Belgique.

L'exigence de calme et de sérénité force le narrateur à s'isoler un peu plus, à quitter son village vers un hameau plus silencieux. Or ce retrait de la civilisation, fût-elle rurale, dégage un paysage plus sauvage, et induit un incontournable rapprochement de la Belgique : « La pinède se prolonge loin au-delà, à travers les plateaux schisteux, accidentés, du pays wallon $\rangle^{5}$. Mais l'inavouable Belge ne peut s'arrêter en si bon chemin. Pour ses provisions, il n'hésitera pas à descendre vers un hameau situé « au-delà de la frontière et

\footnotetext{
${ }^{1}$ Conrad Detrez, La Guerre blanche, p. 45.

${ }^{2}$ Ibid., p. 46.

${ }^{3}$ Ibid., p. 126.

${ }^{4}$ Ibid., p. 163.

${ }^{5}$ Ibid., p. 177.
} 
maintenant je compose mon ode quelque part dans les Ardennes belges $»^{1}$. Ce travail littéraire ébauché en permanence, mais sans cesse mis de côté est cependant et prématurément affublé de titres ridiculement pompeux dont certains renvoient à des clichés nordiques, notamment au vaste patrimoine mystique flamand, comme « La célébration des noces mystiques de René et de la Belle Inconnue $»^{2}$.

Par ailleurs, La Guerre blanche dégage une image problématique et intimidante de la capitale française. Paris est une ville bruyante, inhospitalière pour ce " correcteur » et « dactylographe » d'écrivains français, issu des confins de ses Ardennes natales. Or l'accès à la langue et à la littérature n'est pas immédiatement accordé à cet agent périphérique et maladroit du champ littéraire, naturellement dépossédé de son outil d'expression, mais ne produisant que des titres pompeux et tautologiques : "Bref, depuis des années, je travaille pour la gloire de la littérature française. En dix ans de vie à Paris j'ai dactylographié sept ou huit cents romans. Naturellement j'aimerais y ajouter le mien $»^{3}$. Pas étonnant dès lors que ce fonctionnaire du système littéraire se montre sarcastique dans son pastiche ou sa parodie des écrivains à la mode qui constituent une coterie littéraire parisienne caractérisée par la médiocrité et la pratique courante du plagiat : " Cécile Armor et Valère Algue se sont battus », mais... pour un simple adjectif. Même stratégie substitutive et frontalière dans Le Dragueur de Dieu, roman où Detrez illustre et caricature les rapports entre la sexualité et la mystique. Victor, dont plusieurs traits de caractère et biographiques rejoignent ceux de Detrez, quitte d'une façon tout à fait imprévue son couvent de Saint-Amand - où il était le témoin mystique d'apparitions théophaniques de créatures angéliques - et « monte » à Paris où ces élans mystiques se transforment en périple dans le ghetto homosexuel de la

\footnotetext{
${ }^{1}$ Ibid., p. 183.

${ }^{2}$ Ibid., p. 170.

${ }^{3}$ Ibid., p. 28.
} 
capitale. Ce faisant Victor entraîne à sa suite Lucien, jeune novice naï, que le départ de Victor laisse incrédule, pantois et surtout curieux. Or le couvent de Saint-Amand ${ }^{1}$ se situe dans un nord absolu et vague, mais en tous cas très proche de la frontière belge. Le climat et le paysage, eux, sont aisément identifiables : « On se trouve dans le Nord et il pleut tant de fois, de septembre à juin, entre Dunkerque et Paris. Il pleut sur la Flandre et l'Artois. Il pleut sur Boulogne, sur Lille, sur Givet. Tous les anges se plaisent à pisser ensemble, aux mêmes heures, sur la Picardie et l'Ardenne $»^{2}$.

En outre, Victor a grandi « non loin de la frontière franco-belge $\rangle^{3}$ dans une ville énigmatique signalée par une simple majuscule : V. (Visé ? Valenciennes ?). Cette origine nordique des deux protagonistes (Victor et Lucien) consolide une vision périphérique de leur statut provincial ou rural par rapport au surmoi parisien : « Dans le Nord les gens ne parlent pas ainsi $\gg{ }^{4}$. La dichotomie se montre plus symbolique et culturelle que géographique entre ces parages nordiques, pour ne pas dire simplement « belges » : « Chez nous, à la campagne et même dans les villes, personne ne songerait à transformer sa cave en buvette. Dans le Nord ces locaux servent à entreposer du charbon, des betteraves, des pommes de terre $»^{5}$. Mais le récit profite de la proximité de la Flandre française pour s'imprégner des clichés nordiques que la critique parisienne aime à retrouver dans les lettres belges : beffrois, canaux, béguinages, carillons, brumes et pluies. Dans ce nord flamand, astucieusement non belge, mais toujours référé à la Belgique, « les femmes, une fois veuves, se retiraient dans un béguinage ou dans un couvent $\rangle^{6}$. Qui plus est, la mystique flamande demeure un puissant repère et

\footnotetext{
${ }^{1}$ Une référence toponymique bien nordique et qui renvoie directement à une « Francie » médiévale commune.

${ }^{2}$ Conrad Detrez, Le Dragueur de Dieu, p. 13.

${ }^{3}$ Ibid., p. 15.

${ }^{4}$ Ibid., p. $83 \mathrm{~s}$.

${ }^{5}$ Ibid., p. 92s. C'est nous qui soulignons.

${ }^{6}$ Ibid., p. 30.
} 
En effet, la Libération fut la première occasion pour lui de voir des Noirs à Roclenge-sur-Geer, et ce parmi les pelotons américains :

« Ils [les soldats] galopent, ils font de la gymnastique. L'un d'eux est très brun. C'est un nègre, le premier que j'aie jamais vu. Il s'appelle Jimmy. Les gens l'appellent Congolais. Lui se défend, il réplique : 'American! American...!'»",

sûr de ses racines et de son appartenance identitaire. Cette présence invasive et intrigante pour les villageois hypnotise véritablement le petit enfant : « J'aurais bien voulu toucher sa peau. Il souriait tellement ! Je l'aimais. Il remplaçait mon père $»^{2}$.

Fernando et le carnaval de Rio opèrent finalement l'ouverture du narrateur vers la réalité du métissage et de la mixité en tant que valeur positive de l'ailleurs et qui met à nu le creux inacceptable de l'ici. Dès lors, l'extranéité et l'exotisme, au lieu de susciter un sentiment de répulsion ou de réserve - celui-là même que Detrez prêtait à sa Belgique natale et rurale - préludent à une invitation à la rêverie, à l'exil, à la mixité. Être Belge, pour lui, ce sera avant tout, et par contraste, avouer un statut $d^{\prime}$ '" apatride mental $»^{3}$, d'originaire d'un pays irréel, d'un néant inavouable. La fugue, puis l'exil s'imposent tour à tour pour mieux radicaliser la dialectique du là-bas attrayant et envoûtant, marqué par la couleur de l'autre, et de l'ici blafard.

Dans L'Herbe à brûler, Rodrigo illustre avant la lettre cette dichotomie, rend de la sorte possible la figure de la réfraction et nous rend, par le biais du regard de l'autre, une image insipide, morne et blême de la réalité européenne, belge et blanche. Ainsi, le teint tanné et l'exubérance dont Rodrigo est porteur se répercutent sur l'argumentation de son discours politique. Le Brésil est brouillant de vie et de

\footnotetext{
${ }^{1}$ Conrad Detrez, La Mélancolie du voyeur, p. 161.

${ }^{2}$ Ibid., p. 162. C'est nous qui soulignons.

${ }^{3}$ Ibid., p. 94.
} 
problèmes qui suscitent tous les engagements tandis que la Belgique et la vieille Europe apparaissent ternes et apathiques. C'est ce qu'éclaire l'argumentaire politique de l'étudiant brésilien :

Là-bas aucun prêtre ne peut l'éviter, les enjeux de l'Église sont toujours des enjeux politiques ${ }^{1}$;

Chez lui, on se divise sur des choses plus graves $(. . .)^{2}$;

Ton Europe, elle n'a rien à voir avec mon rêve $(. . .)^{3}$;

L'Europe, pour moi, c'était des noms d'auteurs ${ }^{4}$;

Il disait «ton » Europe comme si je vivais en plein dedans ${ }^{5}$;

Je veux dire chez nous, en Amérique du Sud. Là on se bat pour des questions décisives $(. . .)^{6}$.

Il ressort de cette argumentation que la Belgique n'est qu'une insignifiante parcelle du vieux continent, lequel se résume lui-même à l'accumulation théorique et monumentale de sa culture, de ses auteurs, son humanisme, paralysé par l'ambiance feutrée de son bien-être et de sa sécurité. Rien ne pourra jamais s'y produire, et encore moins une révolution ! Le Brésil, en revanche, incarne la béance dialectique de l'histoire. Il représente l'espoir de tous les progrès et de toutes les révolutions. Il appelle l'application immédiate et pratique de tous les engagements. D'ailleurs, Detrez l'apprendra à ses frais. L'argumentation de Rodrigo finit par gagner l'adhésion et le désir d'engagement de Conrad. Ce qui lui semblait évident et naturel dans son insouciance politique et sociale, lui devient insupportable. À cet égard, Conrad figure l'absence de conscience critique et politique de la nation et de son conservatisme primaire : " Je suis mal, la politique ne m'intéresse pas et d'ailleurs je n'y comprends rien $»^{7}$. Une

\footnotetext{
${ }^{1}$ Conrad Detrez, L'Herbe à brûler, p. 61. C'est nous qui soulignons.

${ }^{2}$ Ibid., p. 60. C'est nous qui soulignons.

${ }^{3}$ Ibid., p. 64. C'est nous qui soulignons.

${ }^{4}$ Idem. C'est nous qui soulignons.

${ }^{5} \mathrm{Idem}$. C'est nous qui soulignons.

${ }^{6}$ Ibid., p. 83. C'est nous qui soulignons.

${ }^{7}$ Ibid., p. 61.
} 
fois initié aux complexités et à l'urgence de la militance au Tiers-Monde, Louvain, métaphore des subtilités belges, lui semble exécrable, un lieu à éviter, à quitter : " J'ai quitté Louvain comme on quitte, recru d'air vicié, un W.-C. public $\gg{ }^{1}$.

Ses expériences amoureuses, ses (més)aventures politiques, il les veut avant tout exogames, en rupture avec l'endogamie ambiante, celle de son village, celle de son pays et de sa culture. Ce métissage culturel, il l'a vécu dans sa peau comme un véritable destin. Roclenge se méfiait de « ces gens-là », venus du côté de Maastricht, des « turcos » païens, des Congolais « rusés » de Saint-Rémy. Désormais, Detrez épouse ces cultures et leurs symboles, mêle son sperme et son sang à ceux des nègres et des métisses, hommes et femmes confondus : « Résultat : aucune vocation, dans ma libido, à l'inceste. Et très peu à l'endogamie. Dans mes lits, la race blanche n'a guère occupé de place $»^{2}$.

Ce destin bâti d'exil et de mixité attendait Conrad Detrez au bon endroit et à point nommé, à Lisbonne en 1974, juste après la Révolution des Eillets. De surcroit, il est correspondant au service de la RTB : « C'est Lisbonne ! J'y vis depuis un an déjà. $\mathrm{S}$ 'y déroule une révolution curieuse (...). Un coup d'État poli, feutré $»^{3}$. Plus qu'ailleurs et qu'avant, semble-t-il, la dialectique et le fossé de l'ici et du là-bas se sont creusés. Detrez semble avoir définitivement déménagé dans une patrie culturelle substitutive, une sorte d'extension lusophone de son expérience brésilienne ${ }^{4}$. Il quitte un pays improbable, rallie l'autre dans sa tête, dans son cour. Vue de ce carnaval politique quotidien, plein de rebondissements et de rumeurs contradictoires, la Belgique des années soixante-dix parait bien distante, monotone, terne, sans intérêt. En effet, « Au royaume de sire Baudouin (et Mme Fabiole) l'insurrection n'est pas inscrite à l'ordre du

\footnotetext{
${ }^{1}$ Ibid., p. 95.

${ }^{2}$ Conrad Detrez, La Mélancolie du voyeur, p. 156.

${ }^{3}$ Ibid., p. 110.

${ }^{4}$ Cf. Conrad Detrez, Les Noms de la tribu, p. 122.
} 
jour. On prévoit plutôt qu'il pleuvra $»^{1}$. La Belgique ne produit aucun événement digne de ce nom. Elle suscite tout au plus des faits divers à la portée et à l'intérêt purement vicinaux.

Cependant, pour le narrateur, les gauchistes de tous bords suivent avec une passion sportive et hypocritement détachée le cours des événements révolutionnaires au Portugal. Et si ce Finistère d'Europe, dont l'existence historique nationale pluricentenaire et la geste épique manifeste sur tous les continents intimidaient facilement le pays d'entre-deux, se mettait à rêver d'un Cuba européen? Dans leurs immeubles feutrés de Bruxelles-Brussel, fonctionnaires, journalistes, intellectuels de gauche appellent de leurs vœux la création d'une Albanie ibérique où ils iraient en tourisme idéologique, mais où ils ne vivraient jamais. Dès lors, la Belgique est affublée d'adjectifs péjoratifs et dépréciatifs. Elle devient soudain « leur » pays :

Mes confrères, là-haut, à la maison mère, dans leur froid pays, la plate Bruxelles, meurent d'envie (...). Ils sont excités, mes braves gauchistes belges, trotskistes, léninistes, soixantehuitards d'outre-frontière, charmants, par procuration... Excités, les braves. Ils faillent, à chaque nouvelle, défaillir² .

Les confères bruxellois de Detrez l'envient, mais lui ne les envie nullement. Ils s'en vont visiter Lisbonne la tumultueuse comme on part en week-end ou en classe de neige, en se remémorant l'abc de la révolution et du socialisme, impraticable chez eux. Mais une fois sur place, la beauté et la grandeur de l'ancienne métropole impériale, manuéline et atlantique les conquièrent. La révolution peut attendre. Detrez raille ces « étrangers » que sont devenus ses compatriotes, touristes de gauche en mal d'émeutes et de pavés qui en voudraient davantage, mais devront finalement se contenter d'un coup d'État poli, inoffensif, très surveillé

${ }^{1}$ Conrad Detrez, La Mélancolie du voyeur, p. 111.

${ }^{2}$ Idem. C'est nous qui soulignons. 
par les alliés américains. Il envie plutôt Chico, ce Portugais retornado des Indes et prêt à reprendre le large en cette fin annoncée d'Empire vers d'autres horizons, fort d'une histoire et d'un état d'âme. Detrez s'approprie cette histoire et emprunte ce sentiment : « Henri, prince des marins, héros de mon pote, je me rapproche. Tes nuages sont les miens : Ton océan, j’y plonge. Tes caravelles, je veux y remonter ${ }^{1}$. Lisbonne, ville de tous les départs et de tous les retours, sera désormais, ne serait-ce que pour un temps, $s a$ ville :

D'où le nom : Olissipone, tous ces passages, ces abordages, ces voyages... Des départs sans retour également. Ville de conquérants, de découvreurs, marins, aventuriers, l'émigration qui continue : un patrimoine vivace, unique, omniprésent : la saudade ${ }^{2}$,

la mélancolie d'un voyeur aux portes du grand et ultime voyage. Saudade, un mot dont on se grise à force de l'éprouver, " vague à l'âme, délices et pleurs en dedans. Tout cela (Dieu merci) résiste aux coups d'État (...) $»^{3}$. Dieu merci pour lui, « le regard est imprenable $»^{4}$. Ce patrimoine sentimental, ce capital historique, cette plus-value destinale ( fado) comme horizon, quand on en est terriblement dépourvu, on est tenté de se les offrir en cadeau, comme une consolation, une compensation de la vie à l'égard d'un Belge, ex-futur curé de campagne et guérillero maoïste des favelas : « (...) la saudade. Je la possède. Lisbonne me l'a donnée. Un pan de ma forteresse $»^{5}$. De ce fait, ce rapport très personnel de Conrad Detrez au Portugal du post-25 avril constitue à sa manière une friche très particulière de la présence de ce pays dans les lettres belges, mais que Marc Quaghebeur omet dans son analyse sur le sujet. Le Portugal y est vénéré dans son éternelle et impériale « splendeur »,

\footnotetext{
${ }^{1}$ Ibid., p. 119.

${ }^{2}$ Idem. C'est nous qui soulignons.

${ }^{3}$ Ibid., p. 120.

${ }^{4}$ Idem.

${ }^{5}$ Idem.
} 
dans la pérennité de ses sentiments humanistes et de sa propension au métissage culturel, et ce en dépit des troubles internes du moment. Les protagonistes de la révolution portugaise (Spínola, Othelo, Gonçalves, Soares, Cunhal, etc.) durant les « deux années d'incertitudes $»^{1}$ qui ont consolidé le régime démocratique, sont vus comme des marionnettes d'un feuilleton trop prévisible.

Detrez se sent blasé. Des révolutions, il en a vu d'autres, des vraies, de celles où l'on meurt. Le guérillero est fatigué. Pris d'une lucidité inouïe, il entame dans cette ville où se joue une " lutte finale », son " autobiographie hallucinée » et se réconcilie avec la pure beauté du monde (incarnée par la vue imprenable sur le Tage au Cais do Sodré) et avec le «pur amour, que toute femme ignore, affaire de cœur, sans cul d'homme à homme $»^{2}$. Paradoxalement, au moment même où Detrez se penche sur son enfance à Roclenge, s'adonne à son autoanalyse et ressasse les raisons profondes de ses échecs, Lisbonne s'offre à lui comme un havre, une patrie mentale, erratique, substitutive et adoptive. Il ne regrette pas cette Belgique brumeuse, pluvieuse et feutrée. Il lui substitue la patrie de Chico, celle de l'autre. Il lui emprunte ses racines (indiennes, timoraises, chinoises, africaines), ses ailes, ses voiles, désir irrépressible de repartir, son « âme océanique » ${ }^{3}$. De même, le portugais devient sa langue adoptive ${ }^{4}$, la seule à même de véhiculer les subtilités de l'âme : "Où ai-je pris, dans quel idiome, les mesures de la nostalgie ? $»^{5}$. Conrad Detrez a choisi la voie de l'exil qu'il a vécu dans le métissage. Mais ce faisant, il n'en ressemble que trop au petit garçon de Roclenge, s'embourbant dans un champ de betteraves, sous un ciel bas, envisageant déjà une fugue :

\footnotetext{
${ }^{1}$ Ibid., p. 132. Cf. Marc Quaghebeur, « Présences du Portugal dans les lettres belges de langue française », conférence à l'Université d'Aveiro, 2002, p. $128 \mathrm{~s}$.

${ }^{2}$ Ibid., p. 131.

${ }^{3}$ Ibid., p. 138.

${ }^{4}$ Cf. Conrad Detrez, Les Noms de la tribu, p. 122.

${ }^{5}$ Conrad Detrez, La Mélancolie du voyeur, p. 147.
} 
《 Les hommes partent pour faire la guerre ou pour partir » ${ }^{1}$, constate le petit narrateur de Ludo, mais « le tout est de se retrouver de l'autre côté, dans l'autre pays $»^{2}$.

\subsection{Sa Belgique malgré tout}

La spécificité de l'œuvre romanesque detrézienne tient à la coexistence de deux extrêmes thématiques et à l'ancrage de l'imaginaire dans deux réalités tout aussi prégnantes, la militance internationaliste et l'attachement au, parfois le repli sur, le cadre de sa Wallonie natale, sans qu'une synthèse soit véritablement dégagée. Malgré sa facette de guérillero gauchiste des peuples opprimés, d'émissaire des révolutions défuntes, de correspondant et témoin lucide de l'accouchement démocratique portugais, de conseiller culturel de la France mitterrandienne au Nicaragua sandiniste, Detrez n'a jamais cessé de revendiquer une conscience très critique, parfois sarcastique de la réalité de son pays natal. L'acuité de son discours politique lui a valu d'être unanimement reconnu comme l'une des contributions les plus utiles dans l'argumentaire de la belgitude. En effet et très tôt, Detrez a produit des textes critiques d'une cohérence et d'une lucidité irréprochables, où il contribue à l'inscription de l'ici dans les lettres belges et à l'assomption des complexités historiques, linguistiques et culturelles de ce pays. C'est sur ce dernier point d'ailleurs que Detrez rejoint le plus intensément l'ordre du jour des manifestes de la génération de la belgitude.

En 1968, de retour du Brésil et de son aventure de guérillero maoïste, il renoue avec la réalité de sa Wallonie natale (c'est le moment du Walen Buiten) et s'inquiète du tour que prend la politique communautaire belge à une époque où la régionalisation s'apprête à succéder à l'état unitaire et où l'agenda linguistique des partis politiques fait une très

${ }^{1}$ Conrad Detrez, Ludo, p. 37.

${ }^{2}$ Idem. 
nette percée. Dans « Les Wallons, les Flamands, et l'Europe » (1968), il n'hésite pas à s'en prendre à l'artificialité de l'État monarchique belge tel qu'il fut imposé par les puissances européennes en 1830, ainsi qu'au mythe unitaire qui l'a longtemps soutenu ou légitimé. Il regrette « la dévotion du peuple envers une monarchie d'importation [et, partant, audessus des particularismes régionaux], la pérennité du gouvernement des nobles et des bourgeois, l'officialisation pour tout le Royaume de l'unique langue française. Un roi, une élite, une langue ${ }^{1}$, mais il finit, dans sa pièce publiée dans La Belgique malgré tout, par rappeler Baudouin.

Mais son raisonnement va plus loin dans le diagnostic négatif de la conjoncture belge. Il accuse la majorité flamande, catholique et conservatrice de diriger le positionnement externe au nom du pays tout entier. Il dénonce sans ambages la politique des grandes familles, des trois piliers centraux de toute la vie politique, sociale et culturelle de la Belgique, notamment l'emprise de l'Église catholique sur des pans entiers de la vie des Belges, de l'accouchement à l'enterrement, responsable de l'attitude profondément acritique de la majorité du peuple, notamment l'intelligentsia. Detrez s'avère un fédéraliste inconditionnel, avant la lettre : « La solution, simple et naturelle, se résume à un mot : le fédéralisme $»^{2}$, mais il se montre clairvoyant quant aux dangers liés aux dérives flamandes, notamment en ce qui concerne le lexique politique : « la race, le sol $»^{3}$. À ceux qui veulent obéir aveuglément aux diktats des majorités, il rappelle l'indispensable respect des minorités : « Trop de manifestants confondent, à Louvain, bourgeois francophones et citoyens wallons $\gg{ }^{4}$. L'avenir devait malheureusement lui donner raison ${ }^{5}$.

${ }^{1}$ Conrad Detrez, « Les Wallons, les Flamands, et l'Europe », repris dans Ludo, p. 189.

${ }^{2}$ Ibid., p. 190.

${ }^{3}$ Ibid., p. 191.

${ }^{4}$ Idem.

5 À ce sujet, voir l'analyse de Marc Quaghebeur, « Politiquement l'année $1991 »$, tapuscrit, s/d. 
Detrez appelait de ses vœux un régionalisme exemplaire et équitable, capable de s'intégrer dans le plus vaste projet de l'Europe des grandes régions nationales, mais c'est bien évidemment l'avenir de sa Wallonie natale qui le préoccupe, un territoire dont il craint l'inexorable décadence au profit de la Flandre dans le contexte unitaire. On remarquera à ce propos l'importance de l'hommage rendu en bas de page aux victimes des incidents de Grâce-Berleur (30 juillet 1950) par l'auteur de Les Plumes du coq ${ }^{1}$. En 1980, en imprécateur baudelairien, il ne ménage pas la « fabuleuse » Belgique alors que le chantier fédéral était largement engagé. Il y décrit sans complaisance, en n'évitant ni l'irrégularité congénitale de ses compatriotes, ni les clichés d'usage associés à ce pays haï et aimé, et auxquels il s'en prend avec un sarcasme frisant la caricature.

La Belgique serait un pays d'irréguliers : « Ses rejetons dès lors ne peuvent être que des tordus ou des commerçants : tordus ses peintres et ses poètes, Jacques Brel, Michaux, Permeke, Magritte, Ruusbroec, William Cliff $»^{2}$. Elle ne constituerait qu'un état artificiel, improbable et imposé de l'extérieur, d'où le recours au pronom personnel indéfini on pour rendre compte des coupables de cette aberration et de cette monstruosité : « On lui a octroyé une reine, un roi, une cour, un grand maréchal (...) », " On lui a construit également, à la ruminante Belgique, des étables grandioses (...) $»^{3}$. Mais Detrez ne s'arrête pas en si bon chemin. L'écrivain belge prend ses distances à l'égard des institutions littéraires officielles du Royaume dont il dénonce et l'artificialité, et l'inutilité : « Pour faire bien on lui a infligé un édifice dit noble [1'Académie Royale] $»^{4}$. La Belgique parodiée selon lui accumule les non-lieux qu'illustre une toponymie instable, pompeuse ou tout bêtement ridicule, ceinture limitrophe et périphérique des marches nordiques de

\footnotetext{
${ }^{1}$ Conrad Detrez, Les Plumes du coq, p. 137 (bas de page).

${ }^{2}$ Conrad Detrez, « Une Belgique fabuleuse », repris dans Ludo, p. 192.

${ }^{3}$ Ibid., p. 193.

${ }^{4}$ Idem. C'est nous qui soulignons.
} 
l'espace francophone : « Mais connait-on Erps-Kwerps, dont le nom à lui seul fait rêver ? Et Houffalize ? Et Arlon, mystérieuses comme les villes où jamais personne ne va $\rangle^{1}$.

Cette Belgique mourante ne procure qu'un mortel ennui. Detrez y signale « un horizon si ennuyeux », des « contrées où il pleut », « cet endroit peut prétendre au titre de Paysage du Néant $\|^{2}$. Autant de cartes postales péjoratives et ternes d'un endroit évoqué en creux. Pas étonnant que les tenants de la belgitude saluent - quand ils ne l'encensent pas - cette œuvre enracinée dans le contexte de l'ici et qui s'entoure d'un discours critique d'escorte des plus tranchés. Pas étonnant non plus de retrouver une contribution de Detrez alliant la critique à l'humour dans le numéro de La Belgique malgré tout. Dans « Le dernier des Wallons », Detrez produit par le truchement d'une " politique-fiction », une approche veritablement critique et politique du fait belge dont la quasitotalité des autres contributions s'est montrée incapable. Dans ce texte singulier, il affirme que «l'anachronisme de Notre état nous accable $(. ..) »^{3}$ et exige l'avènement d'une république Belgique. Dans ce cadre purement fictionnel, l'auteur cherche désespérément le « dernier des derniers » de ses véritables compatriotes.

Cette même année, il épouse la cause et le combat désespérés des paysans des Fourons, pays d'Aubel, dont six villages furent administrativement rattachés à la Flandre en 1960 et qui s'obstinent toujours à refuser l'arbitraire de cette décision. Il leur dédie « La grande grève et le bruissement des chapelets $»^{4}$. Dans ce poème aux accents bucoliques et nostalgiques, Detrez renoue intimement et affectivement avec le pays de Liège, d'Aubel, le paysage de son enfance,

\footnotetext{
${ }^{1}$ Ibid., p. 194.

${ }^{2}$ Idem.

${ }^{3}$ Conrad Detrez, « Le dernier des Wallons », La Belgique malgré tout, Revue de l'Université de Bruxelles, numéro composé par Jacques Sojcher, 1980, p. 117.

${ }^{4} C f$. Conrad Detrez, « La grande grève et le bruissement des chapelets », Il était douze fois Liège, p. 111-118.
} 



\section{CONCLUSION SUR UNE GEUVRE INTERROMPUE}

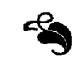

La présente étude sur l'œuvre et la vie de Conrad Detrez s'est donné pour but d'articuler l'écriture romanesque et l'Histoire dans son acception personnelle et collective. En effet, la richesse et la profusion d'expériences et d'aventures imprévisibles ont placé cet acteur belge, que rien ne prédestinait au départ à une projection internationale et cosmopolite, au centre des grands récits sociopolitiques qui firent le XXe siècle finissant. C'est précisément ce côté inattendu et cet emballement de l'Histoire qui nous le rendent si attachant, et en font un ami, un camarade, un compagnon de route, voire un frère.

Né dans un milieu wallon foncièrement catholique et rural, marqué par les rythmes agricoles immémoriaux, et bercé par le récit des souvenirs encore si frais dans les esprits des deux grandes guerres qui virent les troupes allemandes violer la neutralité belge et déchirer le " grand paysage », Detrez résistera, dans un premier temps, aux appels lancinants de la vie et du monde; des voix qu'il confondra naïvement avec la vocation à la prêtrise de la part du Dieu chrétien, ce dieu de l'enfance, simultanément doux et cruel, quand il ne se montre tout simplement pas sous un jour vindicatif ou pervers, à l'instar de l'Époux du collège Saint-Trudon.

C'est d'ailleurs en enfant que le petit Conrad, autobiographique jusqu'à épouser l'onomastique de l'auteur, 
contactera le monde extérieur, où il fera sa première sortie sous forme de découverte de l'autre dans son « jardin ». À ce propos, nous nous sommes attardé dans un premier volet (Ludo) sur les mécanismes du rendu narratif de l'animisme infantile mobilisés par le narrateur pour se remémorer une enfance quelque peu chaotique dans la maison familiale, au bord du Geer.

Mais le jeune garçon et séminariste devait connaître les affres de la vie en institution catholique, l'éruption d'une sexualité encore désorientée et chaotique, ainsi que l'expérience panique de la terreur et de la perversion religieuses, avant de renier, ou de renoncer à ses origines provinciales et à sa foi chrétienne engagée de « missionnaire laïque ». Le deuxième volet de cette étude met, en effet, en lumière les stratégies narratives qui allient les motifs majeurs de ce cheminement individuel: d'une part, l'élaboration d'une mythologie personnelle et, d'autre part, le recours à des poncifs psychanalytiques facilement identifiables, déjà à l'œuvre dans Ludo, mais qui connaissent une étonnante réverbération fantasmatique dans Les Plumes $d u$ coq et L'Herbe à brûler.

Dès lors, l'horizon référentiel de Detrez et l'univers diégétique de sa fiction acquièrent une toute autre dimension. Nous avons donc décrit, dans toutes leurs évolutions et leurs déboires, les rendez-vous (manqués) du personnage Conrad Detrez avec l'Histoire, d'abord en tant que missionnaire catholique, ensuite en tant que guérillero urbain et infiltré pendant l'impitoyable dictature militaire brésilienne, avant de se retrouver comme reporter et témoin d'une révolution plus sereine et pacifique, celle des CEillets, au Portugal entre 1974 et 1975.

Entre-temps, Detrez aura connu le dépucelage (homo)sexuel et fait l'expérience enivrante de l'immersion dans la culture afro-brésilienne, dans la (re)découverte de l'autre fascinant et mystérieux. La question de l'altérité exotique, identitaire et culturelle a retenu toute notre attention critique. En fait, nous avons montré que le narrateur de Ludo 
intéressants et moins bien réussis d'un point de vue narratif, dont La Ceinture de feu (1984) écrit à Managua, ils n'en accusent pas moins une évolution sensible, que nous avons décrite comme étant l'expression d'un désabusement idéologique sincère, le passage à autre chose et une reddition assumée face à la postmodernité.

Mais, d'autre part, cette transformation de l'écriture romanesque signale aussi une mélancolie plus profonde, enracinée dans le « grand paysage » de sa Belgique natale. À cet égard, nous avons illustré les modalités plurielles, et souvent subtiles, de l'attachement de Conrad Detrez à la Belgique. Celui-ci passe par des références allusives, des rapprochements assimilatoires, voire une totale et explicite identification. En fait, l'Histoire qui s'invite dans cette autofiction est aussi quelque part celle du Royaume de Belgique, et nous nous sommes attardé à souligner et à caractériser la prégnance des conflits communautaires belges de l'après-guerre (la Question royale) et de la crise louvaniste dans l'autofiction de l'auteur de Les Plumes du coq, mais aussi la stratégie de dérision et de carnavalisation continues qui, chez Detrez, concourt à la déréalisation des faits historiques.

Enfin, notre perspective a voulu placer la poétique detrézienne dans la tension francophone - un peu dépassée par l'approche transnationale et mondiale du fait littéraire, il est vrai - du centre-périphérie(s) dans ses diverses représentations, figurations ou métaphores. En effet, la poétique detrézienne fait souvent apparaître la Belgique comme un espace liminal et frontalier, et en tous cas en creux, ou effacé par rapport au plein symbolique parisien. Il serait simpliste d'y voir immédiatement une allégorie du vide identitaire belge mais, comme nous l'avons souligné, on ne peut ignorer que Detrez fut aussi très engagé dans le débat de la belgitude au tournant des années quatre-vingt. Il fut même une des voix les plus acerbes contre l'unitarisme de son pays d'origine et en faveur du régionalisme wallon. Comme quoi la projection internationaliste et le souci de l'ici ne sont 
nullement inconciliables, et peuvent même se féconder mutuellement. L'œuvre d'un Pierre Mertens est là qui le prouve à l'envi. Conrad Detrez est cet éternel Belge du monde, mais cet homme du monde né quelque part. 



\section{ORIENTATIONS \\ BIBLIOGRAPHIQUES}

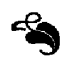

\section{Euvres primaires}

C. DETREZ, Ludo, Bruxelles, Labor, [1974] 1988.

C. DETREZ, Les Plumes du coq, Bruxelles, Labor, [1975] 1995.

C. DETREZ, L'Herbe à brûler, Paris, Calmann-Lévy, 1978.

C. DETREZ, La Lutte finale, Paris, Balland, 1980 [1996].

C. DETREZ, Le Dragueur de Dieu, Paris, Calmann-Lévy, 1980.

C. DETREZ, Les Noms de la tribu, Paris, Seuil, 1981.

C. DETREZ, La Guerre blanche, Paris, Calmann-Lévy, 1982.

C. DETREZ, La Ceinture de feu, Paris, Gallimard, 1984.

C. DETREZ, La Mélancolie du voyeur, Paris, Denoël, 1986.

\section{Articles / interventions de Conrad Detrez}

C. DETREZ, « Le jardin de la vie », Le Figaro, 21 novembre 1978, repris dans C. DETREZ, Ludo, Bruxelles, Labor, 1988.

C. DETREZ, « Une Belgique fabuleuse », Télérama, 9 mai 1979, repris dans C. DETREZ, Ludo, Bruxelles, Labor, 1988.

C. DETREZ, « Une fureur de Wallon », Le Monde, 7 octobre 1979, repris dans C. DETREZ, Ludo, Bruxelles, Labor, 1988.

C. DETREZ, « Le dernier des Wallons », dans J. Sojcher (dir.), La Belgique malgré tout, Revue de l'Université de Bruxelles, 1980.

C. DETREZ, « La grande grève et le bruissement des chapelets », dans Il était douze fois Liège, Liège, Pierre Mardaga, 1980. 
C. DETREZ, « Dévoré par le Brésil », Le Magazine Littéraire, septembre 1982, repris dans C. DETREZ, Ludo, Bruxelles, Labor, 1988.

\section{Correspondance de Conrad Detrez}

Lettre de Conrad Detrez à Jean Remiche, administrateur général au Ministère de la Culture Française, 16 février 1977, AML. Lettre de Conrad Detrez à Anne-Marie La Fère, 10 octobre 1984, AML.

\section{Entretiens avec / sur Conrad Detrez}

Entretien avec Christian Panier, « Du Brésil à Paris et détours », Revue Nouvelle LXXIV, décembre 1981.

«William Cliff : la vie comment ça rime », entretien avec Carmelo Virone, Le Carnet et les Instants 77, 15 mars-15 mai 1993.

\section{Études citées sur Conrad Detrez}

M. BARONHEID, «Conrad Detrez repose parmi les idoles brisées », La Wallonie, 2 novembre 1986.

Fr. BETTO, « Souvenirs d'un ami de Detrez au Brésil », Toudi. Culture et société $2,1988$.

H. BIANCIOTTI, « Une boussole pour Conrad », Le Nouvel Observateur, 22 février 1985.

C. BRAECKMAN, « Les iguanes bavards de la cathédrale en ruine », Le Soir, 14 février 1985.

J. FRANCK, « L'individu dans l'Histoire : Pierre Mertens et Conrad Detrez », La Libre Belgique, 27 septembre 1978.

J. FRANCK, «La pavane de Conrad Detrez pour les révolutions défuntes », La Libre Belgique, 19 septembre 1984.

R. JOUANNY, "L'Afrique et le tiers monde dans L'Herbe à brûler de Conrad Detrez », dans Images de l'Afrique et du Congo / Zaïre dans les lettres françaises de Belgique et 
L. DEMOULIN, « Pour un roman sans manifeste », Écritures 1, «Fin de millénaire », automne 1991.

G.-H. DUMONT, Histoire de la Belgique, Bruxelles, Le Cri, 1997.

G. DURAND, Les Structures anthropologiques de l'imaginaire, Paris, Dunod, 1969.

M. ELIADE, Initiation, rites, sociétés secrètes, naissances mystiques. Essai sur quelques types d'initiation, Paris, Gallimard, 1959.

S. H. FRAIBERG, Les Années magiques, Paris, PUF, 1967.

J.-M. KLINKENBERG, « La production littéraire en Belgique francophone. Esquisse d'une sociologie historique ", Littérature, $\mathrm{n}^{\circ}$ 44, décembre 1981.

$\mathrm{Ph}$. LEJEUNE, Le Pacte autobiographique, Paris, Seuil, 1975.

M. MAETERLINCK, L'Ornement des noces spirituelles de Ruysbroeck l'Admirable, traduit du flamand, Bruxelles, Les Éperonniers, 1990.

P. MERTENS, « Du retour à l'autobiographie », Revue de l'Institut de Sociologie, Bruxelles, ULB, 1990 / 91.

O. M. LOURENÇO, Psicologia do desenvolvimento moral, Coimbra, Almedina, 1992.

J. PIAGET, La Représentation du monde chez l'enfant, Paris, PUF, 1972.

J. PIAGET, La Construction du réel chez l'enfant, Neuchâtel, Delachaux et Niesdé, 1973.

M. QUAGHEBEUR, Lettres belges entre absence et magie, Bruxelles, Labor, 1990.

M. QUAGHEBEUR, « Politiquement l'année 1991 », tapuscrit, $\mathrm{s} / \mathrm{d}$.

M. QUAGHEBEUR, Balises pour l'histoire des lettres belges, Bruxelles, Labor, 1998.

D. RABATÉ, Le Roman français depuis 1900, Paris, PUF, 1998.

G. ROMEY, Dictionnaire de la symbolique. Le vocabulaire fondamental des rêves, t. 1, Paris, Albin Michel, 1996.

J. SCHMIDT, "Éclatements du roman français », in Romans français contemporain, Paris, Ministère des Affaires Etrangères, Sous-Direction du Livre et de l'Écrit, 1997.

M. SUTTER, Le Mensonge chez l'enfant, Paris, PUF, 1956.

T. TODOROV, Introduction à la littérature fantastique, Paris, Seuil, 1970. 
D. VIART, « Le roman en question III », Prétexte 11, automne 1996.

M. ZLOTOWICZ, Les Peurs enfantines, Paris, PUF, 1974.

M. ZUMKIR, « La langue belge et la belge écriture de Patrick Roegiers », Le Carnet et les Instants 127, 15 mars-15 mai 2003.

\section{Autres études sur Conrad Detrez}

C. DESSY, « Conrad Detrez (ré)écrit Paludes », Textyles [En ligne], 46 | 2015, mis en ligne le 01 mai 2015. https://journals.openedition.org/textyles/2595

J. D. DE ALMEIDA, « Conrad Detrez : oscillation entre l'histoire et le mythe, comme "lutte finale" ", in M. Quaghebeur (dir.), Analyse et enseignement des littératures francophones : tentatives, réticences, responsabilités, Bruxelles, P.I.E - Peter Lang, 2008, p. 201-217.

J. D. DE ALMEIDA, « Le Portugal expliqué aux Belges, sur trois "itinéraires" décalés : Albert t'Serstevens, Conrad Detrez et Jean-Claude Pirotte "), Cadernos de Literatura Comparada 24/25, « Deslocações criativas », 2011, p. 211-225.

J. D. DE ALMEIDA, « La guerre comme un jeu d'enfants chez Eugène Savitzkaya, Conrad Detrez et Ahmadou Kourouma », in M. J. Reynaud, F. Outeirinho e J. Almeida (dir.), La Littérature va-t'en guerre : représentations fictionnelles de la guerre et $d u$ conflit dans les littératures contemporaines, 2013,

$18-27$. https://er.letras.up.pt/uploads/ficheiros/11555.pdf

J. D. DE ALMEIDA, « Le Brésil révélateur et l'exil ambigu dans L'Herbe à brûler (C. Detrez) et La Salamandre (J.-Ch. Rufin) », dans E. V. Martin, N. Kermele, M. E. Chaves e J. L. Jobim (dir.), Dialogues France-Brésil. CirculationsReprésentations-Imaginaires, Pau, PUPPA, 2018, p. 465-473.

R. LEFERE, «L'Amérique latine dans l'œuvre romanesque de Conrad Detrez », Revue de littérature comparée, vol. $\mathrm{n}^{\circ} 299$, 3, 2001, p. 471-481.

M. Cl. PELLEGRINI, « Conrad Detrez ou la mémoire comme éthique de la dissidence ", in A. Lasserra (dir.) Histoire, mémoire, identité dans la littérature non fictionnelle. L'exem- 
ple belge, Bruxelles, P.I.E - Peter Lang, coll. « Documents pour l'Histoire des Francophonies / Théorie », 7, p. 105-120.

M. QUAGHEBEUR, " Amado-Detrez, la fraternisation baroque ? », Amerika [En ligne], 10 | 2014, mis en ligne le 22 juin 2014, consulté le 02 mai 2019. URL : http://journals.openedition.org/amerika/4973. 


\section{TABLE DES MATIÈRES}

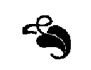

Un écrivain dans le siècle. Un Belge du monde. 9

I. Une biographie hallucinante. L'écrivain aux prises avec l'Histoire.

II. L'autofiction en tant que mythologie personnelle.

III. Images obsédantes : transcriptions thématiques et hématiques.

IV. Variations d'un désir d'absolu.

V. L'inscription de l'ici: entre allusion, réfraction et

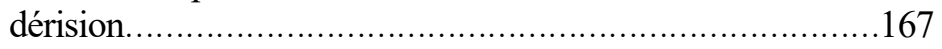

Conclusion sur une æuvre interrompue. .203 
Le suivi éditorial de ce volume a été assuré par José Domingues de Almeida et Dominique Lanni.

Vous pouvez commander Conrad Detrez chez votre libraire ou sur le site des éditions Passage(s) (www.editionspassages.fr).

Achevé d'imprimer par les éditions Passage(s), Les Jardins de Carel, Bâtiment D, Apt. 96, 14 allée du père Jamet, 14000 Caen, sur les presses de l'imprimerie Pulsio, 38 rue Durantin, 75018 Paris.

Dépôt légal : second semestre 2020. 